\author{
UNIVERSIDADE DE SÃO PAULO \\ FACULDADE DE MEDICINA DE RIBEIRÃO PRETO
}

\begin{abstract}
CORRELAÇÃO ENTRE O CONDENSADO DO EXALADO PULMONAR, TESTE DE CAMINHADA DE SEIS MINUTOS E SHUTTLE WALK TEST EM INDIVÍDUOS CARDIOPATAS
\end{abstract}

Marina Neves do Nascimento

RIBEIRÃO PRETO

2014 


\author{
UNIVERSIDADE DE SÃO PAULO \\ FACULDADE DE MEDICINA DE RIBEIRÃO PRETO
}

MARINA NEVES DO NASCIMENTO

\title{
CORRELAÇÃO ENTRE O CONDENSADO DO EXALADO PULMONAR, TESTE DE CAMINHADA DE SEIS MINUTOS E SHUTTLE WALK TEST EM INDIVÍDUOS CARDIOPATAS
}

RIBEIRÃO PRETO

2014 


\section{CORRELAÇÃO ENTRE O CONDENSADO DO EXALADO PULMONAR, TESTE DE CAMINHADA DE SEIS MINUTOS E SHUTTLE WALK TEST EM INDIVÍDUOS CARDIOPATAS}

\begin{abstract}
Dissertação de Mestrado apresentada à Faculdade de Medicina de Ribeirão Preto da Universidade de São Paulo, para obtenção do título de Mestre.
\end{abstract}

Orientador:

Prof. Dr. Alfredo José Rodrigues

Área de Concentração:

Clínica Cirúrgica

RIBEIRÃO PRETO

2014 
Autorizo a reprodução e divulgação total ou parcial deste trabalho, por qualquer meio convencional ou eletrônico, para fins de estudo e pesquisa, desde que citada a fonte.

Nascimento, Marina Neves. Correlação entre o condensado do exalado pulmonar, teste de caminhada de seis minutos e shuttle walk test em indivíduos cardiopatas. Ribeirão Preto, 2014. 93 p. : il. ; $30 \mathrm{~cm}$

Dissertação de Mestrado, apresentada à Faculdade de Medicina de Ribeirão Preto da Universidade de São Paulo/USP. Área de Concentração: Cirurgia. Orientador: Rodrigues, Alfredo José.

1. Condensado do Exalado Pulmonar. 2. Teste de caminhada de 6 minutos. 3. Shuttle walk test. 4. Cirurgia Cardíaca. 


\section{FOLHA DE APROVAÇÃO}

Marina Neves do Nascimento

Correlação entre o condensado do exalado pulmonar, teste de caminhada de seis minutos e shuttle walk test em indivíduos cardiopatas.

Dissertação de Mestrado apresentada à Faculdade de Medicina de Ribeirão Preto da Universidade de São Paulo, para obtenção do Título de Mestre. Área de concentração: Clínica Cirúrgica

Aprovado em:

\section{Banca Examinadora}

Prof. Dr.

Instituição:

Assinatura:

Prof. Dr.

Instituição:

Assinatura:

Prof. Dr.

Instituição:

Assinatura: 


\section{AGRADECIMENTOS}

À Deus, por iluminar o caminho a seguir.

À minha mãe Sandra, minha fortaleza, motivação e força motriz, agradeço pela presença constante, incentivo, fé em mim, companheirismo, carinho e zelo em cada momento da minha vida, a meu pai, Sérgio e minha madrasta Bete pela esperança e torcida pelo sucesso nessa grande realização e ao meu padrasto Eduardo pela presença abençoada e a força que representa desde que entrou em nossas vidas.

Aos meus irmãos, Leonardo e Gustavo, pelo carinho dedicado a mim sempre que estamos juntos e a expectativa do meu retorno sempre que estive distante durante a execução deste trabalho.

Ao Professor Dr. Alfredo José Rodrigues, agradeço pela oportunidade dada a mim para a realização deste projeto e por partilhar seu conhecimento e ensinamentos que me guiaram no desenvolvimento deste trabalho.

Às amigas e companheiras de pesquisa, Daniela Ap. Benite e Carolina Guimarães Reis, pela ajuda e contribuição para as coletas realizadas neste trabalho e pelo apoio, cumplicidade e companhia nesta jornada.

Às pós-graduadas Daniela Alves Vento e Livia Arcêncio pela disposição e por me ensinarem a metodologia e processamento das coletas de condensado essencial para a execução do estudo.

Às amigas, Érika Harumi Tanaka e Vanessa Secolin por todos os conselhos, pelas longas conversas diárias, pela partilha dos anseios e alegrias tornando essa fase da minha vida muito mais prazerosa.

Às novas amigas Rita, Joana, Márcia, Ana Paula e lara, pela participação no meu dia-a-dia na elaboração da fase final deste trabalho sempre me incentivando e compartilhando conhecimento. 
Aos velhos amigos, Mariana, Giovanna, Tauane, Jéssica, Breila, Rafael e Toshi pelo prazer da companhia, pelo incentivo, pela paciência, pela representação especial que cada um tem em minha vida.

Ás funcionárias do Departamento de Cirurgia e Anatomia, Camila e Juliana, pelo incentivo, torcida, aconselhamento e auxílio essenciais à concretização desse sonho.

Às funcionárias do Laboratório de Bioquímica, Cecília, Maria Elisa, Maria Aparecida e Clarice pela presteza e colaboração na realização das análises do material de coleta.

Ás funcionárias da Central de Materiais do HCFMRP - USP, Alexandra, Elaine, Viviane, Ana Paula, Vanessa, Eliana pela prontidão na higienização do material utilizado neste trabalho.

Aos pacientes do Hospital das Clínicas de Ribeirão Preto da Faculdade de Medicina da Universidade de São Paulo pela participação e contribuição que possibilitaram a realização desta pesquisa.

Ao Hospital das Clínicas de Ribeirão Preto da Faculdade de Medicina da Universidade de São Paulo por disponibilizar as instalações e materiais para realização deste e de tantos outros projetos de pesquisa.

Á FAEPA e a FAPESP pelo apoio financeiro. 
A vida nem sempre segue o nosso querer, mas ela é perfeita naquilo que tem que ser.

Chico Xavier 


\section{RESUMO}

Nascimento, Marina Neves. Correlação entre o condensado do exalado pulmonar, teste de caminhada de seis minutos e shuttle walk test em indivíduos cardiopatas. Ribeirão Preto, 2014. 93 p. Dissertação (Mestrado). Faculdade de Medicina de Ribeirão Preto - São Paulo, 2014.

Introdução: As doenças cardíacas ou do aparelho circulatório são as principais causas de morte na população brasileira, sendo responsável por um terço dos óbitos. Embora o tratamento conservador seja amplamente adotado, grande parte das doenças cardiovasculares necessita e tem como tratamento a cirurgia cardíaca, da qual as mais comuns são a cirurgia de revascularização do miocárdio (CRVM) e de troca valvar. Atualmente existem diversos estudos avaliando a função pulmonar ou a capacidade funcional para o acompanhamento do tratamento conservador ou em situação pré-operatória, porém estudos avaliando e correlacionando essas variáveis no pré-cirúrgico são escassos na literatura científica não sendo possível averiguar a existência da relação entre os níveis de nitrito e nitrato e o desempenho nos testes de capacidade funcional. Objetivo: Avaliar a correlação nitrito/nitrato (NOx) do condensado do exalado pulmonar (CEP) e a distância caminhada nos testes de caminhada de 6 minutos (TC6) e shuttle walk test (SWT), além de verificar se a utilização de medicações contendo betabloqueadores, nitrato ou enzima conversora de angiotensina (IECA) podem influenciar nas concentrações de nitrito/nitrato no CEP e nas distâncias caminhadas no TC6 e no SWT e comparar seu comportamento entre valvopatas e coronariopatas no pré operatório de cirurgia cardíaca. Metodologia: Foram selecionados 73 pacientes, dos quais 28 eram coronariopatas e 45 valvopatas, de ambos os sexos, com idade entre 20 e 80 anos, feita coleta do CEP para análise do NOx e submetidos ao TC6 e ao SWT para avaliação da distância caminhada. Resultados: $\mathrm{Na}$ análise das concentrações de NOx do CEP não foi encontrada diferença estatisticamente significativa entre as medicações utilizadas via oral contendo nitrato (dinitrato de isossorbida), IECA (captopril ou enalapril) e/ou betabloqueador ou entre os pacientes do grupo coronariopata e grupo valvopata ( $>00,05)$. Houve diferença estatisticamente significativa no TC6 nos valores de frequência cardíaca (FC) inicial, final e repouso e no valor referente à dispnéia final, e no SWT nos valores de FC inicial, final e repouso, na pressão arterial sistólica (PAS) inicial e no valor referente à dispnéia final entre os grupos coronariopata e valvopata. No entanto, foram interrompidos 4 TC6 e 7 SWT do grupo coronariopata devido ao desencadeamento de dor precordial, fato não ocorrido no grupo valvopata, apresentando nível de significância. A FC inicial e de repouso no TC6 e a FC final no SWT dos pacientes que não ingeriram nenhum medicamento antes do teste é diferente em relação à dos pacientes que fizeram uso de quaisquer medicamentos descritos antes do teste sugerindo a ação de medicamentos que modulam a FC como os betabloqueadores. Foi constatado correlação positiva moderada entre o NOx do CEP e os valores de PAS inicial e final de coronariopatas e correlação negativa fraca a moderada entre 0 NOx do CEP e os valores de FC final e de dispnéia final nos valvopatas no TC6, além da correlação positiva moderada entre o NOx do CEP e os valores de PAS inicial de indivíduos coronariopatas e correlação negativa fraca a moderada entre o NOx do CEP e os valores de FC inicial nos valvopatas no SWT. Foi identificado correlação negativa moderada na distância caminhada no TC6 e no SWT apenas nos indivíduos coronariopatas. Conclusões: Não foram identificadas influências do 
uso de medicações betabloqueadoras, nitrato ou IECA sobre a dosagem de NOx ou a distância caminhada em nenhum dos testes e em nenhum dos grupos, no entanto coronariopatas com níveis mais elevados de NOx apresentaram uma distância deambulada menor.

Descritores: Cirurgia cardíaca; condensado de exalado pulmonar; teste de caminhada de seis minutos; shuttle walk test, betabloqueadores. 
Nascimento, M. N. Correlation between exhaled breath condensate, six minutes walk test and shuttle walk test in heart disease. Ribeirão Preto, 2014. 93 p. Dissertation (Master). Ribeirão Preto School of Medicine - São Paulo University, 2014.

Introduction: Heart disease or circulatory system diseases are the leading causes of death in our population, accounting for one third of deaths. Although conservative treatment is widely adopted, part of cardiovascular disease treatment demands heart surgery, of which the most common are coronary artery bypass grafting (CABG) and valve replacement. Currently there are many studies evaluating lung function or functional capacity for monitoring of conservative treatment or preoperative situation, but studies assessing and correlating these variables in pre surgical are rare in the literature is not possible to ascertain the existence of the relationship between levels of nitrite and nitrate (NOx) in exhaled breath condensate (EBC) and performance in functional ability tests. Methods: were selected 73 patients, 28 with coronary artery diseas and 45 with heart valve disease of both genders, aged 20 to 80 years old. The EBC was collected for analysis of NOx and performed the six minutes walking test (6MWT) and shuttle walk test (SWT) to evaluate the distance walked. Results: the analysis of the concentrations of NOx in EBC has no statistically significant difference found between the medications used, such as oral nitrate (isosorbide dinitrate), ace inhibitors (captopril or enalapril) and/or beta-blockers in both coronary artery disease and heart valve disease ( $p>0.05)$. There was a statistically significant difference in 6MWT for HR initial, final and rest and final dyspnea, and in SWT for HR initial, final and rest, the initial SBP and the final dyspnea between the coronary artery disease $\mathrm{e}$ heart valve disease. However, were interrupted 4 6MWT and 7 SWT from coronary artery disease related to chest pain, this fact was not related in patients with valve disease, presenting a significance level. The initial and resting HR during the 6MWT and in SWT final HRr patients not ingesting any medication before the test is different from patients who used any medications before the test, suggesting the action of drugs that modulate the HR, such as beta blockers. Moderate positive correlation was found between the NOx in EBC and SBP initial and final in coronary disease and weak to moderate correlation between the NOx in EBC and final HR and final dyspnea in 6MWT from heart valve disease. Besides the positive moderate correlation between NOx in the EBC and the SBP initial in coronary disease during 6MWT and weak to moderate negative correlation between NOx in the EBC and the HR initial in valve disease during SWT. Moderate negative correlation was identified in the distance walked during the 6MWT and SWT only between individuals with coronary artery disease. Conclusions: the use of beta-blocker drugs, ace inhibitors or nitrate evidenciates no influence on the NOx or on the distance walked in any tests, and none of the groups, however, individuals with coronary artery disease showed higher NOx levels and performed lower distance walked.

Key-words: Cardiac surgery, exhaled breath condensate, six minutes walk test, shuttle walk test, beta blockers. 


\section{LISTA DE FIGURAS}

Figura 1: Formação do NO a partir do substrato L-arginina.

Figura 2: Tubo de vidro condensador em forma de "U" com aberturas laterais para entrada e saída do fluxo de ar ("A" e "B") e coletor do CEP ("C") conectado na abertura inferior do condensador 34

Figura 3: Aparato para coleta do CEP. A: bocal. B: válvula inspiratória. C: válvula expiratória. D: local de conexão do coletor de vidro.

Figura 4: Aparato para coleta do CEP conectado ao tubo condensador e ao ventilômetro . 35

Figura 5: Foto de modelo realizando coleta do CEP 36

Figura 6: Aparelho analisador de nitrito/nitrato Sievers 280i (Sievers, Boulder, CO, EUA).38

Figura 7: Centrífuga refrigerada (Eppendorf Centrifuge 5810R, Hamburg, Alemanha) 38

Figura 8: Percurso do TC6 40

Figura 9: Voluntário realizando TC6. 41

Figura 10: Percurso do SWT. 44

Figura. 11: Voluntário realizando SWT 44

Figura. 12: Variável de FC inicial no TC6 em cada par de medicamentos comparados 59

Figura 13: Variável de FC repouso no TC6 em cada par de medicamentos comparados ... 60

Figura 14: Variável de FC final no SWT em cada par de medicamentos comparados 62

Figura 15: Correlação entre a concentração do NO exalado e a distância caminhada no teste de caminhada de 6 minutos no grupo coronariopata.

Figura 16: Correlação entre a concentração do NO exalado e a distância caminhada no shuttle walk test no grupo coronariopata 


\section{LISTA DE TABELAS}

Tabela 1: Níveis do teste de caminhada com carga progressiva, com as respectivas velocidades, números de shuttle por nível e tempo de cada shuttle

Tabela 2: Características clínicas dos 73 pacientes cardiopatas

Tabela 3: Características dos indivíduos valvopatas

Tabela 4: Comparação das concentrações de nitrito/nitrato no condensado do exalado pulmonar entre coronariopatas e valvopatas.

Tabela 5: Valores dos sinais vitais, escala de Borg e distância caminhada no teste de caminhada de 6 minutos entre coronariopatas e valvopatas. 53

Tabela 6: Valores dos sinais vitais, escala de Borg e distância caminhada no shuttle walk test entre coronariopatas e valvopatas.

Tabela 7: Testes interrompidos devido ocorrência de precordialgia 55

Tabela 8: Relação de testes interrompidos e concluídos. 55

Tabela 9: Descrição do uso de medicamentos utilizados entre os grupos coronariopatas e valvopatas 56

Tabela 10: Análise da concentração de nitrito/nitrato no condensado do exalado pulmonar conforme tipo de medicação em uso.

Tabela 11: Efeito das medicações utilizadas sobre os sinais vitais, escala de Borg e distância caminhada do TC6

Tabela 12: Variável de FC inicial no TC6 em cada par de medicamentos comparados 59

Tabela 13: Variável de FC repouso no TC6 em cada par de medicamentos comparados ... 60

Tabela 14: Efeito das medicações utilizadas sobre os sinais vitais, escala de Borg e distância caminhada do SWT 
Tabela 15: Variável de FC final no SWT em cada par de medicamentos comparados 62

Tabela 16: Influência dos betabloqueadores na freqüência cardíaca no TC6 e SWT 63

Tabela 17: Correlação da idade e da fração de ejeção entre os grupos coronariopata e valvopata 64

Tabela 18: Correlação da concentração de nitrito/nitrato no condensado do exalado pulmonar entre os pacientes valvopatas e coronariopatas no teste de caminhada de seis minutos 65

Tabela 19: Correlação da concentração de nitrito/nitrato no condensado do exalado pulmonar entre os pacientes valvopatas e coronariopatas no shuttle walk test...... 66 


\section{LISTA DE ABREVIATURA E SIGLAS}

\begin{tabular}{|c|c|}
\hline$\mu \mathrm{M}$ & Micromolar \\
\hline${ }^{\circ} \mathrm{C}$ & Grau Celsius \\
\hline ATS & American Thoracic Society \\
\hline AVC & Acidente Vascular Cerebral \\
\hline AVD & Atividade de Vida Diária \\
\hline CEP & Condensado do Exalado Pulmonar \\
\hline c-NOS & Óxido Nítrico Sintase Constitutiva \\
\hline CRVM & Cirurgia de Revascularização do Miocárdio \\
\hline DAC & Doença Arterial Coronariana \\
\hline DPOC & Doença Pulmonar Obstrutiva Crônica \\
\hline DVP & Doença Vascular Periférica \\
\hline e-NOS & Óxido Nítrico Sintase Endotelial \\
\hline ERDF & Endothelial-Derivated Relaxing Factor \\
\hline FAPESP & Fundação de Amparo à Pesquisa do Estado de São Paulo \\
\hline FC & Frequência Cardíaca \\
\hline FE & Fração de Ejeção \\
\hline FMRP & Faculdade de Medicina de Ribeirão Preto \\
\hline GC & Grupo Coronariopata \\
\hline GV & Grupo Valvopata \\
\hline HAS & Hipertensão Arterial Sistêmica \\
\hline $\mathrm{Hb}$ & Hemoglobina \\
\hline $\mathrm{HCL}$ & Ácido Clorídrico \\
\hline HP & Hipertensão Pulmonar \\
\hline IC & Insuficiência Cardíaca \\
\hline ICC & Insuficiência Cardíaca Crônica \\
\hline IECA & Inibidores de Enzima Conversora de Angiotensina \\
\hline IMC & Índice de Massa Corpórea \\
\hline i-NOS & Óxido Nítrico Sintase Indutível \\
\hline LBA & Lavado Brônquico Alveolar \\
\hline MMII & Membros Inferiores \\
\hline $\mathrm{N}_{2} \mathrm{O}$ & Óxido Nitroso \\
\hline NADPH & Nicotinamida-adeninadinucleotídeo-fosfato-hidrogênio \\
\hline
\end{tabular}




\begin{tabular}{|c|c|}
\hline n-NOS & Óxido Nítrico Sintase Neuronal \\
\hline NO & Óxido Nítrico \\
\hline $\mathrm{NO}_{2}^{-}$ & Nitrito \\
\hline $\mathrm{NO}_{3}^{-}$ & Nitrato \\
\hline NOS & Óxido Nítrico Sintase \\
\hline NOx & Óxido Nítrico Exalado \\
\hline NYHA & Classe Funcional de New York Heart Association \\
\hline $\mathrm{O}_{2}$ & Oxigênio \\
\hline PA & Pressão Arterial \\
\hline PCARP & Prefeitura do Campus de Ribeirão Preto \\
\hline SARA & Síndrome do Desconforto Respiratório Agudo \\
\hline $\mathrm{SpO}_{2}$ & Saturação Periférica de Oxigênio \\
\hline SPSS & Statistical Package of the Social Sciences \\
\hline SWT & Shuttle walk test \\
\hline USP & Universidade de São Paulo \\
\hline TBG & Tabagista \\
\hline TC6 & Teste de Caminhada de 6 Minutos \\
\hline $\mathrm{VO}_{2}$ & Consumo de Oxigênio \\
\hline $\mathrm{VO}_{2}$ máx & Consumo de Oxigênio Máximo \\
\hline
\end{tabular}




\section{SUMÁRIO}

1. INTRODUÇÃO

2. REVISÃO DA LITERATURA

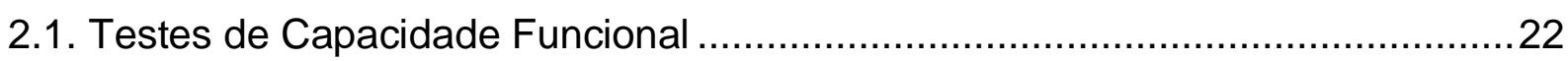

2.1.1. Teste de Caminhada de 6 Minutos.............................................................22

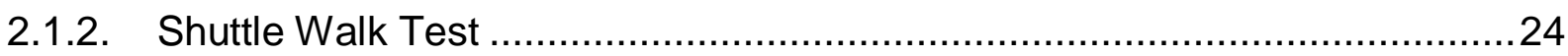

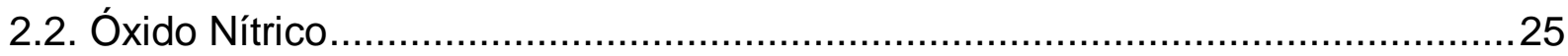

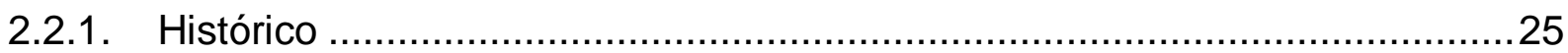

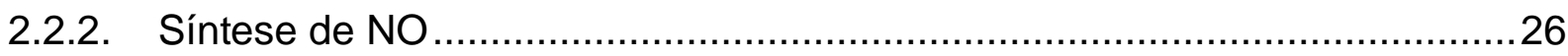

2.2.3. Isoformas de NOS e Sua Ação no Organismo ..........................................27

2.2.4. Condensado do Exalado Pulmonar .......................................................28

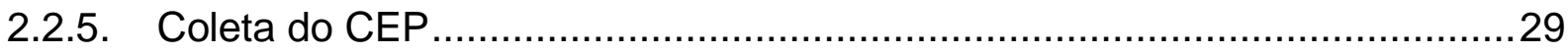

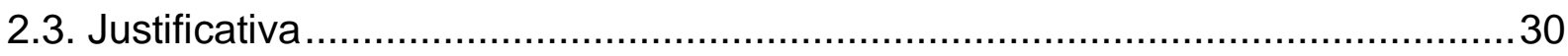

3. OBJETIVOS

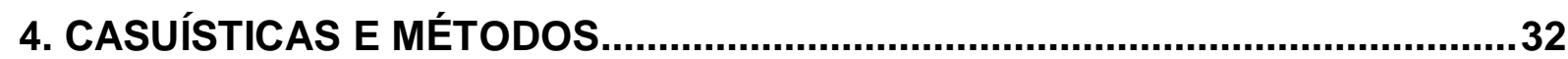

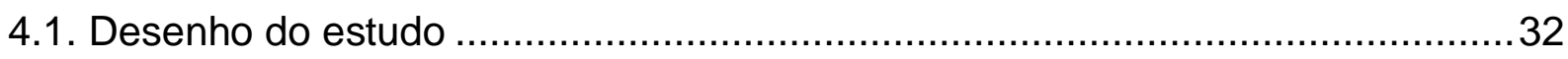

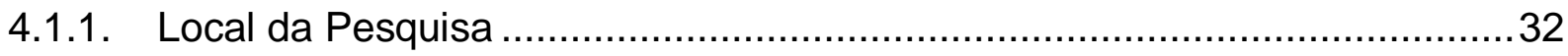

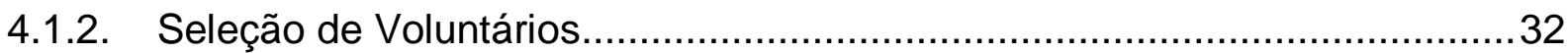

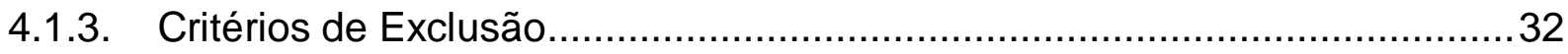

4.2. Coleta do CEP

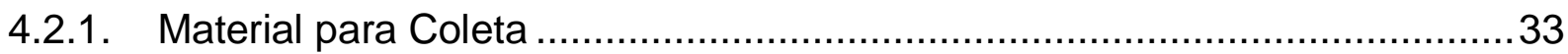

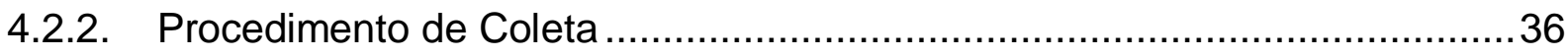

4.2.3. Desinfecção do Dispositivo de Coleta ......................................................37

4.2.4. Mensuração do NO, Nitrito/Nitrato no CEP ………...................................37

4.3. Protocolo do Teste de Caminhada de 6 Minutos ..............................................40 
4.3.1.1. Informações Precedentes ao Teste ..................................................... 41

4.3.2. Equipamentos Utilizados para a Realização do TC6 ...............................43

4.4. Protocolo do Shuttle Walk Test ......................................................... 43

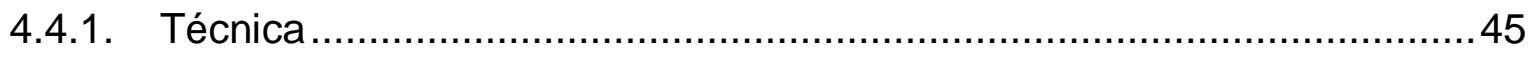

4.4.1.1. Informações Precedentes ao Teste .............................................. 45

4.4.2. Equipamentos Utilizados para a Realização do SWT .........................47

4.5. Critérios para Contra-Indicação do TC6 e o SWT .....................................47

4.6. Medidas de Segurança ........................................................... 48

5. ANÁLISE ESTATÍSTICA

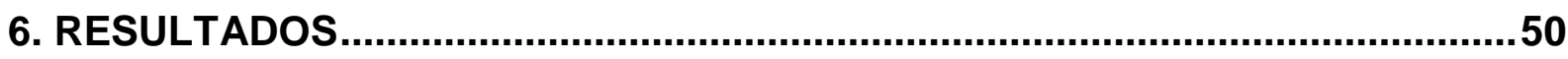

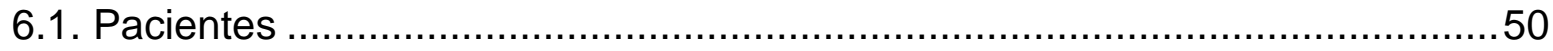

6.1.1. Pacientes Selecionados para o Estudo .........................................50

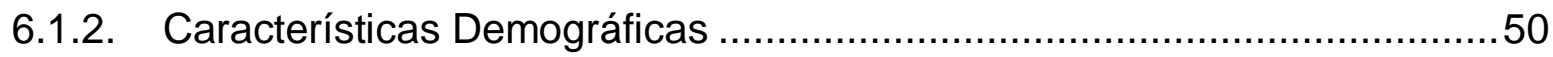

6.2. Análise da Concentração de Nitrito/Nitrato (Nox) no CEP entre Coronariopatas

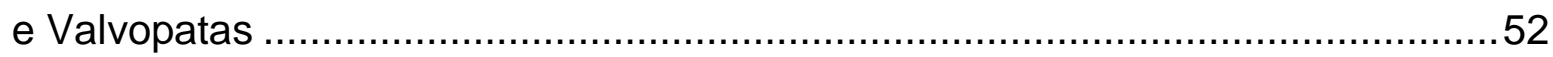

6.3. Análise do Desempenho do TC6 SWT entre Coronariopatas e Valvopatas ...53

6.4. Análise da Influência de Medicações nos Níveis de Nitrito/Nitrato e no

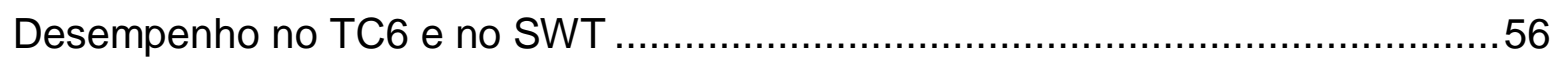

6.5. Correlações entre o NOx do CEP e Idade, Fração de Ejeção e os Parâmetros do TC6 e SWT entre Coronariopatas e Valvopatas .....................................64

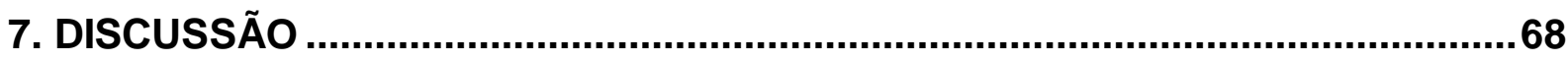

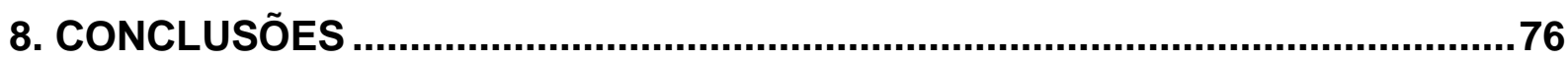

9. REFERÊNCIAS BIBLIOGRÁFICAS ....................................................... 77

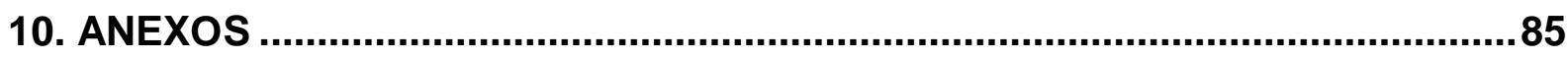




\section{Introdução}

As doenças cardiocirculatórias são atualmente as principais causas de mortalidade e hospitalização no mundo ocidental. No Brasil, em 2009, segundo o Datasus, elas foram a primeira causa de óbito (83.422 de 387.213 ou $21,3 \%$ ), a terceira de internação (1.139.140 de 11.128 .809 ou $10,2 \%$ ) e a de maior custo para o Ministério da Saúde ( $\mathrm{R} \$ 1.972 .767 .561,78$ de $\mathrm{R} \$ 10.124 .918 .629,27$ ou $19,5 \%$ do custo total). No Estado de São Paulo, a taxa de mortalidade por doenças do aparelho circulatório no ano de 2005 foi de 24.325 óbitos, apresentando 262.784 internações no mesmo ano (DATASUS, 2005; 2009).

Parte das doenças cardiovasculares tem como tratamento o procedimento cirúrgico. Para tanto, o número de internações para a realização de cirurgia cardíaca tem aumentado a cada ano correspondendo a 7.520 internações no ano de 2005. O tipo de cirurgia mais freqüente é a de revascularização do miocárdio, seguida pela cirurgia valvar, totalizando 10.652 cirurgias de revascularização do miocárdio e/ou troca valvar durante o período de janeiro a junho de 2008 , sendo o custo total de $R \$$ 91.837.917,24 e a taxa de mortalidade nacional de 7,93\%. Com esse quadro epidemiológico, observa-se o elevado custo que a cirurgia cardíaca tem na atenção de alta complexidade na saúde (DATASUS, 2005, ROSAMOND, 2008).

Nesse contexto, diversas frentes de pesquisa vêm sendo desenvolvidas no intuito de aprofundar o conhecimento a respeito de cirurgia cardíaca, no préoperatório, no intra-operatório e no pós-operatório.

Estudos têm analisado o óxido nítrico (NO) e seus subprodutos como o nitrito e o nitrato (NOx) do condensado do exalado pulmonar (CEP) como marcadores de funções pulmonares e cardíacas (KHARITONOV et al., 1996; KÖVESI et al., 2005; CIKACH JR; DWEIK, 2012), e mais recentemente em situação pré e pós operatória com o intuito de avaliar a inflamação pulmonar e a possível inclusão dessa avaliação no exame clínico de pacientes a serem submetidos à cirurgia cardíaca (AUGUSTO et al., 2009).

Desde a descoberta do NO, pesquisas são realizadas com intuito de esclarecer suas principais funções biológicas, tais como: ação no sistema imunológico, neurotransmissão, vasodilatação e broncodilatação (GASTON et al., 1994; MURAD, 1998). O NO passou a ser visto como uma molécula fundamental em quase todas as reações biológicas humanas (ANGGARD, 1994, MUTO et al., 1996). 
Dependendo do local de síntese, da quantidade produzida, do tipo de isoenzima envolvida e no microambiente onde vai atuar, o NO exercerá diferentes ações. Está bem definida a presença do NO no ar exalado como constituinte normal na respiração humana e animal. O NO funciona como broncodilatador ao agir em oposição aos estímulos colinérgicos broncoconstritores (GARTHWAITE, 1993). Quando produzido pelo endotélio vascular pulmonar, o NO tende a provocar vasodilatação na mucosa brônquica (BARNES; BELVISI, 1993).

Além da participação de processos fisiológicos, o NO exalado tem sido apontado como um possível marcador de afecções pulmonares e é estudado na asma, na DPOC, no tabagismo, na fibrose cística, bronquiectasias, câncer pulmonar, hipertensão pulmonar, insuficiência respiratórias, transplante pulmonar, nas infecções de trato respiratório superior e inferior, etc (CHATKIN et al., 2000).

Ocorre aumento na fração expirada de óxido nítrico (FeNO) nos asmáticos com rápida redução com 0 uso de corticoesteróides dose-dependente (KHARITONOV et al., 1996). Nos tabagistas há redução da FeNO com relação direta com a quantidade de cigarros consumidos e ao grau de obstrução brônquica. Embora seja conflitante no DPOC, com estudos sugerindo ora aumento, ora redução da FeNO, as discrepâncias podem ser explicadas pelos diferentes critérios de seleção de pacientes e técnicas metodológicas (CORRADI et al., 1999).

Além disso, o tratamento farmacológico tem sido coadjuvante de diversas doenças cardiovasculares com o objetivo de melhorar a função cardíaca, a interação entre os sistemas do organismo e, por consequência, a capacidade funcional. É comum o consumo de fármacos betabloqueadores, inibidores da enzima conversora da angiotensina (IECA) e nitratos orais em pacientes cardiopatas. Estudos demonstram uma possível interação medicamentosa com o NO exalado embora seja escasso o levantamento literário à respeito. Sugere-se que a enzima conversora da angiotensina é abundante na superfície endotelial pulmonar e a IECA seria responsável por gerar um maior aumento do NO exalado (SUMINO et al., 2000). Já os betabloqueadores por gerarem um aumento da síntese e liberação de NO endotelial pode acarretar uma redução da liberação de NO exalado. E o uso de nitrato oral, por sua vez, doadores de NO, sugerem um aumento de suas concentrações (VILHENA; LOURO, 2006).

Por outro lado, a redução da capacidade funcional em pacientes cardiopatas com indicação cirúrgica já é bem descrita na literatura. Para quantificar essa 
alteração, tanto o teste de caminhada de seis minutos (TC6) quanto o shuttle walk test (SWT), embora este último em menor escala, são utilizados na prática clínica no pré-cirúrgico cardíaco.

O TC6 é um instrumento válido para avaliar a capacidade funcional em diferentes intervenções clínicas. Uma delas é sua aplicabilidade em pacientes que se preparam para serem submetidos à cirurgia cardíaca, uma vez que é considerado um teste submáximo, de fácil aplicabilidade e baixo custo (NERY et al., 2010), além de estimar o prognóstico, mensurar a qualidade de vida e a capacidade de realizar atividades de vida diária (AVD) (REESINK et al., 2007).

Tanto o TC6 quanto o SWT apresentaram validade para avaliar o consumo máximo de $\mathrm{O}_{2}\left(\mathrm{VO}_{2}\right.$ máx), reprodutibilidade, responsividade e de predição de mortalidade em pacientes com doenças cardiorrespiratórias (FOWLER, SINGH, REVILL, 2005; SINGH, 2007).

A característica não incremental do TC6 gera o comportamento de estabilização das variáveis fisiológicas a partir da metade do teste (ONORATI et al., 2003). O TC6 possibilita avaliação de endurance mais do que a capacidade máxima de caminhada. O SWT tem sido melhor correlacionado com $\mathrm{VO}_{2}$ máx e melhor valor prognóstico que o TC6, sendo de boa confiabilidade e necessário apenas um teste para avaliar a aptidão cardiorrespiratória, sendo assim, o SWT tem maior validade para avaliar a aptidão física enquanto que o TC6 teve melhor correlação com as comorbidades e sintomas cardíacos (BUENO et al., 2012).

Entretanto, ainda não há descrito na literatura estudos avaliando a possibilidade de correlação entre o NO exalado, o TC6 e o SWT. Desse modo, destaca-se a necessidade do estudo da condição pulmonar e funcional do paciente cardiopata pré-cirúrgico que permita elucidar uma interação entre os componentes e estimar a intervenção e a evolução terapêutica. 


\subsection{TESTES DE CAPACIDADE FUNCIONAL}

\subsubsection{Teste de Caminhada de 6 Minutos}

O teste da caminhada de 6 minutos (TC6) é o teste mais freqüentemente utilizado para a determinação da capacidade funcional de cardiopatas e pneumopatas crônicos. É amplamente utilizado após intervenções médicas, intervenções com terapia medicamentosa, oxigenoterapia e prova preditora de morbimortalidade (AMERICAN THORACIC SOCIETY, 2002; RONDELLI et al., 2009). A avaliação funcional confirma a suspeita clínica da doença, quantifica o grau de comprometimento, avalia o prognóstico e auxilia no acompanhamento evolutivo da mesma (CAHALIN et al., 1996; RONDELLI et al., 2009).

O TC6 é um método adaptado do teste de corrida de 12 minutos, descrito originalmente por Cooper em 1968, para a avaliação de indivíduos saudáveis, para a determinação da relação entre a aptidão física e o $\mathrm{VO}_{2}$ máx (ENRIGHT et al., 2003). Essa adaptação foi feita com o intuito de ser aplicado em pessoas portadoras de patologias, e atualmente vem sendo muito utilizado como uma alternativa para avaliar a capacidade física de pacientes com doenças cardíacas e pulmonares (ENRIGHT et al., 2003).

A instrução desse teste é caminhar o mais rápido possível durante os seis minutos em um percurso de 30 metros e o examinado é quem determina a velocidade de caminhada. Portanto, este teste é submáximo, a não ser que o examinado não consiga caminhar por seis minutos. Como a maioria das atividades de vida diária é realizada em nível submáximo de exercício, na qual estudos defendem que a distância percorrida em seis minutos reflete melhor a atividade física diária comparada aos testes de exercício máximo (SOLWAY et al., 2001). Esse teste ainda tem a vantagem de avaliar os indivíduos por uma forma comum de exercício que é a caminhada em uma superfície plana, já que muitas pessoas não conseguem realizar adequadamente um teste na esteira ou cicloergômetro por não estarem habituadas a esta forma de exercício (SWERTS; MOSTERT; WOUTERS, 1990). 
O TC6 é de execução relativamente fácil e de baixo custo, entretanto, como o teste depende principalmente da colaboração do examinado e o ritmo da marcha é definido pelo mesmo, é fundamental que o examinador e o examinado compreendam adequadamente os objetivos e a sistemática do procedimento. O TC6 encontra-se, atualmente, bem padronizado, ainda que alguns aspectos técnicos e interpretativos sejam ainda discutíveis (ARAÚJO et al., 2006).

O TC6 destaca-se no campo da avaliação funcional por permitir sua execução entre pacientes com limitada tolerância aos esforços, dispnéia, fadiga e cianose que são sinais e sintomas característicos de uma cardiopatia isquêmica e/ou doença valvar, refletindo as atividades diárias do paciente, sem exacerbar seus sintomas e limitações cardiorrespiratórias, uma vez que possibilita ao paciente determinar a velocidade e a necessidade de realizar pausas, o que é uma vantagem adicional principalmente entre pacientes idosos (ARAÚJO et al., 2006).

De acordo com os resultados de um estudo, o TC6 se apresentou mais confiável quando se tem como objetivo a avaliação do desempenho do indivíduo durante as atividades de vida diária (AVD’s) (VALENTI et al., 2007). Além disso, estudos demonstram que o TC6 é uma importante ferramenta na predição de mortalidade em pacientes com insuficiência cardíaca (IC) sintomática (CAHALIN et al., 1996).

O TC6 é considerado um teste submáximo o que permite inferir a existência de uma correlação linear entre a distância total percorrida e $0 \mathrm{VO}_{2}$ máx obtido de forma mais simplificada, já que o teste ergoespirométrico é um método complexo, mais caro e disponível apenas em grandes centros de pesquisa para a determinação do condicionamento cardiorrespiratório (CAHALIN et al., 1996; ARAÚJO et al., 2006).

Outras provas de exercício cardiopulmonares fornecem informações abrangentes sobre a resposta ao exercício, a capacidade funcional, determinam a intensidade necessária para realizar um exercício prolongado, quantificam os fatores que limitam o exercício e definem os mecanismos fisiopatológicos subjacentes, tais como a contribuição dos diferentes órgãos e sistemas que participam no exercício. Com isso, as informações fornecidas pelo TC6 devem ser consideradas complementares a estas provas, porém não de substituí-las (AMERICAN THORACIC SOCIETY, 2002). 
Embora os testes de marcha controlada (shuttle walk test - SWT) tenham a vantagem da relativa homogeneização da "carga de trabalho" a ser realizada, o seu emprego, no nosso meio, ainda se restringe a centros terciários especializados e/ou protocolos de pesquisa (RONDELLI et al., 2009).

\subsubsection{Shuttle Walk Test}

O Shuttle walk test (SWT) é um teste clínico de esforço que visa estabelecer a função cardiorrespiratória do indivíduo, avaliar e diagnosticar a presença e a gravidade da doença. O SWT é considerado um teste de esforço incremental, pois nele o sujeito é solicitado a andar de acordo com velocidades crescentes e padronizadas em doze níveis, com duração de um minuto em cada nível, impostas por um sinal sonoro ao redor de um circuito, até a exaustão (SINGH et al., 1992; ROSA et al., 2006; SINGH et al., 2008).

O circuito consiste em uma pista de dez metros onde o paciente caminha ao encontro do final da pista, quando muda o sentido da caminhada, retornando ao local de saída e assim sucessivamente até o final do teste (SINGH et al., 1992; ROSA et al., 2006; SINGH et al., 2008). Os sons que orientam e impõem ritmo ao teste são reproduzidos por um aparelho de som portátil, e é solicitado que a um determinado sinal o paciente esteja em uma das extremidades do percurso, delimitando o tempo no qual será percorrida a distância de 10 metros. A velocidade torna-se crescente, acompanhando o sinal sonoro, que muda a cada nível, obrigando o aumento da velocidade para atingir a extremidade da pista. O teste é continuado até a exaustão, que determina seu término, mensurando-se a distância percorrida (SINGH et al., 1992; HERNANDEZ, 1997; ROSA, 2006; SINGH et al., 2008).

$\mathrm{O} \mathrm{VO}_{2}$ máx é um parâmetro de referência na avaliação da capacidade funcional, porém o procedimento para analisar o gás expirado durante o exercício cardiopulmonar é complexo e de alto custo, portanto um método de avaliação simplificado é mais bem empregado. Em pacientes com DPOC e com insuficiência cardíaca, o SWT demonstrou ser um método de medida objetiva da limitação funcional (MORALES et al., 1999). 
Morales et al. (1999) descrevem em seu estudo a aplicação do SWT para avaliar a capacidade funcional entre pacientes com IC e verificar a eficácia de tratamento farmacológico ou protocolos de reabilitação. Identificaram que quanto maior a distância deambulada durante o teste, maior a possibilidade de apresentar um $\mathrm{VO}_{2}$ máx preservado. Pacientes que alcançaram a distância de $450 \mathrm{~m}$ no SWT, provavelmente apresentam um $\mathrm{VO}_{2}$ máx $>14 \mathrm{~mL} / \mathrm{kg} / \mathrm{min}$. Esta informação pode ajudar a equipe médica na condução do tratamento dos pacientes. Este estudo pode constatar que o SWT é um método adequado para avaliar pacientes com IC classificado de moderado a grave, provando ser um método simples, seguro e reprodutível após apenas uma realização do teste (MORALES et al., 1999).

O SWT tem a capacidade de prever $0 \mathrm{VO}_{2}$ máx de forma mais eficaz que $\mathrm{o}$ TC6, porém mais estudos precisam ser desenvolvidos com o intuito de investigar o desempenho obtido durante o teste, além de avaliar seu comportamento posteriormente à intervenções cirúrgicas e suas implicações prognósticas uma vez que estudos com esse âmbito são escassos na literatura científica (MORALES et al., 1999).

\section{2. ÓXIDO NÍTRICO}

\subsubsection{Histórico}

O óxido nítrico (NO) era descrito, no início dos anos 80, apenas como um poluente ambiental nocivo, presente em combustíveis fósseis, exaustor de automóveis e fumaça de cigarro, contribuindo com a destruição da camada de ozônio e a ocorrência de chuva ácida (RICCIARDOLO, 2003; AUGUSTO et al., 2009). Outro meio de produção do NO é a partir do solo por meio da nitrificação bacteriana que pode ser removido pela denitrificação com formação de óxido nitroso $\left(\mathrm{N}_{2} \mathrm{O}\right)$ (BRUCKDORFER, 2005).

Ao final da década de 80 e início dos anos 90 o conhecimento sobre o NO começou a se modificar quando linhas de estudo passaram a identificar a importante participação da molécula endógena na fisiologia do corpo humano atuando como mensageiro (ou sinalizador inter e intracelular) e como toxina, atuando em inúmeros 
processos patológicos (FLORA FILHO; ZILBERSTEIN, 2000; RICCIARDOLO et al., 2004; BARRETO; CORREIA; MUSCARÁ, 2005).

Nos anos 80, o estudo de Furchgott \& Zawadzki demonstrou que o relaxamento dos vasos sanguíneos pela acetilcolina dependia da presença das células endoteliais, sendo estas diretamente dependentes da liberação de um fator responsável pelo relaxamento vascular denominado endothelial-derivated relaxing factor (ERDF).

Posteriormente nos estudos de Palmer, Ferrige e Moncada e lgnarro et al., ambos de 1987, demonstraram que a liberação de NO pelas células endoteliais foi indistinguível do ERDF em termos de atividade biológica, estabilidade e susceptibilidade como um inibidor ou potencializador, possibilitando deduzir que o ERDF era propriamente o NO.

\subsubsection{Síntese do óxido nítrico}

O NO endógeno é derivado do processo de oxidação e desaminação do aminoácido L-arginina em citrulina e NO, por meio de um sistema de enzimas chamadas NO sintase (NOS) (ELLIS et al., 1998). A reação global é ativada pela NOS, enzima catalisadora, resultando em eventos de óxido/reduções que envolvem diversos cofatores com sítios para ligação de enzimas específicas (BRUCKDORFER, 2005).

Para a formação do NO, a L-arginina é transformada em um intermediário, a NG-hidroxi-L-arginina com a presença de nicotinamida-adeninadinucleotídeo-fostatohidrogênio (NADPH) e a calmodulina $\left(\mathrm{Ca}^{2+}\right)$ (Figura 1) (FLORA FILHO; ZILBERSTEIN, 2000). As células da calmodulina $\left(\mathrm{Ca}^{2+}\right)$ independentes do NO são induzidas por lipopolissacarídeos e pelo interféron- y, sintetizando o NO e a citrulina a partir da L-arginina. O oxigênio molecular é a fonte do oxigênio $\left(\mathrm{O}_{2}\right)$ presente na formação do NO e da citrulina (LEONE et al., 1991). A inibição da síntese de NO pode ocorrer por mecanismos de retroalimentação, produzindo uma molécula de NO para cada citrulina (AUGUSTO et al., 2009). 


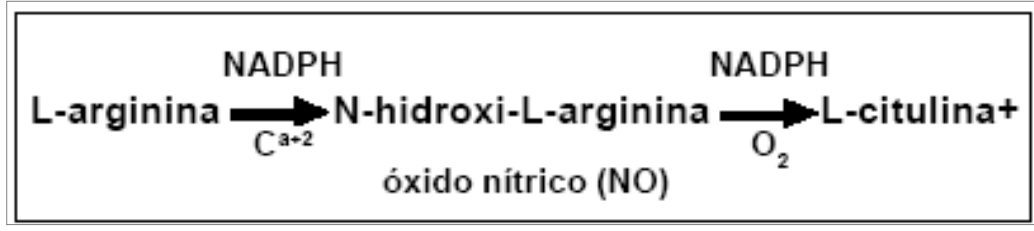

Figura 1: Formação do NO a partir do substrato L-arginina.

\subsubsection{Isoformas do óxido nítrico sintase (NOS) e sua ação no organismo}

O NO é sintetizado por três diferentes isoformas do óxido nítrico sintase (NOS), classificados de acordo com o mecanismo de regulação e distribuição nos tecidos do corpo (MONCADA; PALMER; HIGGS, 1991; KIECHLE; MALINSKI, 1993). Elas são agrupadas em duas categorias: a NOS constitutiva (cNOS), presente na membrana plasmática e é dependente de íons cálcio e de calmodulina, envolvida na sinalização celular. A NOS indutível (iNOS) que é produzida pelos macrófagos e outras células ativadas por citocinas através de um mecanismo de indução (MONCADA; PALMER; HIGGS, 1991; RICCIARDOLO et al., 2004; AUGUSTO et al., 2009). Existem dois tipos de cNOS que são: a NOS neuronal (isoforma I ou nNOS) que é predominantemente expressada nos neurônios e a NOS endotelial (isoforma III ou eNOS) principalmente expressada nas células endoteliais, embora outros tipos de células possam expressá-las (FÖRSTERMANN et al., 1984).

Os genes para essas isoformas estão situados em cromossomos diferentes: nNOS no cromossomo doze, iNOS no cromossomo dezessete e eNOS no cromossomo sete (BRUCKDORFER, 2005).

$\mathrm{O} \mathrm{NO}$ após reagir com $\circ \mathrm{O}_{2}$ forma dois produtos estáveis que são o nitrito $\left(\mathrm{NO}^{2-}\right)$ e o nitrato $\left(\mathrm{NO}^{3-}\right)$ (GASTON et al., 1994). O NO é um intermediário no processo onde os macrófagos transformam a $\mathrm{L}$-arginina em $\mathrm{NO}^{2-}$ e $\mathrm{NO}^{3-}$, e este processo sugere atuar como um sinalizador de ativação para essas células, semelhante ao que é observado nas células endoteliais. Este processo é requerido pelos macrófagos para atingir a atividade essencial de morte celular. Esse mesmo processo quando expressado nas células endoteliais, tem sido reportado para produzir o relaxamento muscular das células lisas. Embora o processo seja quase idêntico para ambas as células, as funções que estas desempenham são muito diferentes (MARLETTA et al., 1988). 
James (1995) aponta que a proporção da produção do NO determina o benefício versus seus efeitos nocivos, de maneira que o excesso de produção de NO pode destruir não apenas fontes celulares, mas também tecidos. Esse efeito sugere que o NO pode estar envolvido na fisiopatologia de muitas doenças pulmonares, como síndrome da angústia respiratória aguda (SARA), doença pulmonar obstrutiva crônica (DPOC), fibrose cística, asma, hipertensão pulmonar (HP), bronquiectasias, disfunção mucociliar primária, doenças pulmonares intersticiais entre outras doenças das vias aéreas (BARNES; BELVISI, 1993).

\subsubsection{Condensado do Exalado Pulmonar}

O Condensado do Exalado Pulmonar (CEP), atualmente, tem sido amplamente pesquisado para a detecção de mediadores inflamatórios nos fluidos que revestem as superfícies das vias aéreas, com o intuito de analisar o grau de inflamação para melhor manejo das doenças respiratórias e adequação da conduta (MONTUSCHI, 2005). Este é coletado por meio do resfriamento do ar exalado de forma não invasiva e sem efeitos adversos (KHARITONOV; BARNES, 2001; MOLONEY et al., 2004; ROBROEKS et al., 2008).

As moléculas do CEP são provenientes da evaporação das superfícies das vias aéreas, dos brônquios e/ou alvéolos, do espaço morto anatômico e das vias aéreas superiores (CORRADI et al., 2003; AMERICAN THORACIC SOCIETY, 2006).

O CEP contém um grande número de mediadores incluindo a adenosina, amônia, peróxido de hidrogênio, isoprostanos, leucotrienos, óxidos de nitrogênio, peptídeos e citocinas (HORVÁTH; HUNT; BARNES, 2005). No ar exalado apenas uma porção formada do NO é liberada. Uma parte é oxidada e tornam-se espécies reativas com efeitos significativos (AMERICAN THORACIC SOCIETY, 2006). O NO²e o $\mathrm{NO}^{3-}$ são subprodutos do metabolismo do $\mathrm{NO}$ nas formas de redução do nitrogênio que estão presentes na cobertura do fluído epitelial no trato respiratório humano e podem ser detectados no CEP (HORVÁTH; HUNT; BARNES, 2005; KOSTIKAS et al., 2008).

A análise do CEP, pelas suas características, pode se tornar parte integrante da avaliação clínica e do teste de função pulmonar de forma a complementar a avaliação do paciente (MONTUSCHI, 2005). 


\subsubsection{Coleta do CEP}

Durante a coleta do CEP deve ser usada uma respiração regular (HORVÁTH; HUNT; BARNES, 2005) sendo que o indivíduo deve ser instruído a respirar normalmente para evitar a hiperventilação (AMERICAN THORACIC SOCIETY, 2006). O tempo de coleta de 10 minutos é recomendável para a maioria dos mediadores, provendo uma amostra adequada para a análise e sendo bem tolerado pelos pacientes (HORVÁTH; HUNT; BARNES, 2005). É sugerido que testes de função pulmonar forçado não sejam executados em um período de 10 minutos antes da coleta (AMERICAN THORACIC SOCIETY, 2006).

A condensação pode ser executada em uma temperatura por volta de $0^{\circ} \mathrm{C}$ usando gelo (salgado) quando o CEP é coletado como um fluído. Também pode ser coletado em baixas temperaturas usando diferentes técnicas (gelo seco e nitrogênio líquido), o que resulta em coleta de material congelado. As amostras do CEP não devem ser deixadas fora de temperatura adequada após as coletas. Isto é importante não apenas por causa da interação com o ar ambiente, mas também porque substâncias serão degradadas e formadas no CEP mais rapidamente nesta temperatura (HORVÁTH; HUNT; BARNES, 2005). Alguns cuidados devem ser levados em consideração na coleta e no armazenamento do CEP quando o NO2- e o NO3- são os íons de investigação, para não haver contaminação ou oxidação das substâncias no fluído (AMERICAN THORACIC SOCIETY, 2006).

O uso do clipe nasal é aconselhável para assegurar que nenhuma amostra seja perdida através do nariz e que a inspiração não passe pelo mesmo (HORVÁTH; HUNT; BARNES, 2005).

O hábito de fumar deve ser documentado, e nos fumantes é aconselhável parar de fumar 3 horas antes do início das medidas para prevenir uma influência aguda do fumo nos níveis dos mediadores (HORVÁTH; HUNT; BARNES, 2005). O uso de certas medicações como nitroprussiato de sódio, enalapril (inibidores da enzima conversora de angiotensina - IECA) também pode interferir nos níveis dos mediadores do CEP e também devem ser documentadas. Além destes também devem ser consideradas as exposições ocupacionais a folmaldeído e ozônio, manobras de espirometria feitas, exercícios físicos, doenças de vias aéreas superiores, ciclo menstrual, altitudes moderadas, fração inspirada de $\mathrm{O}_{2}$ a $100 \%$ e ingestão de álcool (KHARITONOV; BARNES; 2001). 


\subsection{JUSTIFICATIVA}

Pacientes portadores de valvopatias cardíacas e/ou doença arterial coronariana podem apresentar limitações na realização de suas atividades físicas diárias devido a redução da capacidade funcional e desencadeamento da angina pectoris. Embora as classificações funcionais da New York Heart Association e de angina da Canadian sejam uma maneira prática de avaliar tais limitações, essas avaliações são subjetivas. Os testes de caminhada, como o SWT e o TC6, são métodos mais objetivos e amplamente empregados na avaliação da capacidade funcional (ARAÚJO et al., 2006). Tais métodos, além de facilmente realizáveis, não exigem equipamentos complexos. Usualmente são empregados como forma objetiva de comparação da capacidade funcional antes e após os procedimentos cardíacos. Todavia, além da capacidade funcional cardíaca estes testes podem também ser influenciados por alterações respiratórias, sobretudo inflamatórias, e que podem influenciar nos níveis de NO no exalado ou no CEP. Seu emprego em pacientes coronariopatas e/ou valvopatas candidatos a operações cardíacas tem sido pouco explorados o que justifica a realização deste estudo. 
1. Comparar os níveis de nitrito/nitrato (NOx) no condensado do exalado pulmonar (CEP) de indivíduos coronariopatas ou valvopatas.

2. Comparar o desempenho de indivíduos coronariopatas ou valvopatas nos testes de caminhada de seis minutos (TC6) e o shuttle walk test (SWT).

3. Verificar se a utilização de betabloqueadores, nitratos ou inibidores da enzima conversora de angiotensina (IECA) podem influenciar nas concentrações de NOx no CEP e no desempenho do TC6 e SWT.

4. Avaliar a correlação entre os níveis de NOx do CEP com os parâmetros avaliados no TC6 e SWT em indivíduos coronariopatas ou valvopatas. 


\subsection{DESENHO DO ESTUDO}

\subsubsection{Local de Pesquisa}

A pesquisa foi na Enfermaria da Cirurgia Torácica e Cardiovascular do Hospital das Clínicas de Ribeirão Preto - FMRP/USP.

Este estudo foi aprovado pelo Comitê de Ética em Pesquisa (Processo HCRP no. 10989/2010 - ANEXO 1).

\subsubsection{Seleção dos Voluntários}

Foram convidados a participar do estudo pacientes de 20 a 80 anos, de ambos os sexos, internados para serem submetidos à operação valvar ou revascularização do miocárdio no período de maio de 2010 a novembro de 2013. Os voluntários leram e assinaram o "Termo de consentimento livre e esclarecido" após receberem os devidos esclarecimentos sobre sua participação no trabalho (ANEXO 2).

Os voluntários foram avaliados por ficha própria (ANEXO 3) constando dados da história do paciente, avaliação fisioterapêutica, dados antropométricos e resultados de exames de rotina pré-operatórios. O hábito tabágico e a medicação em uso foram documentados, pois os mesmos podem interferir nos valores do nitrito/nitrato encontrados no CEP e no desempenho durante o TC6 e o SWT.

\subsubsection{Critérios de Exclusão}

- Indivíduos operados em caráter de urgência ou emergência.

- Indivíduos submetidos a operações cardíacas associadas.

- Indivíduos em uso de nitroprussiato de sódio ou nitroglicerina endovenosa.

- Indivíduos vítimas de infarto agudo do miocárdio com menos de 30 dias de evolução ou que apresentaram precordialgia em menos de $24 \mathrm{~h}$ do teste. 
- Indivíduos que apresentaram lesão de tronco de coronária maior que 50\% de obstrução averiguada em cateterismo cardíaco ou estenose mitral acentuada indicada em ecodopplercardiograma.

- Indivíduos com história clínica diagnosticada de hipertensão pulmonar moderada a acentuada, asma brônquica ou DPOC.

- Indivíduos portadores de processo infeccioso pulmonar de qualquer natureza.

- Indivíduos que não conseguiram realizar quaisquer testes inclusos na metodologia desta pesquisa por motivo de déficit cognitivo ou do aparelho músculoesquelético.

- Indivíduos que apresentaram desconforto respiratório impedindo realizar os testes, dor precordial, dessaturação, vertigem, câimbras ou fadiga intensa de membros inferiores (MMII) previamente a realização dos testes ou qualquer outra razão de prevenção clínica.

\subsection{COLETA DO CONDENSADO DO EXALADO PULMONAR}

\subsubsection{Material para Coleta}

Para a realização da coleta do CEP, foi utilizado um dispositivo não invasivo (figura 2), desenvolvido na Divisão de Cirurgia Cardiovascular e Torácica da FMRPUSP (VENTO, ARCÊNCIO E RODRIGUES, 2012).

O dispositivo é composto de um tubo de vidro do tipo borosilicato Duran® (Schott-Rohrglas, Mitterteich, Germany) com $18 \mathrm{~mm}$ de espessura. Tem forma de "U" com extremidades horizontalizadas, com comprimento interno total de ponta a ponta de 53,5cm e externo de $63,5 \mathrm{~cm}$, o corpo do tubo em "U" possui $42 \mathrm{~cm}$ de diâmetro e $20 \mathrm{~cm}$ de comprimento de cada lado, as partes horizontais possuem um menor diâmetro, sendo de $22 \mathrm{~cm}$ e comprimento de $5 \mathrm{~cm}$. A parte inferior consiste num tubo de junta 14/20, ou seja, $14 \mathrm{~mm}$ de espessura por $20 \mathrm{~cm}$ de diâmetro e possui comprimento de $5 \mathrm{~cm}$, este possui um orifício no qual é conectado um encaixe confeccionado em resina Teflon® (Polifluor, São Paulo, Brasil) para escoamento do condensado para um microtubo de polipropileno 
(AxygenInc.,UnionCity, California, EUA) onde é armazenado o condensado durante a coleta.
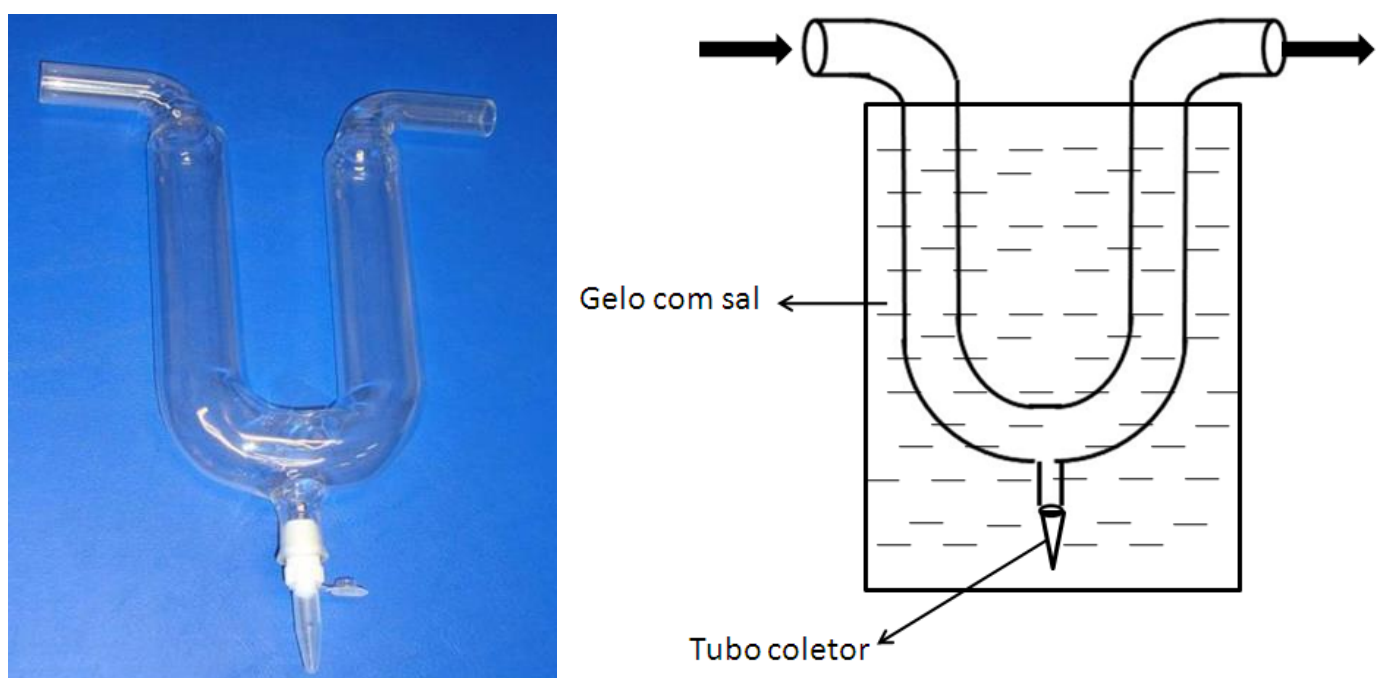

Figura 2: Tubo de vidro condensador em forma de "U" com aberturas laterais para entrada e saída do fluxo de ar e coletor do CEP conectado na abertura inferior do condensador.

O coletor fica totalmente submerso em gelo picado salgado protegido por um recipiente de isopor durante a coleta do CEP. Foi conectado ao coletor um aparato (figura 3) que possui um bucal e intermediários em plástico e silicone para a conexão de duas válvulas unidirecionais sendo representadas pela válvula exalatória do respirador mecânico BIRD Mark 7® (válvula $B$ e $C$ ), sendo que, a válvula $B$ funciona como válvula de abertura inspiratória direcionando o ar do meio ambiente para o interior do coletor até o indivíduo através do bocal, e a válvula $\mathrm{C}$ funciona como válvula expiratória, esta por sua vez, direciona o fluxo expiratório proveniente do indivíduo para o interior do coletor. Durante a inspiração a válvula para expiração permanece fechada garantindo que todo o ar inspirado pelo indivíduo venha do meio ambiente.

A extremidade oposta do tubo foi conectada a um ventilômetro digital (DHD Healthcare, New York, USA) com o objetivo de se monitorizar os valores de volume minuto e volume corrente durante a coleta de CEP. O ventilômetro foi posicionado a extremidade oposta do tubo de vidro para não haver interferência durante a coleta (Figura 4). 

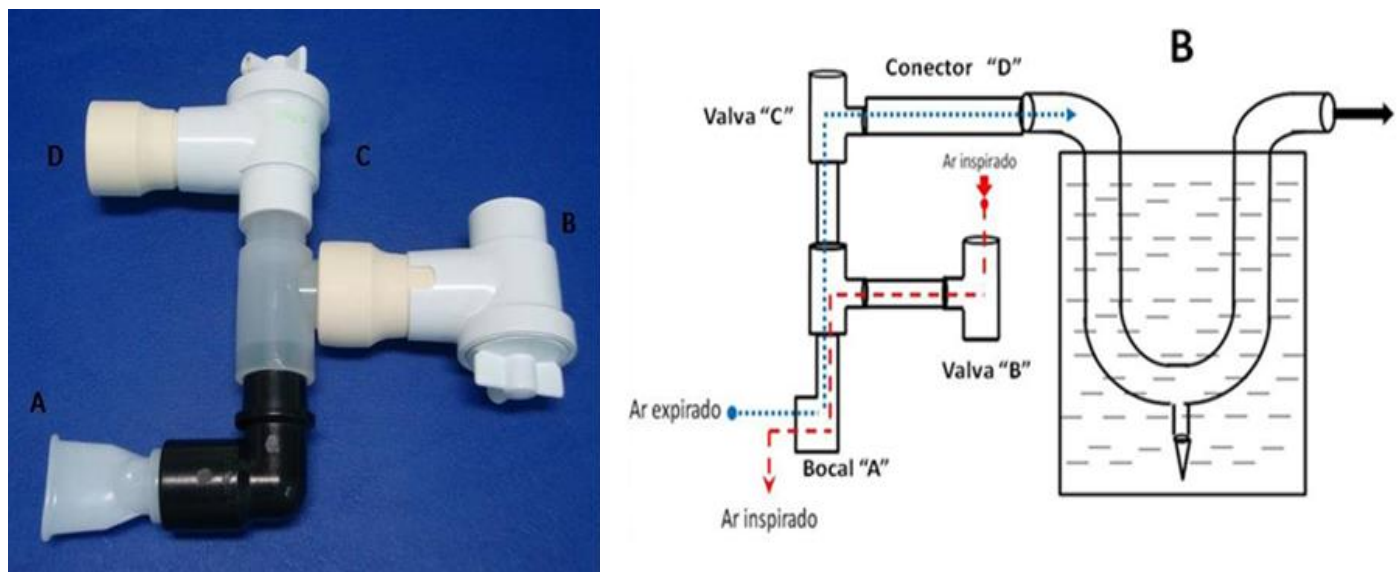

Figura 3: Aparato para coleta do CEP. A: bucal. B: válvula inspiratória. C: válvula expiratória. D: local de conexão do coletor de vidro.

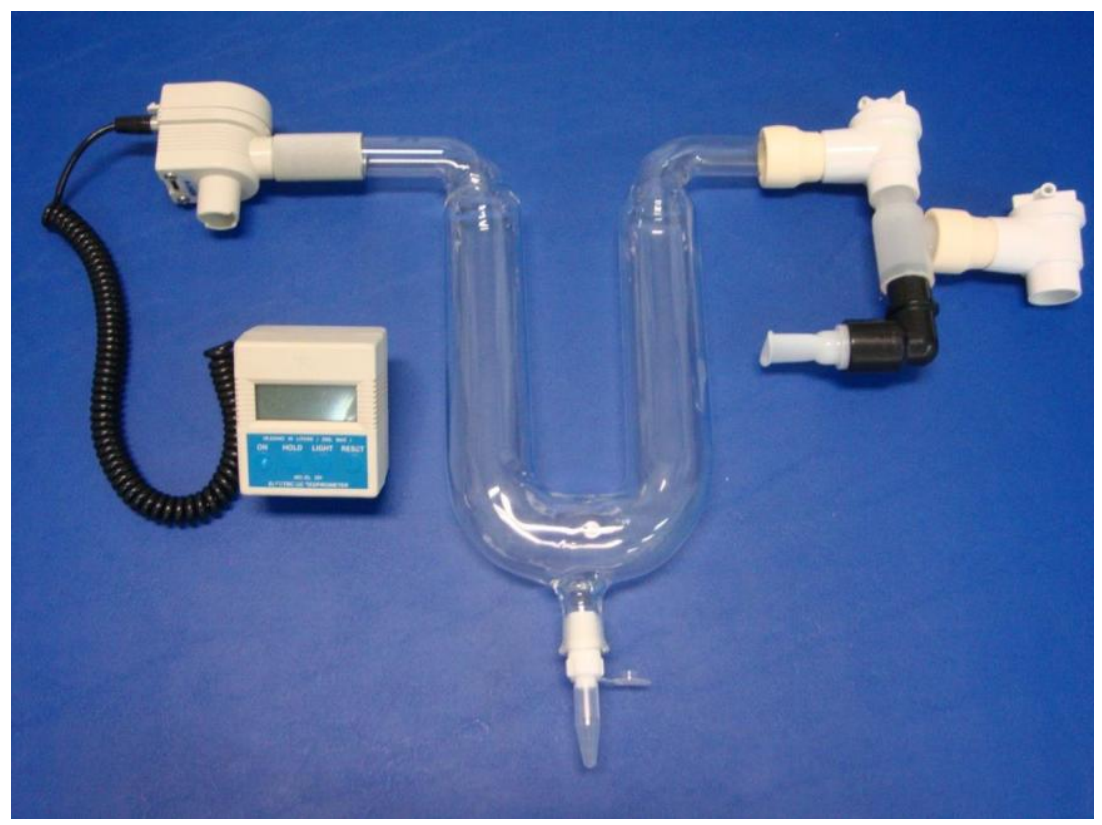

Figura 4: Aparato para coleta do CEP conectado ao tubo condensador e ao ventilômetro. 


\subsubsection{Procedimento de Coleta}

As coletas foram realizadas de acordo com as recomendações da American Thoracic Society (2006). As coletas foram realizadas previamente aos testes de esforço físico e antes de realizarem a cirurgia cardíaca, ao serem internados na Enfermaria da Cirurgia Torácica e Cardiovascular.

Foi solicitado ao voluntário realizar um enxague bucal com água antes da coleta. Em seguida, posicionado sentado, permanecendo em repouso por 5 minutos, no mínimo. O mesmo recebeu instruções, antes de iniciar a coleta, de como proceder. Havendo um ensaio com o dispositivo sem o aparato conectado, para que o voluntário se familiarize e para que possíveis erros possam ser corrigidos e evitados. Dadas as orientações, o voluntário aguarda mais 5 minutos antes de iniciar a coleta. Após esse período e com a certificação de que o bucal está bem acoplado e o clipe nasal foi posicionado corretamente o voluntário foi orientado a respirar normalmente pelo aparato durante 10 minutos (figura 5).

Caso o voluntário tenha apresentado sinais e sintomas como tonturas, desconforto respiratório, mal estar e dispnéia durante a execução da coleta a mesma foi interrompida.

O material obtido permanece acumulado no microtubo de polipropileno, através do orifício inferior do coletor, transportado resfriado em gelo a $-20^{\circ} \mathrm{C}$, e estocado em freezer a $-70^{\circ} \mathrm{C}$ e analisado posteriormente.

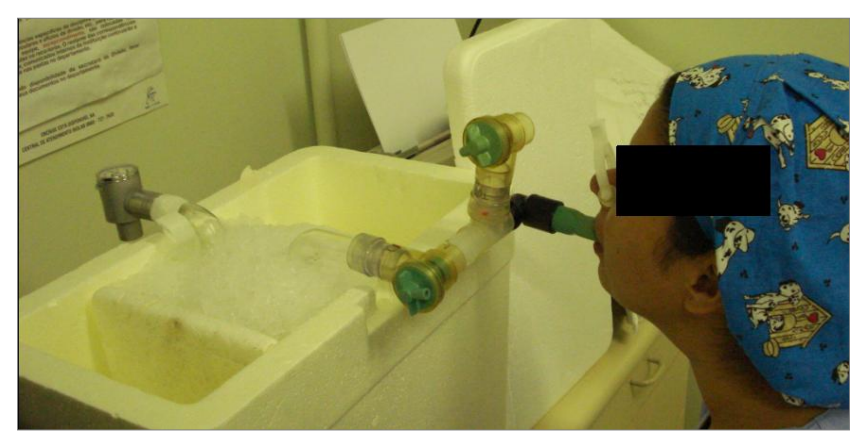

Figura 5: Foto de modelo realizando coleta do CEP. 


\subsubsection{Desinfecção do Dispositivo de Coleta}

Ainda não existem procedimentos padronizados para descontaminação dos condensadores, mas é necessária uma esterilização cuidadosa a fim de evitar a contaminação cruzada. As peças constituídas por material plástico, silicone e teflon foram encaminhadas para a Central de Materiais do Hospital das Clínicas FMRP/USP para limpeza e esterilização. Inicialmente foram lavadas com água e sabão, depois mergulhadas em solução de ácido peracético Anioxyde 1000 (Anios, Pavê Du Moulin, Lille, França) com concentração de 1471 ppm por 30 minutos. Terminado este procedimento as peças foram novamente enxaguadas em água e secas o que elimina qualquer resíduo do ácido peracético. As peças foram acondicionadas em saco plástico lacrado até a utilização.

O tubo de vidro em "U" foi lavado em água corrente seguida por lavagem em água destilada, deionizada e ultrafiltrada (Milli-q). Após estes procedimentos o tubo foi encaminhado a Central de Materiais do HC-FMRP/USP para esterilização na Autoclave HI VAC (Baumer AS, Mogi-Mirim, São Paulo, Brasil) a uma temperatura

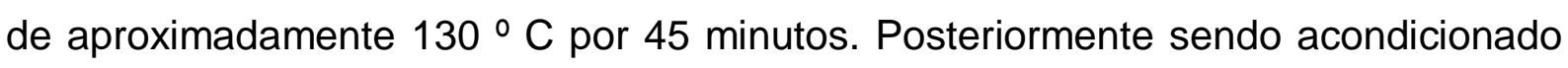
em tecido de algodão ou em tecido SMS constituído de propileno $100 \%$.

\subsubsection{Mensuração dos níveis de nitrito/nitrato (NOx) no CEP}

A técnica empregada para análise do NOx foi a quimioluminescência. $A$ deteç̧ão do NO é baseada na observação da interação do ozônio com o NO para gerar luz. Esta luminescência gerada é mensurada por um tubo sensível fotomultiplicador e é diretamente proporcional aos níveis de NO. A análise foi realizada no aparelho Nitric Oxide Analyzer, 280i NOA (Sievers, Boulder, CO, EUA), adquirido com verba do projeto 00/08537-3-FAPESP, que se encontra no Laboratório de Função Endotelial da FMRP-USP, do departamento de Cirurgia e Anatomia (Figura 6). 


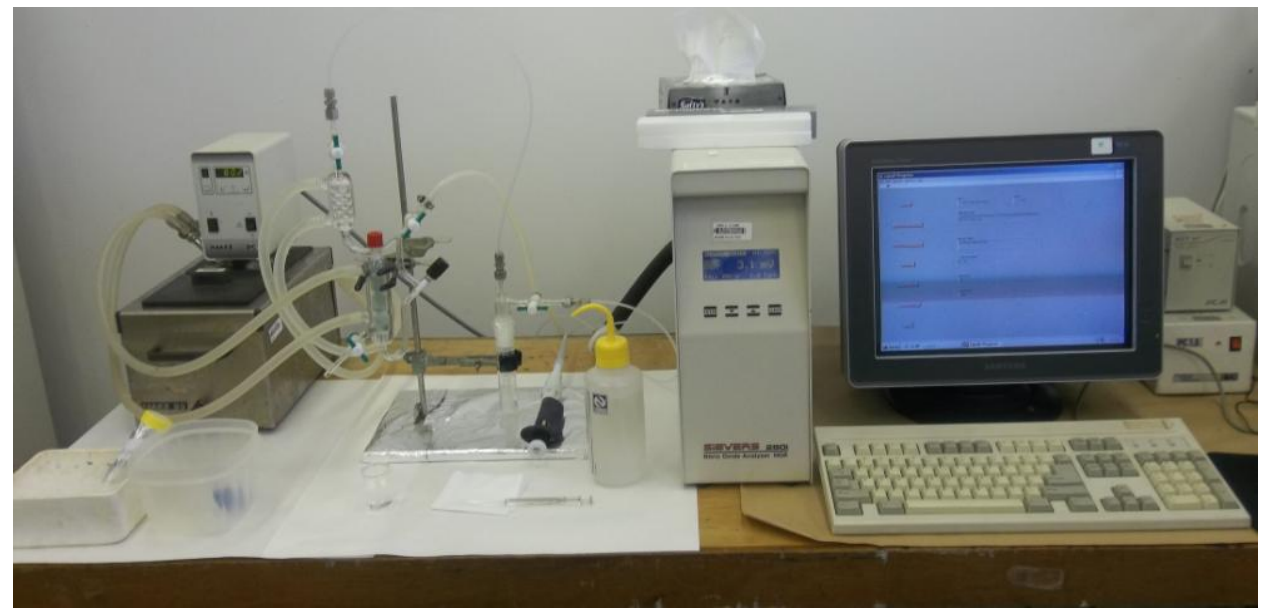

Figura 6: Aparelho analisador de nitrito/nitrato Sievers 280i (Sievers, Boulder, CO, EUA).

As amostras do CEP foram desproteinizadas antes da análise, 0 procedimento adotado, consistiu em: pipetar $0,5 \mathrm{~mL}$ da amostra em um microtubo de polipropileno de $1,5 \mathrm{~mL}$ e adicionar $1 \mathrm{~mL}$ de etanol frio, em seguida agitado no vórtex e mantido na geladeira por 30 minutos a $0^{\circ} \mathrm{C}$, posteriormente, a amostra foi centrifugada a aproximadamente 10.000 rotações por minuto durante 5 minutos (Eppendorf Centrifuge 5810R, Hamburg, Alemanha) (Figura 7). O sobrenadante foi então utilizado para dosagem dos produtos do óxido nítrico exalado (NOx) (nitrito/nitrato).

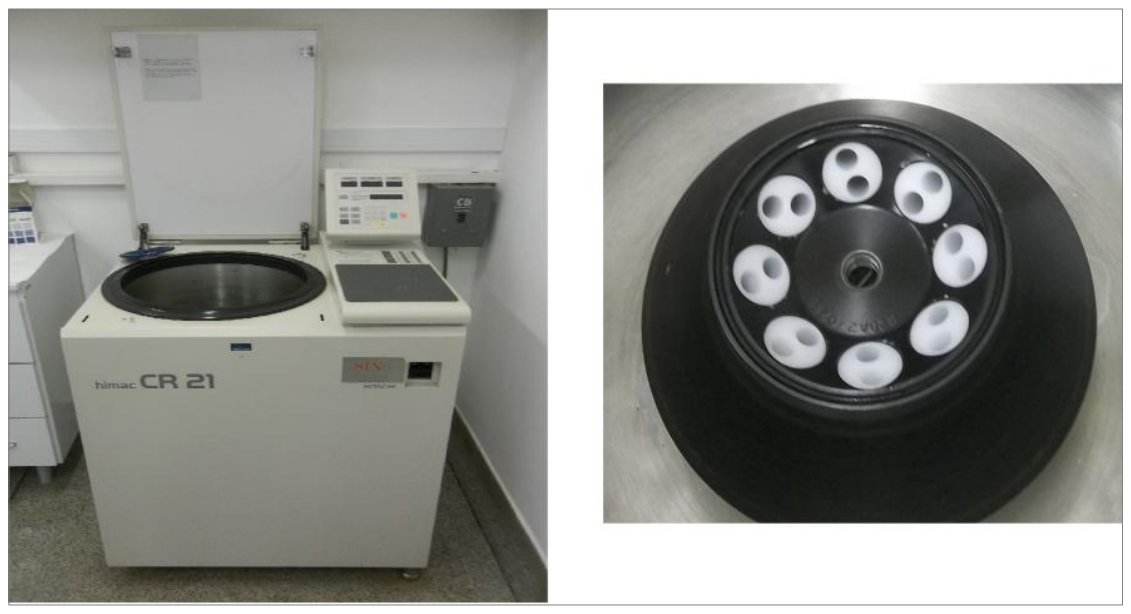

Figura 7: Centrífuga refrigerada (Eppendorf Centrifuge 5810R, Hamburg, Alemanha). 
As concentrações dos NOx foram obtidas utilizando $200 \mu \mathrm{l}$ da amostra injetada em um vaso de reação contendo $20 \mathrm{ml}$ de um agente redutor (constituído por ácido acético glacial, iodeto de potássio e flocos de iodo sublimado) em $15 \mathrm{ml}$ de $\mathrm{HCL} 1 \mathrm{~N}$, que converte o nitrito em NO em quantidades equimolares. Assim este NO é dragado, utilizando gás nitrogênio, para câmara de quimioluminescência do Sievers 280i NOA.

Todo material utilizado nesta técnica foi enxaguado com água MilliQ, livre de contaminantes. As análises foram realizadas por pesquisadores especializados e capacitados, integrantes do Laboratório de Função Endotelial da FMRP-USP, do Departamento de Cirurgia e Anatomia. 


\subsection{PROTOCOLO DO TESTE DE CAMINHADA DE 6 MINUTOS}

O TC6 foi realizado segundo padronização da American Thoracic Society (ATS, 2002).

Os indivíduos realizaram o teste após a coleta de CEP, em ordem aleatória à realização do SWT e previamente à cirurgia cardíaca ao serem internados na Enfermaria da Cirurgia Torácica e Cardiovascular.

O teste foi realizado em um corredor plano, de superfície firme, livre de circulação de pessoas, com demarcação de 30 metros de comprimento. Este sendo marcado a cada $3 \mathrm{~m}$ e os pontos de rotação delimitados com cones com distância de 29 metros entre eles permitindo 0,5 metro em cada extremidade para a rotação.

O indivíduo permaneceu em repouso por pelo menos 15 minutos antes e após o teste. Nesse período de repouso foram coletados e registrados em ficha específica (ANEXO 4) os dados referentes a PA, FC, FR, $\mathrm{SpO}_{2}$ e aplicada a escala de Borg (ANEXO 5). Esta escala é um instrumento que gradua a intensidade da sensação subjetiva de desconforto respiratório e fadiga.

O indivíduo foi orientado quanto à realização do teste, onde o mesmo deve caminhar o mais rápido possível, sem correr, durante 6 minutos. Sendo informado que o mesmo pudesse descansar, desacelerar o passo ou até parar caso fosse necessário, porém sem parar o cronômetro (Figura 8 e 9).

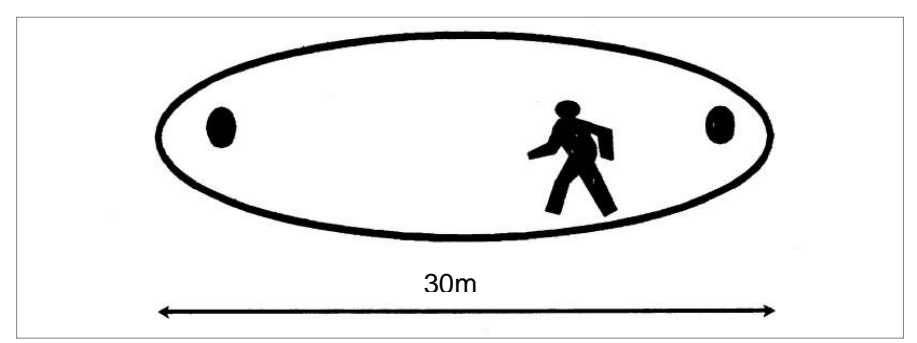

Figura 8: Percurso do TC6 


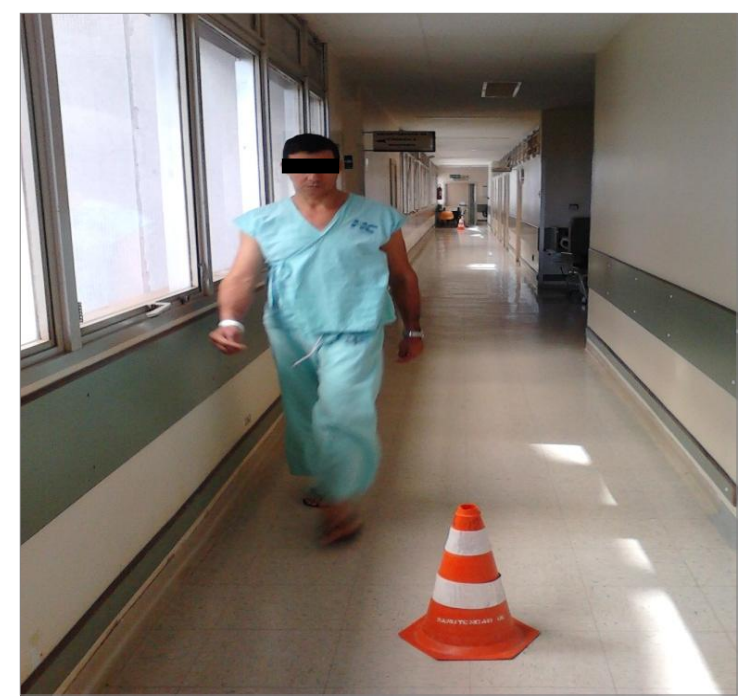

Figura 9: Voluntário realizando o TC6

\subsubsection{Técnica}

\subsubsection{Informações Precedentes ao Teste}

Os voluntários foram orientados a utilizar vestimentas adequadas, assim como de dispositivos habituais (bengala, etc) e a não realizar exercícios vigorosos dentro das 2 horas que antecedem a prova e ingerir alimentos leves. As medicações prescritas não foram suspensas.

- Antes do TC6

O indivíduo permanece em repouso por 15 minutos antes de iniciar o teste. Registrar:

- Pressão arterial (PA)

- Frequência cardíaca (FC)

- Frequência respiratória (FR)

- Saturação periférica de oxigênio $\left(\mathrm{SpO}_{2}\right)$

- Escala de Borg (Fadiga e dispnéia).

- Durante o TC6

Durante cada minuto da realização do teste frases encorajadoras foram ditas ao paciente, como: 
"Você está indo bem. Você tem 5 minutos".

"Mantenha um bom trabalho. Você tem 4 minutos para ir."

"Você está indo bem. Está na metade do caminho".

"Mantenha o bom trabalho. Você só tem 2 minutos restantes."

"Você está indo bem. Você tem apenas 1 minuto".

- Interrupção do TC6

O TC6 é interrompido quando:

- O indivíduo referir muito desconforto respiratório para continuar.

- O indivíduo atingir 85\% da FC máxima predita ( $F C_{\text {máx: }} 210$ - 0.65 x idade)

- O indivíduo apresentar qualquer dos seguintes sinais e sintomas:

- Dor no peito com suspeita de angina.

- Confusão mental ou incoordenação.

- Visão turva.

- Dispnéia intolerável.

- Câibras ou fadiga intensa de membros inferiores

- Persistência de $\mathrm{SpO}_{2} \leq 85 \%$

- Qualquer outra razão de prevenção clínica.

- Ao término do TC6

Ao término do teste senta-se o voluntário:

- Registrados a PA, FC, FR, $\mathrm{SpO}_{2}$ e Borg imediatamente após a interrupção do teste.

- Anotado o número de voltas e registrar a distância adicional da última volta com auxílio dos marcadores de distância da parede. Calcula-se a distância total percorrida, arredondando para o metro mais próximo.

- Após cinco minutos, registrado novamente a $\mathrm{SpO}_{2}$, a $\mathrm{FR}$, a $\mathrm{FC}$, a PA e a Escala de Borg para avaliação da recuperação.

O indivíduo permanece em repouso por 15 minutos após o teste. 


\subsubsection{Equipamentos utilizados para a realização do TC6}

- Frequencímetro cardíaco (Polar RS300X, Kempele, Finlândia)

- Cronômetro (Nokia Xpress 5310, Helsinki, Finlândia)

- Cones para demarcar os pontos da volta

- Uma cadeira que pode ser transportada facilmente em todo o percurso

- Esfigmomanômetro (Premium, Missouri, EUA)

- Oxímetro de pulso (PM100C New Tech, Guandong, China)

- Estetoscópio (Classic II, Littmann, Minessota, EUA)

\subsection{PROTOCOLO DO SUTTLE WALK TEST}

A padronização do SWT foi feito baseando-se no método proposto por Singh et al. (1992). O teste foi realizado no mesmo corredor utilizado para o TC6, com a redução do comprimento do percurso para 10 metros, este sendo marcado a cada 3 $\mathrm{m}$ e os pontos de rotação delimitados com cones com distância de 9 metros entre eles permitindo 0,5 metro em cada extremidade para a rotação.

Os indivíduos realizaram o teste após coleta do CEP e previamente à cirurgia cardíaca ao serem internados na Enfermaria da Cirurgia Torácica e Cardiovascular de forma aleatória para ordem de realização entre o TC6 e o SWT, obtida através de sorteio.

O sujeito foi orientado a caminhar pelo percurso delimitado no corredor seguindo um ritmo gravado e reproduzido por aparelho de som portátil, de acordo com velocidades crescentes padronizadas, em doze níveis, com duração de um minuto em cada nível, impostas por um sinal sonoro (bipe) que indica o momento de atingir as extremidades do trajeto demarcadas pelos cones nas extremidades do percurso (figura 10 e 11, tabela 1).

O percurso foi igual para todos os testes e indivíduos, em que os cones respeitaram a distância de 9 metros entre eles, totalizando uma distância percorrida em torno dos cones de 10 metros. 
O indivíduo foi orientado a caminhar entre dois cones realizando uma volta a cada bipe. Inicialmente, a velocidade de caminhada é baixa, mas a velocidade aumenta progressivamente a cada minuto. O indivíduo caminha até a exaustão, na qual não sustenta mais o ritmo de caminhada de acordo com os bipes e/ou apresente dispnéia que impeça a continuidade do teste.

Apenas instruções do som portátil devem ser seguidas. Diferente do TC6, os indivíduos não foram ser encorajados durante o SWT.

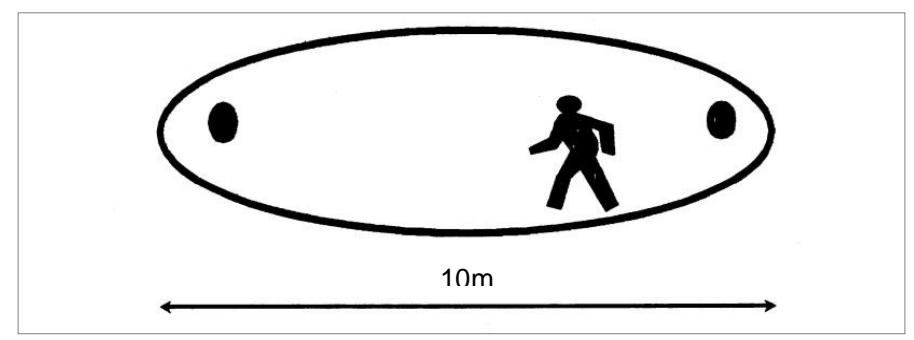

Figura 10: Percurso do SWT

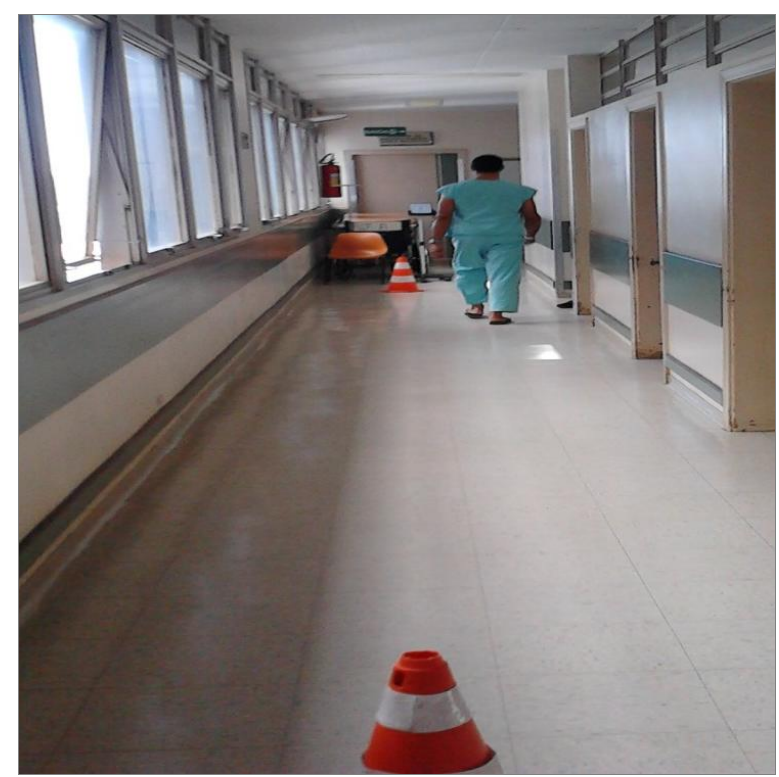

Figura 11: Voluntário realizando o SWT 
Tabela 1: Níveis do teste de caminhada com carga progressiva, com as respectivas velocidades, números de shuttle por nível e tempo de cada shuttle

\begin{tabular}{|c|c|c|c|c|c|}
\hline \multirow{2}{*}{ Nível } & \multicolumn{2}{|c|}{ Velocidade } & \multirow{2}{*}{$\begin{array}{c}\text { No. de } \\
\text { shuttle por } \\
\text { nível }\end{array}$} & \multirow{2}{*}{$\begin{array}{c}\text { Tempo por } \\
\text { shuttle } \\
\text { segundo }\end{array}$} & \multirow{2}{*}{$\begin{array}{c}\text { Distância } \\
\text { percorrida ao fim } \\
\text { da cada nível }\end{array}$} \\
\hline & $\mathrm{m} / \mathrm{s}$ & mph & & & \\
\hline 1 & 0.50 & 1.12 & 3 & $20 "$ & 30 \\
\hline 2 & 0.67 & 1.50 & 4 & $15 "$ & 70 \\
\hline 3 & 0.84 & 1.88 & 5 & $12 "$ & 120 \\
\hline 4 & 1.01 & 2.26 & 6 & $10 "$ & 180 \\
\hline 5 & 1.18 & 2.64 & 7 & $8 " 57$ & 250 \\
\hline 6 & 1.35 & 3.02 & 8 & $7 " 50$ & 330 \\
\hline 7 & 1.52 & 3.40 & 9 & $6 " 66$ & 420 \\
\hline 8 & 1.69 & 3.78 & 10 & $6 "$ & 520 \\
\hline 9 & 1.86 & 4.16 & 11 & $5 " 45$ & 630 \\
\hline 10 & 2.03 & 4.54 & 12 & $5 "$ & 750 \\
\hline 11 & 2.20 & 4.92 & 13 & $4 " 61$ & 880 \\
\hline 12 & 2.37 & 5.30 & 14 & 4"28 & 1020 \\
\hline
\end{tabular}

\subsubsection{Técnica}

\subsubsection{Informações Precedentes ao Teste}

Utilizar vestimentas adequadas, assim como de dispositivos habituais (bengala, etc);

Medicamentos usuais não foram suspensos;

Ingestão de alimentos leves;

Não realizar exercícios vigorosos dentro das 2 horas que antecedem a prova. 
- Antes do SWT

O indivíduo permaneceu em repouso por 15 minutos antes de iniciar o teste. Registrado (ANEXO 6):

$$
\begin{aligned}
& -P A \\
& \text { - FC } \\
& \text { - FR }
\end{aligned}
$$$$
-\mathrm{SpO}_{2}
$$

- Escala de Borg (Fadiga e dispnéia)

- Durante o SWT

Seguir as instruções da gravação, e uso das orientações padrão:

- Ao ouvir o bipe de incremento de velocidade:

"Agora aumente a sua velocidade de caminhada."

- Uso da frase a seguir se o indivíduo estiver $0.5 \mathrm{~m}$ distante do cone ao soar o bipe:

"Você não está rápido o bastante; tente melhorar a velocidade desta vez."

- Registrado cada volta completada na folha de registro do SWT.

- Monitorização do indivíduo acerca de possíveis sinais e sintomas.

- Interrupção do SWT

O SWT foi interrompido quando:

- O indivíduo estava mais de $0.5 \mathrm{~m}$ distante do cone quando soou o bipe.

- O indivíduo referiu muito desconforto respiratório para continuar.

- O indivíduo atingiu $85 \%$ da FC máxima predita ( $F_{\text {máx }}: 210$ - 0.65 x idade)

- O indivíduo apresentou qualquer dos seguintes sinais e sintomas:

- Dor precordial com suspeita de angina.

- Confusão mental ou incoordenação.

- Visão turva.

- Dispnéia intolerável.

- Câibras ou fadiga intensa de MMII.

- Persistência de $\mathrm{SpO}_{2} \leq 85 \%$

- Qualquer outra razão de prevenção clínica. 
Ao término do teste senta-se o voluntário:

- Registrado a PA, FC, FR, $\mathrm{SpO}_{2}$ e Borg imediatamente após a interrupção do teste.

- Após cinco minutos, registra-se novamente a $\mathrm{SpO}_{2}$, a $\mathrm{FR}$, a $\mathrm{FC}$, a PA e a Escala de Borg para avaliar a recuperação.

- Registro do total de voltas

- Registro do motivo de interrupção do teste. Deve-se perguntar ao indivíduo:

"O que você acha que o impediu de seguir o ritmo dos bipes?"

O indivíduo permanece em repouso por 15 minutos após o teste.

\subsubsection{Equipamentos utilizados para a realização do SWT}

- Frequencímetro cardíaco (Polar RS300X, Kempele, Finlândia)

- Gravação dos sons padronizados (SINGH et al., 1992)

- Cones para demarcar os pontos da volta

- Esfigmomanômetro (Premium, Missouri, EUA)

- Oxímetro de pulso (PM100C New Tech, Guandong, China)

- Estetoscópio (Classic II, Littmann, Minessota, EUA)

\subsection{CRITÉRIOS PARA CONTRA-INDICAÇÃO DO TC6 E O SWT}

Embora o TC6 e o SWT sejam provas de capacidade funcional considerados simples, eficazes, de baixo custo, com boa aceitação e de fácil aplicabilidade, não devem ser realizados sem considerar alguns critérios e precauções, apresentando as seguintes contra-indicações absolutas e relativas:

- Absolutas:

- Angina instável e infarto agudo do miocárdio recentes;

- $\mathrm{SpO}_{2}$ basal menor que $90 \%$;

- Arritmia cardíaca não controlada;

- Déficit cognitivo e distúrbios de comportamento;

- Hipertensão pulmonar severa;

- Insuficiência renal de moderada a grave. 
- Relativas:

- FC de repouso acima de $120 \mathrm{bpm}$;

- PA sistólica acima de $180 \mathrm{mmHg}$;

- PA diastólica acima de $100 \mathrm{mmHg}$;

- Angina estável (realizar o teste somente após usar medicação antiangina);

- Presença de problemas músculo-esqueléticos ou neuromusculares;

- Anemia e quaisquer doenças febris ou infecciosas.

\subsection{MEDIDAS DE SEGURANÇA}

As provas foram realizadas em um lugar que possibilitasse emergências ou atenção médica rápida. Oxigênio, nitroglicerina sublingual, aspirina e salbutamol (inalador ou nebulizador) eram disponíveis para quaisquer necessidades, assim como telefone ou outros meios de comunicação.

O avaliador capacitado em ressuscitação cardiopulmonar com um mínimo de suporte de vida. Os médicos não eram obrigados a estarem presentes durante todas as provas, porém estavam prontamente disponíveis para intervir, se necessário.

Caso o indivíduo fizesse uso de terapia crônica de oxigênio, o mesmo seria ofertado em sua taxa usualmente utilizada. 
$\mathrm{Na}$ análise estatística, foi realizado o teste de normalidade KolmogorovSmirnov. Os dados foram expressos em média \pm desvio-padrão e mediana para as variáveis de distribuição paramétrica e não paramétrica, respectivamente.

As comparações foram realizadas mediante os testes de Kruskal-Wallis e Mann-Whitney. A correlação entre nitrito/nitrato do CEP e aos parâmetros obtidos do TC6 e SWT foi verificada mediante o coeficiente de correlação de Spearman. As diferenças foram consideradas significativas se $p<0,05$. Empregou-se o programa estatístico "Statistical Package for the Social Sciences", versão 18.0 (SPSS Inc., Chicago, IL, EUA). 


\subsection{PACIENTES}

\subsubsection{Pacientes selecionados para o estudo}

Foram selecionados 84 indivíduos para o estudo mediante avaliação dos pesquisadores. Destes, 11 foram excluídos pelos seguintes motivos: 1 considerado cirurgia congênita com estenose valva pulmonar associada, 1 aneurisma de aorta ascendente associado, 9 testes incompletos dos quais 3 receberam alta e foram encaminhados para tratamento conservador, 1 recusa do paciente devido mal estar no dia da realização de um dos testes e 5 encaminhados para cirurgia antes da conclusão dos 3 testes. Sendo assim, 73 voluntários foram incluídos no estudo e completaram as coletas, sendo $28(38,4 \%)$ do grupo coronariopata e $45(61,6 \%)$ do grupo valvopata.

\subsubsection{Características demográficas}

As tabelas 2 e 3 demonstram as características clínicas dos 73 sujeitos submetidos aos testes e características do grupo valvopata, respectivamente. 
Tabela 2: Características clínicas dos pacientes cardiopatas.

\begin{tabular}{|c|c|c|c|c|c|c|c|c|c|c|}
\hline & & Todos & & & ronariopat & & & alvopatas & & \\
\hline & Mediana & Media $\pm D P$ & $\mathbf{N}(\%)$ & Mediana & Media $\pm D P$ & $\mathrm{~N}(\%)$ & Mediana & Media $\pm D P$ & $\mathrm{~N}(\%)$ & \\
\hline $\begin{array}{l}\text { Fem. } \\
\text { Masc. }\end{array}$ & & & $\begin{array}{l}22(30,1) \\
51(69,9)\end{array}$ & & & $\begin{array}{c}3(4,1) \\
25(34,2)\end{array}$ & & & $\begin{array}{l}19(26,1) \\
26(35,6)\end{array}$ & \\
\hline Idade & 56,0 & $55,1 \pm 11,4$ & & 58,0 & $58,2 \pm 8,5$ & & 55,0 & $53,2 \pm 12,5$ & & 0,075 \\
\hline IMC & 26,6 & $27,2 \pm 4,9$ & & 27,6 & $28,3 \pm 4,3$ & & 26,3 & $26,5 \pm 5,1$ & & 0,148 \\
\hline $\mathrm{FE}$ & 0,61 & $0,58 \pm 0,1$ & & 0,55 & $0,54 \pm 0,1$ & & 0,64 & $0,61 \pm 0,1$ & & $0,011^{*}$ \\
\hline NYHA & & & & & & & & & & 0,242 \\
\hline CF I & & & $15(20,5)$ & & & $8(29,6)$ & & & $7(15,2)$ & \\
\hline CF II & & & $40(54,8)$ & & & $13(48,1)$ & & & $27(58,7)$ & \\
\hline CF III & & & $17(23,3)$ & & & $5(18,5)$ & & & $12(26,1)$ & \\
\hline CF IV & & & $1(1,4)$ & & & $1(3,7)$ & & & $0(0)$ & \\
\hline FA crôn & & & $9(12,3)$ & & & $0(0)$ & & & $9(19,6)$ & $0,014^{*}$ \\
\hline Diabetes & & & $20(27,4)$ & & & $16(59,3)$ & & & $4(8,7)$ & $0,000^{*}$ \\
\hline OC & & & $1(1,4)$ & & & $1(3,7)$ & & & $0(0)$ & 0,189 \\
\hline DPOC & & & $1(1,4)$ & & & $1(3,7)$ & & & $0(0)$ & 0,189 \\
\hline EXTBG & & & $26(35,6)$ & & & $13(48,1)$ & & & $13(28,3)$ & 0,087 \\
\hline TBG & & & $12(16,4)$ & & & $3(11,1)$ & & & $9(19,6)$ & 0,347 \\
\hline AVC & & & $4(5,5)$ & & & $2(7,4)$ & & & $2(4,3)$ & 0,579 \\
\hline DVP & & & $3(4,1)$ & & & $1(3,7)$ & & & $2(4,3)$ & 0,894 \\
\hline CR alta & & & $1(1,4)$ & & & $1(3,7)$ & & & $0(0)$ & 0,189 \\
\hline HAS & & & $50(68,5)$ & & & $26(96,3)$ & & & $24(52,2)$ & $0,000^{*}$ \\
\hline$P A P>40$ & & & $3(4,1)$ & & & $0(0)$ & & & $3(6,5)$ & 0,175 \\
\hline Nitrato & & & $21(28,8)$ & & & $18(66,7)$ & & & $3(6,5)$ & $0,000^{*}$ \\
\hline bBLoq & & & $43(58,9)$ & & & $27(100)$ & & & $16(34,8)$ & $0,000^{*}$ \\
\hline IECA & & & $30(41,1)$ & & & $12(44,4)$ & & & $18(39,1)$ & 0,656 \\
\hline $\begin{array}{l}\text { P; desvio- } \\
\text { assificaçã } \\
\text { rótida, DF } \\
\text { VP: doen } \\
\text { essão sis }\end{array}$ & $\begin{array}{l}\text { drão; Fe } \\
\text { uncional } \\
\text { C: doen } \\
\text { vascular } \\
\text { ca da a }\end{array}$ & $\begin{array}{l}\text { Sexo fen } \\
\text { classifica } \\
\text { pulmonar } \\
\text { eriférica, } \\
\text { ria pulmo }\end{array}$ & $\begin{array}{l}\text { no; Mas } \\
\text { New } \\
\text { strutiva } \\
\text { creatir } \\
\text {, Nitrat }\end{array}$ & $\begin{array}{l}\text { Sexo Ma } \\
\text { Heart A } \\
\text { nica, EX } \\
\text { IAM: in } \\
\text { so de di }\end{array}$ & $\begin{array}{l}\text { 3G: ex-tak } \\
\text { to agudo } \\
\text { rato de is }\end{array}$ & $\begin{array}{l}\text { dice de } \\
\text { fibrilaça } \\
\text { sta, TE } \\
\text { miocá } \\
\text { orbida, }\end{array}$ & $\begin{array}{l}\text { assa cor } \\
\text { trial, DN } \\
\text { tabagist } \\
\text { HAS: } \\
\text { loq: uso }\end{array}$ & $\begin{array}{l}\text { ea; FE: fra } \\
\text { abete meli } \\
\text { AVC: acide } \\
\text { rtensão ar } \\
\text { betabloqu }\end{array}$ & $\begin{array}{l}\text { de eje } \\
\text {, OC: } 0 \\
\text { vascul } \\
\text { ial sisté } \\
\text { dor, IE }\end{array}$ & $\begin{array}{l}\text { NYHA } \\
\text { rução d } \\
\text { cerebra } \\
\text { ca, PAP } \\
: \text { uso d }\end{array}$ \\
\hline
\end{tabular}

Tabela 3: Características dos indivíduos valvopatas.

\begin{tabular}{cccccc}
\hline Tipo de valvopatia & $\mathbf{n}(\%)$ & Mitral & $\mathbf{n}(\%)$ & Aórtica & $\mathbf{n}(\%)$ \\
\hline Mitral & $16(35,6)$ & Insuficiência & $6(13,3)$ & Insuficiência & $11(24,4)$ \\
Aórtica & $26(57,8)$ & Estenose & $6(13,3)$ & Estenose & $13(28,9)$ \\
Mitral e aórtica & $3(6,7)$ & Dupla & $8(17,8)$ & Dupla & $6(13,3)$ \\
& & & & & \\
\hline
\end{tabular}

Número de pacientes (n). 


\subsection{ANÁLISE DA CONCENTRAÇÃO DE NITRITO/NITRATO (NOx) NO CONDENSADO DO EXALADO PULMONAR ENTRE CORONARIOPATAS E VALVOPATAS}

A tabela 4 mostra os níveis de NOx no CEP dos pacientes coronariopatas e valvopatas. Não foram observadas diferenças estatisticamente significativas entre os pacientes coronariopatas e valvopatas.

Tabela 4: Comparação das concentrações de nitrito/nitrato no condensado do exalado pulmonar entre coronariopatas e valvopatas.

\begin{tabular}{lccccccc}
\hline \multicolumn{2}{c}{ Todos } & \multicolumn{2}{c}{ Coronariopatas } & \multicolumn{2}{c}{ Valvopatas } \\
\hline & Mediana & Media \pm DP & Mediana & Media \pm DP & Mediana & Media \pm DP & P \\
\hline NOx CEP & 7,9 & $9,3 \pm 5,5$ & 7,7 & $8,7 \pm 4,2$ & 8,5 & $9,6 \pm 6,1$ & 0,896 \\
\hline DP: desvio padrão, NOx CEP: concentração de nitrito/nitrato no condensado do exalado pulmonar. *Mann-Whitney
\end{tabular}

DP: desvio padrão, NOx CEP: concentração de nitrito/nitrato no condensado do exalado pulmonar. *Mann-Whitney 


\subsection{ANÁLISE DO DESEMPENHO DO TESTE DE CAMINHADA DE 6 MINUTOS E SHUTTLE WALK TEST ENTRE CORONARIOPATAS E VALVOPATAS}

Houve diferença estatisticamente significativa nos valores de FC inicial, final e de repouso e no valor referente à dispnéia final da escala de Borg entre os grupos coronariopata e valvopata no TC6, conforme demonstrado na tabela 5.

Tabela 5: Valores dos sinais vitais, escala de Borg e distância caminhada no teste de caminhada de 6 minutos entre coronariopatas e valvopatas.

\begin{tabular}{cccccccc}
\hline & \multicolumn{2}{c}{ Todos } & \multicolumn{2}{c}{ Coronariopatas } & \multicolumn{2}{c}{ Valvopatas } \\
\hline & MEDIAN & MEDIA \pm DP & MEDIANA & MEDIA \pm DP & MEDIANA & MEDIA \pm DP & p \\
\hline FCi & 70,0 & $71,7 \pm 11,5$ & 65,0 & $66,2 \pm 10,0$ & 75,0 & $74,9 \pm 11,1$ & $0,000^{*}$ \\
FCf & 89,0 & $90,5 \pm 21,6$ & 79,0 & $79,8 \pm 15,2$ & 95,5 & $96,8 \pm 22,5$ & $0,000^{*}$ \\
FCr & 71,0 & $73,2 \pm 13,2$ & 65,0 & $65,9 \pm 10,1$ & 76,5 & $77,4 \pm 13,1$ & $0,000^{*}$ \\
PASi & 110,0 & $114,5 \pm 16,1$ & 120,0 & $119,3 \pm 18,6$ & 110,0 & $111,6 \pm 13,8$ & 0,094 \\
PASf & 130,0 & $125,7 \pm 17,0$ & 130,0 & $130,9 \pm 17,4$ & 120,0 & $122,6 \pm 16,1$ & 0,061 \\
PASr & 120,0 & $115,5 \pm 16,1$ & 120,0 & $118,3 \pm 16,6$ & 110,0 & $113,8 \pm 15,7$ & 0,334 \\
PADi & 70,0 & $71,4 \pm 10,7$ & 70,0 & $73,1 \pm 9,7$ & 70,0 & $70,4 \pm 11,2$ & 0,206 \\
PADf & 75,0 & $76,6 \pm 12,1$ & 80,0 & $77,4 \pm 9,8$ & 70,0 & $76,1 \pm 13,3$ & 0,484 \\
PADr & 70,0 & $72,7 \pm 10,9$ & 70,0 & $73,9 \pm 8,4$ & 70,0 & $72,0 \pm 12,2$ & 0,388 \\
FRi & 19,0 & $18,7 \pm 2,7$ & 19,0 & $19,3 \pm 3,2$ & 18,5 & $18,4 \pm 2,3$ & 0,534 \\
FRf & 24,0 & $24,0 \pm 3,5$ & 24,0 & $23,6 \pm 3,1$ & 24,0 & $24,2 \pm 3,8$ & 0,639 \\
FRr & 20,0 & $19,5 \pm 2,6$ & 20,0 & $19,7 \pm 2,9$ & 20,0 & $19,4 \pm 2,4$ & 0,829 \\
SpO2i & 97,0 & $96,6 \pm 1,7$ & 97,0 & $96,7 \pm 1,6$ & 97,0 & $96,6 \pm 1,8$ & 0,815 \\
SpO2f & 97,0 & $97,1 \pm 1,8$ & 98,0 & $97,3 \pm 1,6$ & 97,0 & $97,0 \pm 2,0$ & 0,502 \\
SpO2r & 97,0 & $97,1 \pm 1,6$ & 97,0 & $96,7 \pm 1,6$ & 98,0 & $97,4 \pm 1,5$ & 0,061 \\
FADi & 0,0 & $0,3 \pm 0,9$ & 0,0 & $0,0 \pm 0,2$ & 0,0 & $0,4 \pm 1,1$ & 0,172 \\
FADf & 1,0 & $1,9 \pm 2,3$ & 1,0 & $1,6 \pm 2,0$ & 2,0 & $2,1 \pm 2,4$ & 0,452 \\
FADr & 0,0 & $0,4 \pm 1,0$ & 0,0 & $0,1 \pm 0,5$ & 0,0 & $0,5 \pm 1,2$ & 0,292 \\
DISPi & 0,0 & $0,1 \pm 0,4$ & 0,0 & $0,0 \pm 0,2$ & 0,0 & $0,2 \pm 0,5$ & 0,270 \\
DISPf & 2,0 & $2,3 \pm 2,5$ & 0,0 & $1,2 \pm 2,0$ & 3,0 & $2,9 \pm 2,6$ & $0,002^{*}$ \\
DISPr & 0,0 & $0,5 \pm 1,0$ & 0,0 & $0,2 \pm 0,6$ & 0,0 & $0,7 \pm 1,1$ & 0,051 \\
Distância & 470,0 & $460,0 \pm 88,0$ & 450,0 & $435,9 \pm 114,8$ & 470,5 & $474,1 \pm 65,0$ & 0,142 \\
\hline
\end{tabular}

FCi, f, r: freqüência cardíaca no início, final e em 5 minutos de repouso após o teste, PASi, f, r: pressão arterial sistólica no início, final e em 5 minutos de repouso após o teste, PADi, f, r: pressão arterial diastólica no início, final e em 5 minutos de repouso após o teste, $\mathrm{FRi}, \mathrm{f}$, r: freqüência respiratória no início, final e em 5 minutos de repouso após o teste, SpO2i, f, r: saturação periférica de oxigênio no início, final e em 5 minutos de repouso após o teste, FADi, $f$, $r$ : valor da escala de Borg referente à fadiga no início, final e em 5 minutos de repouso após o teste, DISPi, f, $r$ : valor da escala de Borg referente à dispnéia no início, final e em 5 minutos de repouso após o teste, Distância: distância caminhada total no teste. * Mann-Whitney *diferença estatística significativa. 
No SWT houve diferenças estatisticamente significativas nos valores de FC inicial, final e repouso, na pressão sistólica inicial e no valor referente à dispnéia final da escala de Borg entre os grupos coronariopata e valvopata conforme demonstrado na tabela 6.

Tabela 6: Valores dos sinais vitais, escala de Borg e distância caminhada no shuttle walk test entre coronariopatas e valvopatas.

\begin{tabular}{|c|c|c|c|c|c|c|c|}
\hline & \multicolumn{2}{|c|}{ Todos } & \multicolumn{2}{|c|}{ Coronariopatas } & \multicolumn{2}{|c|}{ Valvopatas } & \multirow[b]{2}{*}{$\bar{P}$} \\
\hline & MEDIANA & MEDIA $\pm D P$ & MEDIANA & MEDIA $\pm D P$ & MEDIANA & MEDIA $\pm D P$ & \\
\hline$\overline{F C i}$ & 69,0 & $71,9 \pm 11,3$ & 66,0 & $67,2 \pm 11,0$ & 72,5 & $74,7 \pm 10,6$ & $0,003^{\star}$ \\
\hline $\mathrm{FCf}$ & 93,0 & $99,9 \pm 26,3$ & 85,0 & $86,0 \pm 14,5$ & 102,0 & $108,1 \pm 28,4$ & $0,000^{*}$ \\
\hline $\mathrm{FCr}$ & 72,0 & $73,6 \pm 12,4$ & 67,0 & $67,3 \pm 10,7$ & 73,0 & $77,3 \pm 11,9$ & $0,000^{*}$ \\
\hline PASi & 110,0 & $114,5 \pm 18,0$ & 120,0 & $121,1 \pm 19,7$ & 110,0 & $110,7 \pm 16,0$ & $0,024^{*}$ \\
\hline PASf & 130,0 & $127,9 \pm 22,3$ & 130,0 & $134,1 \pm 23,1$ & 120,0 & $124,3 \pm 21,2$ & 0,077 \\
\hline PASr & 110,0 & $114,8 \pm 18,9$ & 120,0 & $119,3 \pm 20,0$ & 110,0 & $112,2 \pm 18,0$ & 0,105 \\
\hline PADi & 70,0 & $71,0 \pm 11,1$ & 80,0 & $73,9 \pm 11,6$ & 70,0 & $69,2 \pm 10,5$ & 0,052 \\
\hline PADf & 80,0 & $76,6 \pm 13,2$ & 80,0 & $78,1 \pm 12,4$ & 70,0 & $75,7 \pm 13,6$ & 0,290 \\
\hline PADr & 70,0 & $71,7 \pm 10,8$ & 80,0 & $74,1 \pm 11,5$ & 70,0 & $70,3 \pm 10,2$ & 0,098 \\
\hline FRi & 18,0 & $18,6 \pm 3,0$ & 19,0 & $18,8 \pm 3,9$ & 18,0 & $18,5 \pm 2,4$ & 0,931 \\
\hline FRf & 26,0 & $25,4 \pm 3,6$ & 26,0 & $25,4 \pm 4,1$ & 26,0 & $25,3 \pm 3,2$ & 0,986 \\
\hline $\mathrm{FRr}$ & 20,0 & $19,5 \pm 2,7$ & 20,0 & $19,4 \pm 3,4$ & 20,0 & $19,7 \pm 2,3$ & 0,670 \\
\hline SPO2i & 97,0 & $96,6 \pm 1,9$ & 96,0 & $96,5 \pm 1,8$ & 97,0 & $96,6 \pm 2,0$ & 0,395 \\
\hline SPO2f & 97,0 & $97,0 \pm 1,8$ & 97,0 & $97,2 \pm 1,6$ & 97,0 & $96,9 \pm 1,9$ & 0,705 \\
\hline SPO2r & 97,0 & $97,2 \pm 1,6$ & 97,0 & $97,3 \pm 1,4$ & 97,0 & $97,1 \pm 1,7$ & 0,911 \\
\hline FADi & 0,0 & $0,2 \pm 0,8$ & 0,0 & $0,2 \pm 1,0$ & 0,0 & $0,2 \pm 0,7$ & 0,219 \\
\hline FADf & 2,0 & $2,8 \pm 2,8$ & 1,0 & $2,0 \pm 2,4$ & 2,5 & $3,3 \pm 3,0$ & 0,062 \\
\hline FADr & 0,0 & $0,5 \pm 1,4$ & 0,0 & $0,3 \pm 1,0$ & 0,0 & $0,6 \pm 1,6$ & 0,254 \\
\hline DISPi & 0,0 & $0,2 \pm 0,6$ & 0,0 & $0,1 \pm 0,6$ & 0,0 & $0,2 \pm 0,6$ & 0,638 \\
\hline DISPf & 3,0 & $3,2 \pm 2,6$ & 2,0 & $2,1 \pm 2,1$ & 4,0 & $3,8 \pm 2,8$ & $0,012^{*}$ \\
\hline DISPr & 0,0 & $0,4 \pm 1,1$ & 0,0 & $0,3 \pm 0,8$ & 0,0 & $0,5 \pm 1,2$ & 0,262 \\
\hline Distância & 350,0 & $383,1 \pm 154,0$ & 340,0 & $351,9 \pm 175,0$ & 360,0 & $401,5 \pm 139,0$ & 0,101 \\
\hline
\end{tabular}

$\overline{\mathrm{FCi}} \mathrm{f}, \mathrm{r}$ : freqüência cardíaca no início, final e em 5 minutos de repouso após o teste, PASi, f, r: pressão arterial sistólic a no início, final e em 5 minutos de repouso após o teste, PADi, f, r: pressão arterial diastólica no início, final e em 5 minutos de repouso após o teste, $\mathrm{FRi}, \mathrm{f}, \mathrm{r}$ : freqüência respiratória no início, final e em 5 minutos de repouso após o teste, SpO2i, f, $r$ : saturação periférica de oxigênio no início, final e em 5 minutos de repouso após o teste, FADi, $f$, $r$ : valor da escala de Borg referente à fadiga no início, final e em 5 minutos de repouso após o teste, DISPi, $f, r$ : valor da escala de Borg referente à dispnéia no início, final e em 5 minutos de repouso após o teste, Distância: distância caminhada total no teste. * Mann-Whitney *diferença estatística significativa. 
A interrupção do TC6 e do SWT devido desencadeamento de precordialgia está demonstrada na tabela 7. Apenas no grupo coronariopata houve interrupção de teste, sendo 4 TC6 e 7 SWT interrompidos. Na tabela 8 está a relação de testes interrompidos e concluídos dos quais 69 indivíduos (94,5\%) completaram o TC6 e 66 indivíduos $(90,4 \%)$ completaram o SWT.

Tabela 7: Testes interrompidos devido ocorrência de precordialgia.

\begin{tabular}{cccc} 
& Coronariopatas & Valvopatas & \multirow{2}{*}{$\mathrm{p}$} \\
\cline { 2 - 3 } & $\mathrm{n}(\%)$ & $\mathrm{n}(\%)$ & \\
\hline TC6 & $4(14,8)$ & $0(0)$ & $0,017^{*}$ \\
SWT & $7(25,9)$ & $0(0)$ & $0,001^{*}$ \\
\hline
\end{tabular}

n: Número de pacientes TC6: teste de caminhada de 6 minutos, SWT: shuttle walk test. ${ }^{*}$ Chi- quadrado *diferença estatística significativa.

Tabela 8: Relação de testes interrompidos e concluídos.

\begin{tabular}{ccc}
\hline & Interrompidos & Completos \\
\cline { 2 - 3 } & $\mathrm{n}(\%)$ & $\mathrm{n}(\%)$ \\
\hline TC6 & $4(5,5)$ & $69(94,5)$ \\
SWT & $7(9,6)$ & $66(90,4)$ \\
\hline
\end{tabular}

n: Número de testes, TC6: teste de caminhada de 6 minutos, SWT: shuttle walk test. 


\subsection{ANÁLISE DA INFLUÊNCIA DE MEDICAMENTOS NOS NIVEIS DE NITRITO/NITRATO NO CEP E NO DESEMPENHO DO TC6 E SWT}

A tabela 9 mostra a proporção de pacientes valvopatas e coronariopatas que faziam uso de beta-bloqueadores, inibidores da enzima conversora da angiotensina (IECA) e nitratos. Todos os pacientes coronariopatas faziam uso de pelo menos uma destas medicações (versus $64,4 \%$ nos valvopatas) e todos os indivíduos coronariopatas faziam uso de beta-bloqueadores isoladamente ou em associação a outras medicações (versus $35,5 \%$ dos valvopatas). Embora nenhum paciente fizesse uso isolado de nitrato, esta medicação era utilizada por $66,6 \%$ dos coronariopatas e $4,4 \%$ dos valvopatas.

Tabela 9: Descrição do uso de medicamentos utilizados entre os grupos coronariopatas e valvopatas.

\begin{tabular}{ccccccc}
\hline & Nenhum & bBloq & IECA & $\begin{array}{c}\text { bBloq + } \\
\text { Nitrato }\end{array}$ & $\begin{array}{c}\text { bBloq + Nitrato } \\
+ \text { IECA }\end{array}$ & $\begin{array}{c}\text { bBloq + } \\
\text { IECA }\end{array}$ \\
\hline & $\mathrm{n}(\%)$ & $\mathrm{n}(\%)$ & $\mathrm{n}(\%)$ & $\mathrm{n}(\%)$ & $\mathrm{n}(\%)$ & $\mathrm{n}(\%)$ \\
\hline $\begin{array}{c}\text { Coronariopatas } \\
\text { Valvopatas }\end{array}$ & $0(0,0)$ & $7(25,9)$ & $0(0,0)$ & $8(29,6)$ & $10(37,0)$ & $3(7,5)$ \\
\hline
\end{tabular}

Bbloq: uso de beta-bloqueador, IECA: uso de inibidor da enzima conversora da angiotensina, Nitrato: dinitrato de isossorbida.

Não se observou diferença estatisticamente significante na proporção das medicações utilizadas via oral contendo nitrato (dinitrato de isossorbida), IECA (captopril ou enalapril) e/ou betabloqueador na análise das concentrações de nitrito/nitrato do CEP $(p=0,696)$ (Tabela 10). 
Tabela 10: Análise da concentração de nitrito/nitrato no condensado do exalado pulmonar conforme o tipo de medicação em uso.

\begin{tabular}{cccccccc}
\hline & Nenhum & bBloq & IECA & bBloq+Nitrato & bBloq+Nitrato+IECA & bBloq+IECA & Pediana \\
\hline Mediana & Mediana & Mediana & Mediana & Mediana & Med \\
NOx & 9,965 & 7,810 & 6,750 & 7,455 & 7,850 & 7,140 & 0,696
\end{tabular}

Bbloq: uso de beta-bloqueador, IECA: uso de inibidor da enzima conversora da angiotensina, Nitrato: dinitrato de isossorbida, NOx CEP: concentração de nitrito e nitrato no condensado do exalado pulmonar. * Kruskal-Wallis

As tabelas 11 e 12 mostram os resultados dos parâmetros do TC6 e SWT, respectivamente, conforme a medicação em uso. Observou-se que as diferenças estatisticamente significantes foram na FC inicial e repouso no TC6 e FC final no SWT. 
Tabela 11: Efeito das medicações utilizadas sobre os sinais vitais, escala de Borg e distância caminhada do TC6.

\begin{tabular}{|c|c|c|c|c|c|c|c|}
\hline & Nenhum & bBloq & IECA & bBloq+Nitrato & bBloq+Nitrato+IECA & bBloq+IECA & \\
\hline & Mediana & Mediana & Mediana & Mediana & Mediana & Mediana & $P$ \\
\hline$\overline{F C i}$ & 76 & 66 & 69 & 70 & 63 & 63 & $0,014^{*}$ \\
\hline FCf & 97 & 82 & 89 & 82 & 76 & 81 & 0,078 \\
\hline $\mathrm{FCr}$ & 79 & 68 & 71 & 69 & 68 & 68 & $0,022^{*}$ \\
\hline PASi & 110 & 110 & 120 & 115 & 110 & 110 & 0,915 \\
\hline PASf & 120 & 130 & 130 & 130 & 130 & 130 & 0,920 \\
\hline PASr & 110 & 120 & 120 & 120 & 120 & 120 & 0,945 \\
\hline PADi & 70 & 70 & 70 & 70 & 70 & 70 & 0,964 \\
\hline PADf & 73 & 80 & 75 & 80 & 80 & 70 & 0,955 \\
\hline PADr & 70 & 70 & 70 & 70 & 70 & 70 & 0,889 \\
\hline $\mathbf{F R i}$ & 20 & 18 & 18 & 20 & 19 & 18 & 0,783 \\
\hline FRf & 23 & 24 & 24 & 24 & 24 & 24 & 0,994 \\
\hline $\mathbf{F R r}$ & 20 & 20 & 20 & 20 & 20 & 20 & 0,918 \\
\hline SPO2i & 97 & 97 & 97 & 97 & 97 & 97 & 0,896 \\
\hline SPO2f & 97 & 98 & 98 & 97 & 98 & 98 & 0,676 \\
\hline SPO2r & 98 & 97 & 98 & 97 & 97 & 97 & 0,790 \\
\hline FADi & 0 & 0 & 0 & 0 & 0 & 0 & 0,740 \\
\hline FADf & 2 & 1 & 1 & 1 & 0 & 0 & 0,868 \\
\hline FADr & 0 & 0 & 0 & 0 & 0 & 0 & 0,465 \\
\hline DISPi & 0 & 0 & 0 & 0 & 0 & 0 & 0,681 \\
\hline DISPf & 3 & 1 & 1 & 0 & 0 & 0 & 0,059 \\
\hline DISPr & 0 & 0 & 0 & 0 & 0 & 0 & 0,230 \\
\hline Distância & 475 & 465 & 471 & 441 & 420 & 470 & 0,700 \\
\hline \multicolumn{8}{|c|}{ 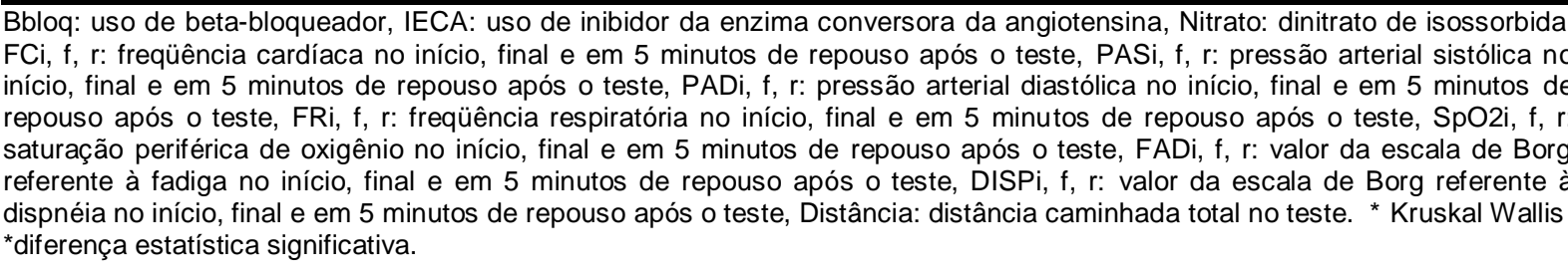 } \\
\hline
\end{tabular}

Para FC inicial e FC repouso, aplicou-se o teste de Mann-Whitney, com nível $5 \%$ de significância, em cada par de tipos de medicamentos comparados (Tabelas 12 e 13, figuras 12 e 13). 
Tabela 12: Variável de FC inicial no TC6 em cada par de medicamentos comparados.

\begin{tabular}{llcccc}
\hline Grupo 1 & Grupo 2 & Mediana 1 & Mediana 2 & Estatística M-W & P \\
\hline Nenhum & bBloq & 76 & 66 & $-3,106$ & $0,002^{*}$ \\
Nenhum & IECA & 76 & 69 & $-2,194$ & $0,028^{*}$ \\
Nenhum & bBloq+Nitrato & 76 & 70 & $-2,264$ & $0,023^{*}$ \\
Nenhum & bBloq+Nitrato+IECA & 76 & 63 & $-2,867$ & $0,003^{*}$ \\
Nenhum & bBloq+IECA & 76 & 63 & $-3,375$ & $0,000^{*}$ \\
bBloq & IECA & 66 & 69 & $-1,038$ & 0,299 \\
bBloq & bBloq+Nitrato & 66 & 70 & $-0,444$ & 0,657 \\
bBloq & bBloq+Nitrato+IECA & 66 & 63 & $-0,376$ & 0,707 \\
bBloq & bBloq+IECA & 66 & 63 & $-0,649$ & 0,516 \\
IECA & bBloq+Nitrato & 69 & 70 & $-0,357$ & 0,721 \\
IECA & bBloq+Nitrato+IECA & 69 & 63 & $-1,209$ & 0,237 \\
IECA & bBloq+IECA & 69 & 63 & $-1,576$ & 0,115 \\
bBloq+Nitrato & bBloq+Nitrato+IECA & 70 & 63 & $-0,663$ & 0,528 \\
bBloq+Nitrato & bBloq+IECA & 70 & 63 & $-0,963$ & 0,341 \\
bBloq+Nitrato+IECA & bBloq+IECA & 63 & 63 & $-0,142$ & 0,890 \\
\hline Bbloq: uso de beta-bloqueador, IECA: uso de inibidor da enzima conversora da angiotensina, Nitrato: dinitrato de \\
isossorbida. M-W: Mann-Whitney *diferença estatística significativa. & & &
\end{tabular}

A FC inicial no TC6 dos pacientes que não ingeriram nenhum medicamento antes do teste é diferente em relação à dos pacientes que fizeram uso de betabloqueador, nitrato oral ou IECA antes do teste, evidenciando medianas superiores.

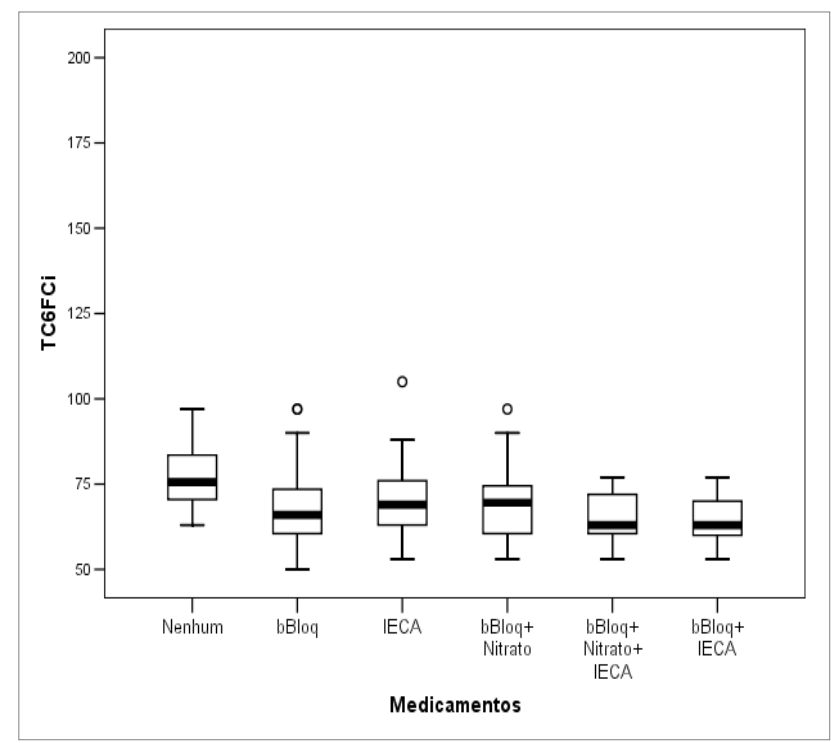

Figura 12: Variável de FC inicial no TC6 em cada par de medicamentos comparados. 
Tabela 13: Variável de FC repouso no TC6 em cada par de medicamentos comparados.

\begin{tabular}{llcccc}
\hline Grupo 1 & Grupo 2 & Mediana 1 & Mediana 2 & Estatística M-W & P \\
\hline Nenhum & bBloq & 79 & 68 & $-2,817$ & $0,005^{*}$ \\
Nenhum & IECA & 79 & 71 & $-1,293$ & 0,196 \\
Nenhum & bBloq+Nitrato & 79 & 69 & $-1,961$ & $0,049^{*}$ \\
Nenhum & bBloq+Nitrato+IECA & 79 & 68 & $-2,572$ & $0,009^{*}$ \\
Nenhum & bBloq+IECA & 79 & 68 & $-2,726$ & $0,005^{*}$ \\
BBloq & IECA & 68 & 71 & $-1,875$ & 0,061 \\
BBloq & bBloq+Nitrato & 68 & 69 & $-0,629$ & 0,529 \\
BBloq & bBloq+Nitrato+IECA & 68 & 68 & $-0,172$ & 0,863 \\
BBloq & bBloq+IECA & 68 & 68 & $-0,370$ & 0,711 \\
IECA & bBloq+Nitrato & 71 & 69 & $-0,962$ & 0,336 \\
IECA & bBloq+Nitrato+IECA & 71 & 68 & $-1,681$ & 0,097 \\
IECA & bBloq+IECA & 71 & 68 & $-1,920$ & 0,055 \\
bBloq+Nitrato & bBloq+Nitrato+IECA & 69 & 68 & $-0,724$ & 0,476 \\
bBloq+Nitrato & bBloq+IECA & 69 & 68 & $-0,886$ & 0,390 \\
bBloq+Nitrato+IECA & bBloq+IECA & 68 & 68 & $-0,142$ & 0,890 \\
\hline
\end{tabular}

Bbloq: uso de beta-bloqueador, IECA: uso de inibidor da enzima conversora da angiotensina, Nitrato: dinitrato de isossorbida. M-W: Mann-Whitney *diferença estatística significativa.

Da mesma forma a FC repouso no TC6 dos pacientes que não ingeriram nenhum medicamento antes do teste é diferente em relação à dos pacientes que fizeram uso de betabloqueador isolado ou associado a nitrato e/ou IECA antes do teste, evidenciando medianas superiores, de forma que têm resultados diferentes a nível 5\% de significância para esta variável.

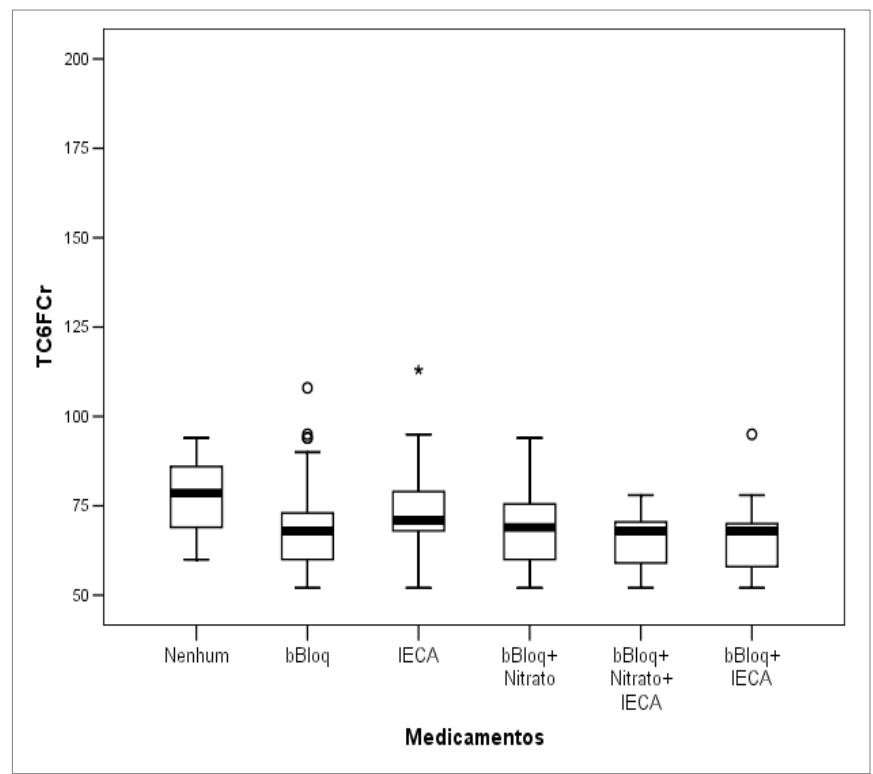

Figura 13: Variável de FC repouso no TC6 em cada par de medicamentos comparados. 
Verificando as medicações via oral utilizadas contendo nitrato (dinitrato de isossorbida), IECA (captopril ou enalapril) e/ou betabloqueador na análise do desempenho no SWT foi observada diferença estatisticamente significante no teste de Kruskal-Wallis a nível $5 \%$ nos valores de FC final, ou seja, alguns medicamentos apresentam diferenças nessa variáveis (Tabela 14).

Tabela 14: Efeito das medicações utilizadas sobre os sinais vitais, escala de Borg e distância caminhada do SWT.

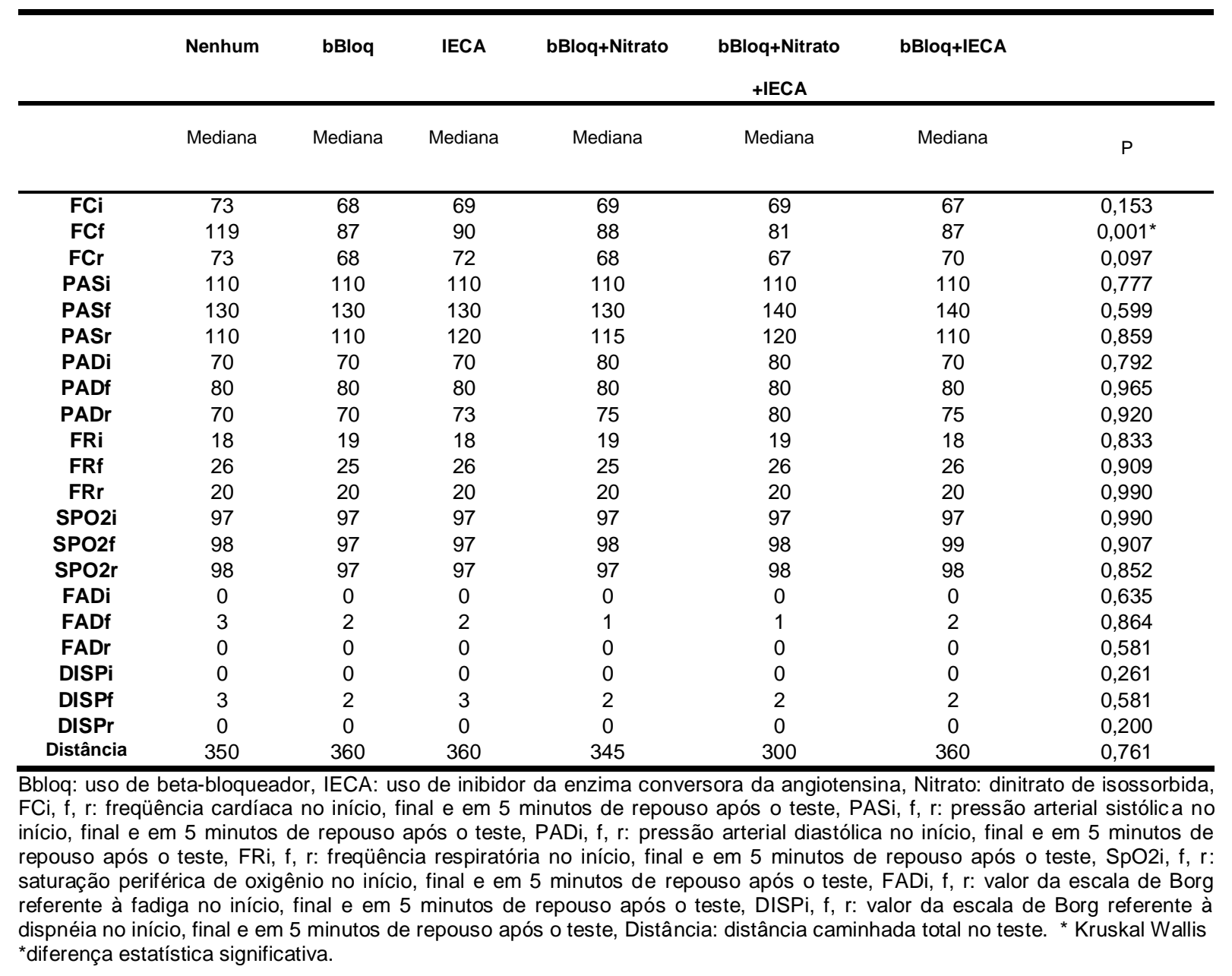

Para FC final aplicou-se o teste de Mann-Whitney, com nível 5\% de significância, em cada par de tipos de medicamentos comparados (Tabela 15, figura 14). 
Tabela 15: Variável de FC final no SWT em cada par de medicamentos comparados.

\begin{tabular}{llcccc}
\hline \multicolumn{1}{c}{ Grupo 1 } & \multicolumn{1}{c}{ Grupo 2 } & Mediana 1 & Mediana 2 & Estatística M-W & P \\
\hline Nenhum & bBloq & 119 & 87 & $-3,812$ & $0,000^{*}$ \\
Nenhum & IECA & 119 & 90 & $-3,184$ & $0,001^{*}$ \\
Nenhum & bBloq+Nitrato & 119 & 88 & $-3,647$ & $0,000^{*}$ \\
Nenhum & bBloq+Nitrato+IECA & 119 & 81 & $-3,575$ & $0,000^{*}$ \\
Nenhum & bBloq+IECA & 119 & 87 & $-3,477$ & $0,000^{*}$ \\
BBloq & IECA & 87 & 90 & $-0,404$ & 0,686 \\
BBloq & bBloq+Nitrato & 87 & 88 & $-0,148$ & 0,882 \\
BBloq & bBloq+Nitrato+IECA & 87 & 81 & $-1,096$ & 0,273 \\
BBloq & bBloq+IECA & 87 & 87 & $-0,591$ & 0,554 \\
IECA & bBloq+Nitrato & 90 & 88 & $-0,446$ & 0,650 \\
IECA & bBloq+Nitrato+IECA & 90 & 81 & $-1,252$ & 0,215 \\
IECA & bBloq+IECA & 90 & 87 & $-0,853$ & 0,393 \\
bBloq+Nitrato & bBloq+Nitrato+IECA & 88 & 81 & $-0,889$ & 0,381 \\
bBloq+Nitrato & bBloq+IECA & 88 & 87 & $-0,397$ & 0,707 \\
bBloq+Nitrato+IECA & bBloq+IECA & 81 & 87 & $-0,542$ & 0,611 \\
\hline
\end{tabular}

Bbloq: uso de beta-bloqueador, IECA: uso de inibidor da enzima conversora da angiotensina, Nitrato: dinitrato de isossorbida. M-W: Mann-Whitney *diferença estatística significativa.

A FC final no SWT dos pacientes que não ingeriram nenhum medicamento antes do teste é diferente em relação à dos pacientes que fizeram uso de betabloqueador, nitrato oral ou IECA antes do teste, evidenciando medianas superiores.

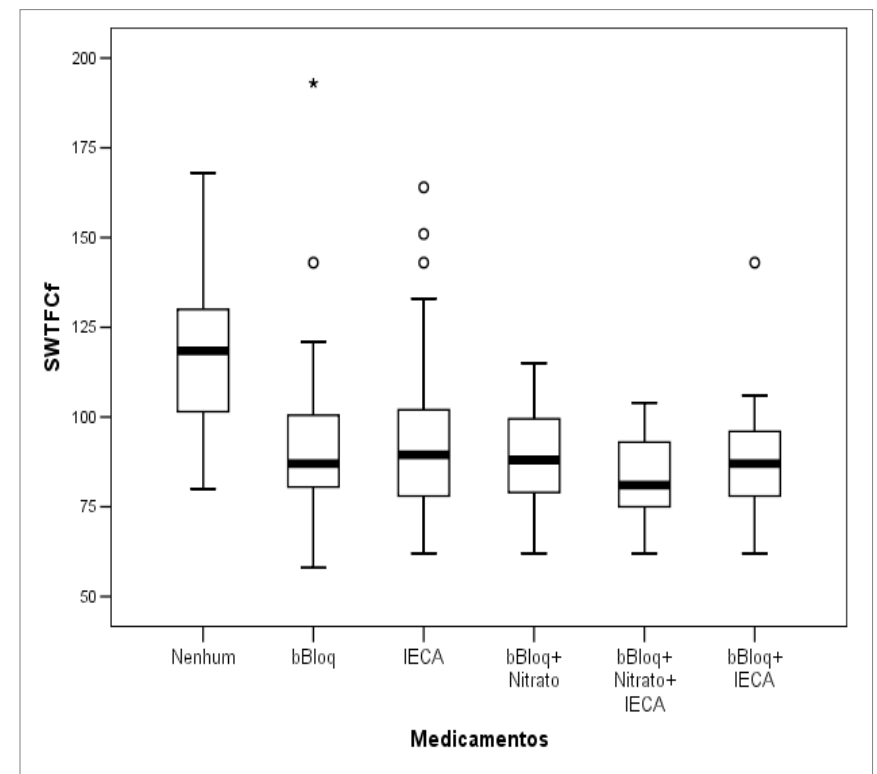

Figura 14: Variável de FC final no SWT em cada par de medicamentos comparados. 
Observando os valores significativos nos valores de FC em pacientes que fizeram uso isolado de betabloqueadores ou associado a nitrato oral e/ou IECA em coronariopatas e valvopatas analisamos os valores de FC inicial, final e repouso no TC6 e SWT entre pacientes que fizeram e não fizeram uso de betabloqueadores e observamos diferença significativa na FC final no SWT, com valores de mediana inferiores nos pacientes betabloqueados (Tabela 16).

Tabela 16: Influência dos betabloqueadores na freqüência cardíaca no TC6 e SWT

\begin{tabular}{cccc}
\hline & \multicolumn{2}{c}{ Uso de Betabloqueadores } & \\
\cline { 2 - 3 } & não & sim & p \\
\cline { 2 - 3 } & Mediana & Mediana & 0,255 \\
\cline { 2 - 3 } TC6FCi & 76 & 66 & 0,090 \\
TC6FCf & 96 & 82 & 0,225 \\
TC6FCr & 79 & 68 & 0,421 \\
SWTFCi & 73 & 68 & $0,044^{*}$ \\
SWTFCf & 104 & 87 & 0,181 \\
SWTFCr & 73 & 68 & \\
\hline
\end{tabular}

TC6: Teste de caminhada de seis minutos, SWT: Shuttle walk test, FC i, f, r: Freqüência cardíaca inicial, final e em 5 minutos de repouso após o teste. * Mann-Whitney *diferença estatística significativa. 


\subsection{CORRELAÇÕES ENTRE O NOx DO CEP E IDADE, FRAÇÃO DE EJEÇÃO E OS PARÂMETROS DOS TESTES TC6 E SWT ENTRE CORONARIOPATAS E VALVOPATAS}

A tabela 17 mostra o coeficiente correlação entre idade e gênero com o NOx no CEP. Houve correlação significativa e moderada entre a idade e a fração de ejeção e os níveis de NOx apenas no grupo de coronariopatas.

Tabela 17: Correlação da idade e da fração de ejeção entre os grupos coronariopata e valvopata.

\begin{tabular}{ccc}
\hline & Coronariopatas & Valvopatas \\
\hline Idade & $\mathbf{r}(\mathbf{p})$ & $\mathbf{r}(\mathbf{p})$ \\
\hline Fração de ejeção & $0,399(0,044)^{*}$ & $-0,142(0,357)$ \\
\hline
\end{tabular}

r: valor de correlação. *Spearman *diferença estatística significativa.

Identificou-se correlação significativa positiva moderada entre o NOx do CEP e as pressões arterial sistólica inicial e final e correlação negativa moderada e distância caminhada no TC6 nos coronariopatas. Já no grupo valvopata observou-se correlação negativa fraca entre o NOx do CEP e os valores de frequência cardíaca final e de dispnéia final (Tabela 18 e Figura 15). 
Tabela 18: Correlação da concentração de nitrito/nitrato no condensado do exalado pulmonar entre os pacientes valvopatas e coronariopatas no teste de caminhada de seis minutos.

\begin{tabular}{ccc}
\hline & Coronariopatas & Valvopatas \\
\hline FCi & $\mathbf{r}(\mathbf{p})$ & $\mathbf{r}(\mathbf{p})$ \\
\hline FCf & $-0,098(0,634)$ & $-0,242(0,113)$ \\
PASi & $-0,208(0,308)$ & $-0,386(0,010)^{*}$ \\
PASf & $0,561(0,003)^{*}$ & $-0,282(0,063)$ \\
PADi & $0,544(0,040)^{*}$ & $-0,242(0,114)$ \\
PADf & $0,364(0,067)$ & $-0,160(0,300)$ \\
FRi & $0,383(0,053)$ & $0,034(0,828)$ \\
FRf & $0,058(0,778)$ & $-0,038(0,806)$ \\
SPO2i & $0,006(0,978)$ & $-0,206(0,179)$ \\
SPO2f & $-0,075(0,716)$ & $0,232(0,130)$ \\
FADi & $0,052(0,800)$ & $0,261(0,087)$ \\
FADf & $0,013(0,948)$ & $0,057(0,714)$ \\
DISPi & $0,152(0,948)$ & $-0,239(0,118)$ \\
DISPf & $0,013(0,948)$ & $-0,260(0,089)$ \\
Distância & $-0,058(0,780)$ & $-0,301(0,047)^{*}$ \\
\end{tabular}

r: valor de correlação, FCi, f: freqüência cardíaca no início e final, PASi, f, pressão arterial sistólica no início e final, PADi, f: pressão arterial diastólica no início e final, FRi, f: freqüência respiratória no início e final, SpO2i, f: saturação periférica de oxigênio no início e final, FADi, f: valor da escala de Borg referente à fadiga no início e final, DISPi, f: valor da escala de Borg referente à dispnéia no início e final, Distância: distância caminhada total no teste. " Spearman *diferença estatística significativa.

No SWT foi identificado correlação positiva moderada entre o NOx no CEP e os valores de pressão arterial sistólica inicial e correlação negativa moderada na distância entre coronariopatas. No grupo valvopata observou-se correlação negativa fraca a moderada entre o NOx do CEP e os valores de frequência cardíaca inicial (Tabela 19 e Figura 16). 
Tabela 19: Correlação da concentração de nitrito/nitrato no condensado do exalado pulmonar entre os pacientes valvopatas e coronariopatas no shuttle walk test.

\begin{tabular}{ccc}
\hline & Coronariopatas & Valvopatas \\
\hline FCi & $\mathbf{r}(\mathbf{p})$ & $\mathbf{r}(\mathbf{p})$ \\
\hline FCf & $-0,195(0,339)$ & $-0,363(0,015)^{*}$ \\
PASi & $-0,141(0,493)$ & $-0,279(0,067)$ \\
PASf & $0,597(0,001)^{*}$ & $-0,105(0,499)$ \\
PADi & $0,377(0,057)$ & $0,006(0,969)$ \\
PADf & $0,385(0,052)$ & $0,142(0,357)$ \\
FRi & $0,338(0,092)$ & $0,118(0,446)$ \\
FRf & $-0,377(0,058)$ & $0,028(0,858)$ \\
SPO2i & $-0,127(0,535)$ & $-0,083(0,590)$ \\
SPO2f & $-0,047(0,820)$ & $0,225(0,141)$ \\
FADi & $-0,143(0,485)$ & $-0,063(0,687)$ \\
FADf & $0,200(0,327)$ & $-0,025(0,872)$ \\
DISPi & $0,071(0,730)$ & $-0,059(0,704)$ \\
DISPf & $0,142(0,489)$ & $0,011(0,944)$ \\
Distância & $0,072(0,728)$ & $-0,204(0,185)$ \\
\hline
\end{tabular}

r: valor de correlação, FCi, f: freqüência cardíaca no início e final, PASi, f, pressão arterial sistólica no início e final, PADi, f: pressão arterial diastólica no início e final, FRi, f: freqüência respiratória no início e final, SpO2i, f: saturação periférica de oxigênio no início e final, FADi, f: valor da escala de Borg referente à fadiga no início e final, DISPi, f: valor da escala de Borg referente à dispnéia no início e final, Distância: distância caminhada total no teste. ${ }^{*}$ Spearman *diferença estatística significativa. 


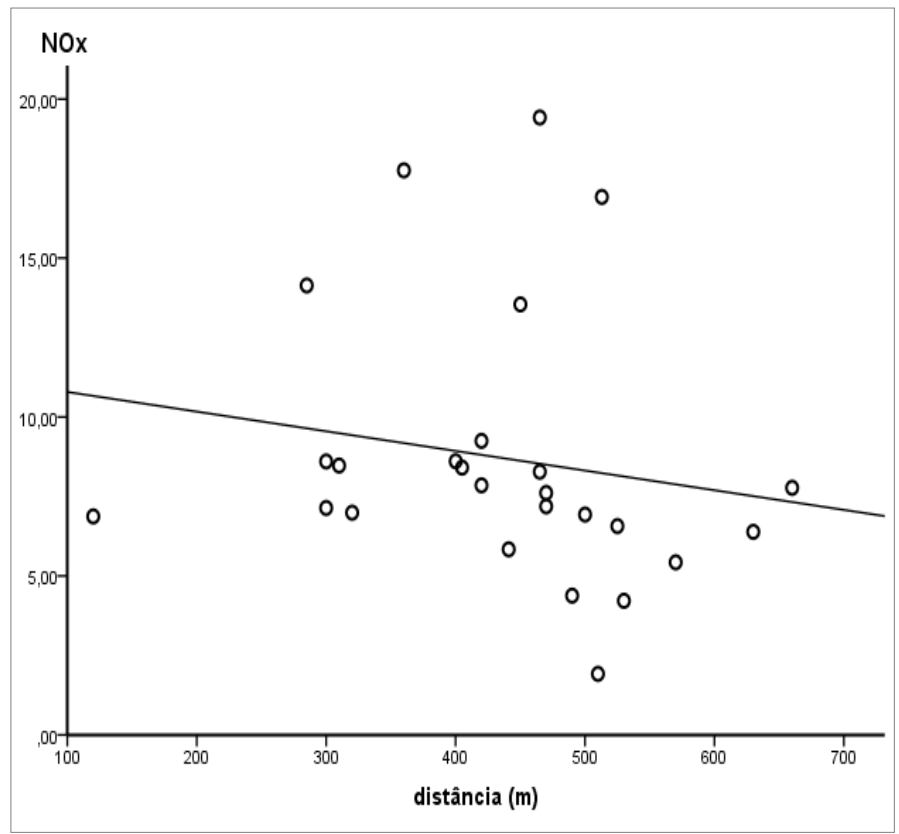

Figura 15: Correlação entre a concentração do NO exalado e a distância caminhada no teste de caminhada de 6 minutos no grupo coronariopata. Os dados são apresentados com 95\% do intervalo de confiança.

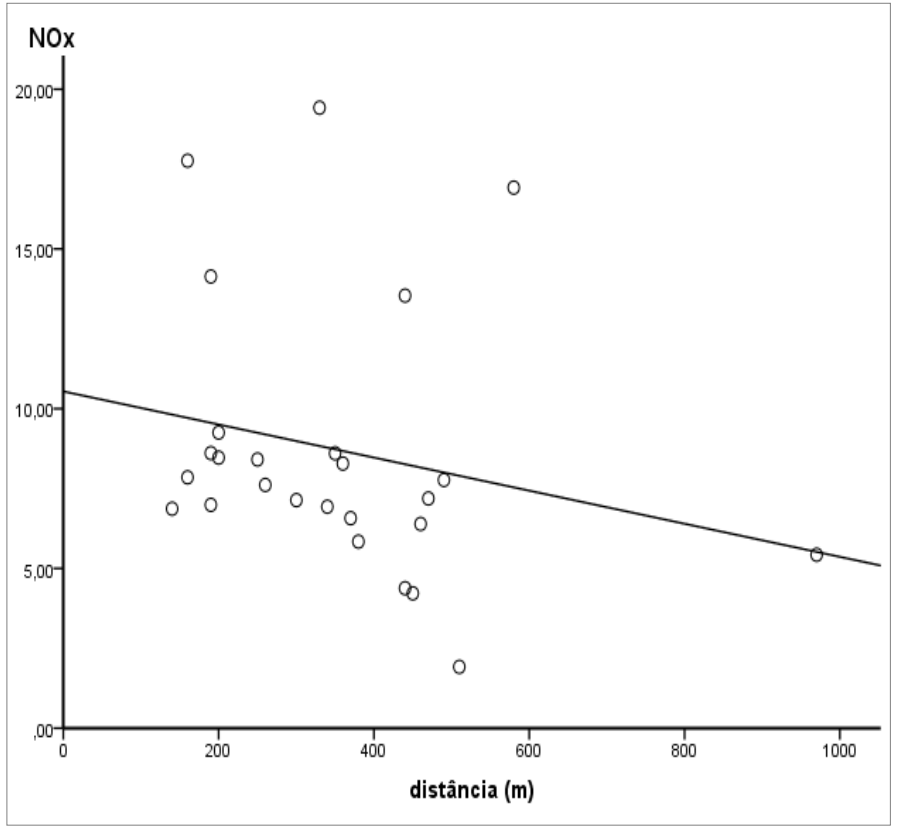

Figura 16: Correlação entre a concentração do NO exalado e a distância caminhada no shuttle walk test no grupo coronariopata. Os dados são apresentados com $95 \%$ do intervalo de confiança. 


\section{Discussão}

Nossos resultados mostraram que não houve diferença significativa dos níveis de nitrito/nitrato (NOx) no CEP entre valvopatas e coronariopatas. No TC6 e no SWT os valores de FC e sensação de dispnéia foram maiores no grupo valvopata, além de um maior número de interrupções de testes pelos coronariopatas devido ao desencadeamento de precordialgia. Não pudemos observar influências significativas do uso de medicamentos sobre o NOx do CEP, porém observamos essa influência nos valores de FC tanto no TC6 quanto no SWT, ao reduzir seus valores em uso isolado de betabloqueador ou associado a IECA e nitrato. Observamos uma correlação inversa entre o NOx do CEP e as distâncias deambuladas nos coronariopatas em ambos os testes.

A monitoração dos níveis de NO no exalado ou no CEP como método de monitorização da terapia asma brônquica, situação onde ocorre um aumento na produção do NO, ou, na hipertensão arterial pulmonar que é responsável pela redução na produção do NO, já estão mais consolidadas (KHARITONOV et al., 1996; CHATKIN et al., 2000). Ainda, mais recentemente estudos identificaram o aumento na concentração de NO exalado em pacientes com insuficiência cardíaca associado a uma anormalidade na vasorregulação e a evidência da sua relação com a severidade da doença (CIKACH JR \& DWEIK, 2012).

Atualmente vem se considerando a avaliação do NO como um importante biomarcador de lesão pulmonar em cirurgia cardíaca (KÖVESI et al., 2005) e um dos meios de análise clínica de biomarcadores cardiovasculares no ar exalado $(\mathrm{CIKACH}$ JR; DWEIK, 2012).

Em nosso estudo, o objetivo foi avaliar os pacientes na situação préoperatória apenas, não havendo diferenças significativas entre os grupos coronariopata e valvopata para os valores de NOx, corroborando com dados encontrados por Arcêncio (2012) e Augusto et al. (2009) que da mesma maneira não observaram diferenças entre os grupos cororariopatas e valvopatas no período préoperatório. No estudo de Augusto et al. (2009) houve diferença apenas quando os cardiopatas foram comparados ao grupo controle de indivíduos saudáveis. Augusto et al. (2009) observaram concentrações de NO aumentadas no ar exalado em pacientes no período pré-operatório de cirurgia cardíaca quando comparados a uma 
condição pós-operatória e mais uma vez inferior comparados aos indivíduos saudáveis.

$\mathrm{Na}$ doença cardiovascular é comum a associação de terapia medicamentosa como o uso de betabloqueadores e parte desses medicamentos podem acarretar modificações na frequência cardíaca (FC). Uma vez que os valores de FC máxima e de repouso são utilizados para a realização de testes de esforço físico, eles podem ressaltar cuidados a serem tomados quando aplicados em portadores de doença cardiovascular (VANZELLI et al., 2005).

Nossos resultados mostraram que a realização do TC6 e SWT em pacientes coronariopatas e/ou valvopatas cardíacos candidatos a operações cardíacas é factível e segura. As diferenças observadas no TC6 entre coronariopatas e valvopatas eram previsíveis, uma vez que a utilização de beta-bloqueadores foi unânime entre os coronariopatas. Ademais, diante das diferenças na fisiopatologia coronariana e valvar, era de se esperar que nos valvopatas a dispnéia alcançasse escores significativamente mais altos ao final dos testes de caminhada e que a angina fosse o principal fator limitante entre os coronariopatas, embora a distância percorrida por coronariopatas e valvopatas seja semelhante em ambos os testes.

Observamos que foram interrompidos 4 testes de caminhada de 6 minutos e 7 shuttle walk tests do grupo coronariopata devido ao desencadeamento de dor precordial, evento este não manifestado no grupo valvopata. O maior número de interrupções podem evidenciar que o SWT exija um maior nível de esforço referido quando comparado ao TC6, uma vez que os resultados não demonstraram diferenças nas distâncias deambuladas entre os testes em nenhum dos grupos.

Tanto o TC6 quanto testes de caminhada incrementais têm sido utilizados e adequados para medir a tolerância ao exercício de pacientes com IC (KAVANAGH et al., 1996; KETEYIAN et al., 1996). No entanto, dados da literatura sugerem que o TC6 corresponde mais aproximadamente às demandas de atividade de vida diária (AVD) quando comparados a outros testes submáximos (SULLIVAN et al., 1984). No entanto, foi demonstrado em alguns estudos recentes que estes resultados não estão relacionados à função cardíaca e sim moderadamente à capacidade de exercício. Mckelvie e colaboradores (2002) sugeriram que a atitude dos voluntários, auto-motivação e humor podem ter um impacto no desempenho do teste, tornando-o menos sensível à mudanças da capacidade funcional que a medida direta do $\mathrm{VO}_{2}$ máx. Este argumento também foi defendido por Opasich et al. (2001) que sugeriram 
que o desempenho nos testes de caminhada não fornece informações a respeito do prognóstico que possam complementar ou substituir a mensuração do $\mathrm{VO}_{2}$ máx ou a classificação da NYHA.

No TC6 o paciente determina a sua velocidade de caminhada e a distância caminhada irá depender da capacidade do ritmo que conseguir impor a si mesmo. Já no SWT o ritmo é padronizado e tem aumentos graduais na velocidade de $0.17 \mathrm{~m} / \mathrm{s}$ a cada nível (MEHRA; LAVIE; MILANI, 1996). Por estes motivos os pacientes podem considerar o TC6 mais fácil de ser realizado que o SWT. Esses dados corroboram com o estudo de Morales et al. (1999) uma vez que verificaram que o SWT é mais estressante para os pacientes pois é mais extenuante que o TC6 gerando valores significativamente maiores de FC, PAS, e na escala de Borg (escala de percepção de esforço). Além disso, verificaram que a distância caminhada tanto no TC6 quanto no SWT têm correlação com o $\mathrm{VO}_{2}$, embora apontem que a distância deambulada no SWT apresente uma melhor correlação com o $\mathrm{VO}_{2}$ que a distância do TC6. Adedoyin et al. (2010) afirmaram haver correlação entre a distância caminhada no TC6 e o $\mathrm{VO}_{2}$ máx, já que entre os diversos modos de avaliação de capacidade funcional, o TC6 é o mais amplamente empregado, e a sua relação entre $\mathrm{O} \mathrm{VO}_{2}$ e a distância caminhada já está mais consolidada na literatura (CAHALIN et al., 1996).

Verificando as medicações utilizadas via oral contendo nitrato (dinitrato de isossorbida), IECA (captopril ou enalapril) e/ou betabloqueador na análise das concentrações de nitrito/nitrato do CEP não foram observadas diferenças significativas. No grupo coronariopata, todos os pacientes faziam uso de pelo menos umas das medicações entre beta-bloqueadores, IECA e nitratos, enquanto que no grupo valvopata apenas $64,4 \%$. Embora nenhum paciente fizesse uso isolado de nitrato, esta medicação era utilizada por 66,6\% dos coronariopatas e 4,4\% dos valvopatas. Com relação ao uso de nitrato por via oral, corroborando com nossos resultados, Nadziakiewicz et al. (2006) também não observaram influências do uso de nitrato oral na concentração de NO exalado de pacientes com doença arterial coronariana (DAC). No entanto, discordando de nossos dados, Arcêncio (2012) verificou concentrações de NO significativamente maiores no CEP de pacientes que fizeram uso de dinitrato de isossorbida. Quanto ao uso de medicação contendo IECA Sumino et al. (2000), puderam observar um aumento significativo dos níveis de NO plasmático em normotensos após 4 horas da ingesta oral de IECA (enalapril), 
no entanto não observaram a mesma resposta em indivíduos hipertensos. Donmez et al. (2002) observaram o aumento de NOx em pacientes hipertensos após 9 semanas de tratamento com ingestão oral de IECA (enalapril e losartana), justificando que este aumento pode auxiliar na recuperação das funções endoteliais.

Diferentemente dos nosso estudo, com relação ao uso de medicação betabloqueadora, Adding et al. (1999) observaram um menor incremento de NOx em coelhos com a infusão de propanolol após estímulo com infusão intravenosa de adrenalina. Neste estudo a adrenalina gerou incrementos dose-dependente na concentração do NOx. A diminuição da produção de NOx pelo propanolol sugere um efeito vasodilatador e broncodilatador balanceando as forças constritivas.

Não foram utilizadas as dosagens de NO plasmático para este estudo uma vez que a correlação do NO plasmático com o NO exalado seja pouco evidenciado devido à meia vida curta do NO em meio ao oxigênio e à hemoglobina. Estudos recentes não têm constatado correlações o que pode indicar que o NO exalado reflita mais a formação de NO local do que a produção sistêmica (DILLON et al., 1996; BIBAN et al., 2001).

No que se refere ao uso de medicações utilizadas via oral contendo nitrato (dinitrato de isossorbida), IECA (captopril ou enalapril) e/ou betabloqueador na análise do desempenho no TC6, pudemos observar diferenças significativas referentes aos valores de FC inicial e de repouso e no valor de FC final reduzidas no SWT em pacientes que fizeram uso de betabloqueador isolado ou associado a IECA e/ou nitrato quando comparado aos pacientes que não fizeram uso de nenhum medicamento. A IECA isolada evidenciou o mesmo efeito do uso do betabloqueador com redução nos valores de FC inicial no TC6 e FC final no SWT de pacientes que fizeram uso de betabloqueador comparado a pacientes que não utilizaram medicações.

Foi verificado que todos os coronariopatas faziam uso de betabloqueador isolado ou associado a outras medicações e o nitrato, embora nunca utilizado isolado, era utilizado por $66 \%$ do grupo coronariopata e apenas $4,4 \%$ do grupo valvopata, que possivelmente justifica essas alterações. As diferenças entre os grupos nos valores de FC inicial, final e repouso em ambos os testes de caminhada e de PAS inicial apenas no SWT dos quais os valvopatas apresentaram valores médios superiores aos coronariopatas possivelmente está relacionado ao consumo de medicações betabloqueadoras por grande parte dos pacientes do grupo 
coronariopata gerando menores variações de FC mesmo durante o esforço. A maior variação da FC também pode estar associada a uma percepção de esforço maior apontada pelos valores significativos de sensação de dispnéia elevada entre os valvopatas em ambos os testes. Evidenciando um comportamento muito semelhante no uso de medicações, desempenho ou de sinais vitais tanto no TC6 quanto no SWT. Não pudemos observar influências dos medicamentos nos distâncias percorridas em nenhum dos grupos e em nenhum dos testes de caminhada.

Van Baak (1988) propôs que após a administração de betabloqueador há redução da FC e da PA embora esta última em menor grau que a $\mathrm{FC}$, o que pode justificar os dados encontrados no presente estudo. Porém, Van Baak (1988) verificou que a capacidade de exercícios aeróbicos máxima é reduzida em normotensos e hipertensos com o uso de medicação betabloqueadora. Observou que após a administração de betabloqueadores a performance submáxima foi prejudicada em ambos os grupos. Por outro lado, em pacientes com doença coronariana a capacidade de exercício sintoma-limitado é aprimorada com o tratamento com betabloqueador, desacordando assim de nossos dados.

Uma correlação entre o pico de FC no exercício e alteração na capacidade de exercício máxima está presente em pacientes com IC em uso de betabloqueadores (METRA et al., 1998). A incapacidade de atingir $80 \%$ da FC pico predita pela idade durante o exercício é denominada incompetência cronotrópica e é evidenciada em alguns pacientes com IC e está relacionada ao uso do betabloqueador.

Outros resultados divergem do encontrado no presente estudo, como os de Nodari, Metra e Dei Cas (2003) onde em estudo com betabloqueador (nebivolol) observaram melhora para a tolerância ao exercício e Matsunami et al. (2013) que verificaram que beta 3-antagonistas melhoram o enchimento do VE na diástole, aumentam a contratilidade do VE e sua eficiência mecânica melhorando assim o desempenho físico. Conraads et al. (2012), em contrapartida, em estudo também com nebivolol em pacientes com IC associada redução da fração de ejeção do ventrículo esquerdo (FEVE) não evidenciaram efeitos favoráveis ao desempenho físico no TC6 comparado ao grupo placebo após 6 meses de tratamento, sendo justificado pela inibição da resposta cronotrópica ao exercício gerado por medicamentos betabloqueadores. 
Kelbaek et al. (1993) sugerem que embora a ação da IECA possa gerar influência sobre os valores de FC, esta parece não desempenhar grande influência para alterações no desempenho durante o exercício físico. Van den Heuvel et al. (2001) concluíram que a IECA pode reduzir a isquemia miocárdica gerada pelo exercício em pacientes com função ventricular normal. No estudo de Willenheimer et al. (1999) após 6 meses de tratamento com IECA (ramipril), pacientes com doença isquêmica estável sem disfunção ventricular apresentaram melhora da função ventricular com redução da anormalidade de enchimento na diástole apenas em repouso. De forma semelhante, Kelbaek et al. (1993) verificaram melhora da função de VE após administração diária de IECA (zofenopril) em pacientes com IC moderada durante o repouso, mas não durante o exercício. Ramadan et al. (2013) verificaram que pacientes que fizeram uso de IECA tiveram menos que a metade dos riscos de desenvolver isquemia durante o estresse mental porém não obtiveram o mesmo resultado para o estresse físico.

Embora a IECA isolada não represente melhora no desempenho físico, o uso associado ao nitrato demonstrou a melhora da capacidade de exercício comparado à pacientes que só utilizaram IECA (enalapril) ou o grupo placebo de pacientes infartados (MACIEJEWICZ et al., 2003). O uso de nitrato (mononitrato de isossorbida) por sua ação de redução de crises anginosas está relacionado ao aumento da tolerância ao exercício (KAZACHKINA et al., 2005).

Observamos em nosso estudo correlação positiva moderada entre a idade e a fração de ejeção e o NOx do CEP apenas no grupo coronariopata ( $r=0,399 ; p=0,044$ e $r=0,425 ; p=0,031$, respectivamente), o qual revela ser o grupo com média de idade superior $(58,2 \pm 8,5 \times 53,2 \pm 12,5$ do grupo valvopata) e média de FE inferior $(0,54 \pm 0,1 \times 0,61 \pm 0,1$ do grupo valvopata), embora a diferença seja pequena.

Identificamos uma correlação positiva moderada entre o NOx do CEP e os valores de PA sistólica inicial e final, correlação moderada na distância caminhada no TC6 de indivíduos coronariopatas. Já no grupo valvopata observou-se correlação negativa fraca a moderada entre o NOx do CEP e os valores de FC final e de dispnéia. Foi identificado correlação positiva moderada entre o NOx do CEP e os valores de PA sistólica inicial e correlação negativa moderada na distância caminhada no SWT e o NOx do CEP de indivíduos coronariopatas. No grupo valvopata observou-se correlação negativa fraca a moderada entre o NOx do CEP e os valores de FC inicial. 
Verificamos o possível efeito do uso de betabloqueadores entre os indivíduos coronariopatas, os quais todos faziam uso isolado ou associado a IECA e nitrato, apresentando valores menores de FC e PA nos testes em relação aos valvopatas, onde estas medicações foram utilizadas em menor escala. Ainda, maiores variações de PA e FC podem estar relacionadas à maior sensação de dispnéia referida pelo grupo valvopata.

No sistema cardiovascular, a liberação de NO gerado é responsável pelo relaxamento da musculatura lisa e conseqüentemente pelo aumento do diâmetro dos vasos sangüíneos, aumentando o fluxo sanguíneo, reduzindo a PA e provocando variações na FC (IGNARRO et al. 2001). No presente estudo, observamos a existência de correlação negativa moderada entre o NOx e as distâncias caminhadas tanto no TC6 quanto no SWT apenas no grupo coronariopata. Sugerimos o NOx elevado pode indicar inflamação em vias aéreas e tal inflamação pode ser responsável por gerar limitações ao exercício físico e acarretando um desempenho inferior nos testes. No entanto, tivemos dificuldades em identificar estudos que afirmem este achado.

Diferente do que relatamos, Clini et al. (2000) observaram níveis reduzidos de NOx em pacientes com IC quando comparados a indivíduos saudáveis. Ainda, observaram que quanto mais severa a doença, de acordo com a NYHA (III - IV) mais reduzidos são os níveis de NOx. Os autores justificam esses resultados conflitantes com a literatura devido a diferente metodologia aplicada em diferentes estudos. Também evidenciam que nesses pacientes a capacidade de exercício está diretamente relacionada a produção de NOx.

Comportamentos divergentes aos relatados no presente estudo também foram constatados na avaliação de pacientes valvopatas com estenose mitral severa. No exercício ocorre uma redução do NO, porém essa redução é ainda maior em pacientes com uma capacidade funcional reduzida, com baixo $\mathrm{VO}_{2}$, comparados aos valvopatas com menor limitação e a indivíduos saudáveis (OMÈDE et al., 2004).

Bussotti et al. (2004) observaram um NOx em repouso menor em pacientes com IC comparado aos indivíduos saudáveis e, durante exercício o NOx não reduziu em pacientes com IC como aconteceu em indivíduos normais. Esse comportamento foi justificado pela inibição da síntese de cNOS associado a hipóxia pulmonar crônica. Além disso, o NO tem a função de vasodilatação pulmonar e a ausência de 
vasodilatação induzida pelo exercício é frequentemente relatada em pacientes com ICC.

Stamler et al. (1997) defendem que a Hb passa por uma transição entre a forma oxidada e desoxigenada, na desoxigenação libera NO e na oxigenação se liga ao NO. É possível que as mudanças no NOx observadas durante o exercício ocorram devido a uma maior absorção de NO nos pulmões em indivíduos saudáveis quando comparados a pacientes cardiopatas. Um menor número de moléculas de $\mathrm{Hb}$ circulando nos pulmões pode estar relacionado a um maior $\mathrm{VO}_{2}$ para a mesma carga de esforço comparando pacientes com IC com saudáveis, ou mesmo numa situação onde $0 \mathrm{VO}_{2}$ é o mesmo em uma população com redução da saturação de $\mathrm{Hb}$ venosa e redução da concentração de $\mathrm{Hb}$ como pode ocorrer em pacientes com IC. De fato na ICC, a anemia é frequentemente identificada e há limitação da hemoconcentração induzida pelo exercício podendo prejudicar no desempenho físico.

Estudando pacientes com DPOC, McCurdy et al. (2011) puderam verificar um comportamento semelhante ao dos pacientes coronariopatas apresentados em nosso trabalho. Indicaram que o aumento do NO está associado a uma capacidade funcional inferior identificada por uma distância deambulada menor no TC6, corroborando com nossos dados nos quais também foi constatado uma menor distância no SWT.

Winlaw et al. (1994) em estudo do nitrato plasmático verificaram níveis mais elevados do NO em indivíduos cardiopatas e também puderam verificar a direta relação com a severidade da doença. Embora dados da literatura sejam conflitantes, sugerimos que elevados níveis de NOx pode estar relacionado a um pior quadro geral da doença, refletindo em um pior desempenho e uma capacidade funcional inferior identificada em pacientes coronariopatas. 


\section{Conclusões}

Não há diferença significativa nos níveis de NOx do CEP de pacientes coronariopatas comparados aos valvopatas e as medicações não influenciaram os níveis de NOx no CEP.

Verificamos que o TC6 e o SWT são factíveis e seguros em pacientes coronariopatas e valvopatas candidatos a operações cardíacas sendo a dispnéia o fator limitante entre os valvopatas e a precordialgia entre os coronariopatas, além de observarmos valores de $\mathrm{FC}$ inferiores neste último grupo.

A utilização de beta-bloqueadores diminuiu significativamente a resposta cronotrópica aos testes de caminhada, enquanto que o uso exclusivo de IECA ou nitratos não influenciaram no desempenho do TC6 e no SWT.

O NOx correlacionou-se com o TC6 e o SWT apenas nos indivíduos coronariopatas de forma a apresentarem uma distância deambulada menor nos pacientes que apresentaram níveis mais elevados de NOx. 
ADDING L.C.; AGVALD, P.; ARTLICH, A.; PERSSON, M.G.; GUSTAFSSON, L.E. Beta-adrenoceptor agonist stimulation of pulmonary nitric oxide production in the rabbit. Brit J Pharmacol, v.126, p.833-839, 1999.

ADEDOYIN, R.A.; ADEYANJU, S.A.; BALOGUN, M.O.; ADEBAYO, R.A.; AKINTOMIDE, A.O.; AKINWUSI, P.O. Prediction of functional capacity during six minute walk among patients with chronic heart failure. Nig J Clinical Practice, v.13, n.4, p.379-381, 2010.

AMERICAN THORACIC SOCIETY. Committee on Proficiency Standards for Clinical Pulmonary Function Laboratories. ATS statement guidelines for the six-minute walk test. Am J Respir Crit Care Med, v.166, n.1, p.111-7, 2002.

AMERICAN THORACIC SOCIETY. Workshop Proceedings: Exhaled Nitric Oxide and Nitric Oxide Oxidative Metabolism in Exhaled Breath Condensate. Proc Am Thorac Soc, v. 3, p. 131-145, 2006.

ANGGARD, E. Nitric oxide: mediator, murderer, and medicine. Lancet, v.343, p.1199-1206, 1994.

ANUÁRIO ESTATÍSTICO DE SAÚDE NO BRASIL - 2005 - DATASUS. Disponível em: http://www.datasus.com.br. Acesso em: 10 dez. 2013.

ANUÁRIO ESTATÍSTICO DE SAÚDE NO BRASIL - 2009 - DATASUS. Disponível em: http://www.datasus.com.br. Acesso em: 10 dez. 2013.

ARAÚJO, C.O.; MAKDISSE, M.R.P.; PERS, P.A.T.; TEBEXRENI, A.S.; RAMOS, L.R.; MATSUSHITA, A.M.; CARVALHO, A.C. Diferentes padronizações do teste da caminhada de seis minutos como método para mensuração da capacidade de exercício de idosos com e sem cardiopatia clinicamente evidente.Arq Bras Cardiol, v. 86, n. 3, 2006.

ARCÊNCIO, L. Estudo do nitrito/nitrato no condensado do exalado pulmonar e no plasma de pacientes valvopatas e coronariopatas submetidos a cirurgia cardíaca com circulação extracorpórea. 2012. 90f. Dissertação (Mestrado em Cirurgia). Faculdade de Medicina de Ribeirão Preto, Universidade de São Paulo, Ribeirão Preto.

AUGUSTO, V.S. A utilização do condensado do exalado pulmonar poderá ser incorporada à rotina de unidades de tratamento intensivo? Rev Bras Ter Intensiva, v.21, n.2, p.204-11, 2009.

BARNES, P.J.; BELVISI, M.G. Nitric oxide and lung disease. Thorax, v. 48, p. 10341043, 1993.

BARRETO, R. L.; CORREIA, C. D.; MUSCARA, M. N. Óxido nítrico: propriedades e potenciais usos terapêuticos. Quím Nova, v. 28, n. 6, p. 1046-1054, 2005. 
BIBAN, P.; ZANGARDI, T.; BARALDI, E.; DUSSINI, N.; CHIANDETTI, L.; ZACCHELLO, F. Mixed exhaled nitric oxide and plasma nitrites and nitrates in newborn infants. Life Sciences, v.68, p. 2789-2797, 2001.

BRUCKDORFER, R. The basics about nitric oxide. Molec Aspects Med, v. 26, p. 3$31,2005$.

BUENO, F.R.; CORRÊA, F.R.; ALVES, M.A.S.; BARDIN, M.G.; MODESTO, J.A.; DOURADO, V.Z. Physical exercise capacity and its prognostic value in postoperative cardiac surgery. Fisioter Mov, v.25, n.4, p.839-847, 2012.

BUSSOTTI, M.; ANDREINI, D.; AGOSTONI, P. Exercise-induced changes in exhaled nitric oxide in heart failure. Eur J Heart Failure, v. 6, p. 551-554, 2004.

CAHALIN, L.P.; MATHIER, M.A.; SEMIGRAN, M.J.; DEC, G.W.; DISALVO, T.G.The six minute walk test predicts peak oxigen uptake and survival in patients with advanced heart failure. Chest, v.110, p.325-32, 1996.

CHATKIN, M.J.; DJUPESLAND, P.; QIAN, W.; HAIGHT, J.; ZAMEL, N. Óxido nítrico exalado no diagnóstico e acompanhamento de doenças respiratórias. J Pneumol, v.26, n.1, 2000.

CIKACH JR, F.S.; DWEIK, R.A. Cardiovascular biomarkers in exhaled breath. Progress in Cardiovasc Diseases, v.55, p. 34-43, 2012.

CLINI, E.; VOLTERRANI, M.; PAGANI, M.; BIANCHI, L.; PORTA, R.; GILE, L.S. Endogenous nitric oxide in patients with chronic heart failure (CHF): relation to functional impairment and nitrate-containing therapies. Int $\mathbf{J}$ Cardiol, v.73, p.123-130, 2000.

CONRAADS, M.V,; METRA, M.; KAMP, O.; DE KEULENAER, G.W.; PIESKE, B.; ZAMORANO, J. VARDAS, P.E.; BO"HM, M.; DEI CAS, L. Effects of the long-term administration of nebivolol on the clinical symptoms, exercise capacity, and left ventricular function of patients with diastolic dysfunction: results of the ELANDD study. Eur J Heart Failure, v.14, p.219-225, 2012.

CORRADI, M; MAJORI, M; CACCIANI, G.C.; CONSIGLI, G.F.; MUNARI, E.; PESCI, A. Increased exhaled nitric oxide in patients with stable chronic obstructive pulmonary disease. Thorax, v.54, p.572-575, 1999.

CORRADI, M.; PESCI, A.; CASANA, R.; ALINOVI, R.; GOLDONI, M.; VETTORI, M.V.; CUOMO, A. Nitrate in exhaled breath condensate of patients with different air way diseases. Nitric Oxide, v. 8, p. 26-30, 2003.

DILLON, W.C.; HAMPL, V.; SHULTZ, P.J.; RUBINS, J.B.; ARCHER, S.L. Origins of breath nitric oxide in humans. Chest, v.110, p.930-938, 1996.

DONMEZ, G.; DERICI, U.; ERBAS, D.; ARINSOY, T.; ONK, A.; SINDEL, S.; HASANOGLU, E. The effects of losartan and enalapril therapies on the levels of nitric 
oxide by vascular, malondialdehyde and glutathione in patients with esencial hypertension. Jpn J Physiol, v.52, n.5, p. 435-440, 2002.

ELLIS, G.; ADATIA, I.; YAZDANPANAH, M.; MAKELA, S.K. et al. Nitrite and nitrate analyses: a clinical biochemistry perspective. Clin Biochem, v.31, n.4, p.195-220, 1998.

ENRIGHT, P. L; SHERRILL, D.L. Reference equations for six-minute walk in healthy adults. Am J Respir Crit Care Med, v.158, p.1384-7, 1998.

ENRIGHT, P. L.; MCBURNIE, M.A.; BITTNER, V. RUSSELL, P.T.; MCNAMARA, R.;ARNOLD, A.; NEWMAN, A.B. The 6-min walk test: a quick measure of functional status in elderly adults. Chest, v. 123, n. 2, p. 387-398, 2003.

FLORA FILHO, R. ZILBERSTEIN, B. Óxido nítrico: o simples mensageiro percorrendo a complexidade. Metabolismo, síntese e funções. Rev Ass Med Brasil, v.46, n.3, p.265-71, 2000.

FÖRSTERMANN, U.; TROGISCH, G.; BUSSE, R. Species-dependent differences in the nature of endothelium-derivated relaxing factor. Eur J Pharmacol, v.106, n.3, p.639-43, 1984.

FOWLER, S.J.; SINGH, S.J.; REVILL S. Reproducibility and validity of the incremental shuttle walking test in patients following coronay artery bypass surgery. Physiotherapy, v.91, n.1, p.22-27, 2005.

FURCHGOTT, R.F. ZAWADZKI, J.V. The obligatory role of endotelial cells in the relation of arterial smooth muscle by acetylcholine. Nature, v. 288, n. 27, p. 373-375, 1980.

GARTHWAITE, J. Nitric oxide signalling in the nervous system. Semin Neurosci, v.5, p.171-180, 1993.

GASTON, B.; DRAZEN, J.M.; LOSCALZO, J.; STAMLER, J.S. The biology of nitrogen oxides in the airways. Am. J. Respir. Crit. Care Med, v.149, p. 538-551, 1994.

HERNÁNDEZ, E.M.T.; FERNÁNDEZ-GUERRA, J.; MARÍN, T.J.; RUIZ, O.F.; RIERA, S.H.; MONTEMAYOR, T. Reproducibility of a shuttle walking test in pacients with chronic obstructive pulmonary disease. Arch Bronconeumol. v.33, n.2, p.6468, 1997.

HORVÁTH, I.; HUNT, J.; BARNES, P.J. Exhaled breath condensate: methodological recommendations and unresolved questions. Eur Respir J, v. 26, p. 523-548, 2005.

IGNARRO, L.J.; BUGA, G.M.; WOOD, K.S.; BYRNS, R.E.; CHAUDHURI, G. Endothelium-derivated relaxing factor produced and released from artery and vein in nitric oxide. Proc Natl Acad Sci USA, v. 84, n.24, p. 9265-9269, 1987. 
IGNARRO, L.J.; BUGA, G.M.; WEI, L.H.; BAUER, P.M.; WU, G.; DEL SOLDATO, P. Role of the arginine-nitric oxide pathway in the regulation of vascular smooth muscle cell proliferation. Proc Natl Acad Sci USA, v.27, n.98, p.4202-4208, 2001.

IWAMA, A.M.; ANDRADE, G.N.; SHIMA, P.; TANNI, S.E.; GODOY, I.; DOURADO, V.Z. The six-minute walk test and body weight-walk distance product in healthy brazilian subjects. Braz J Med Biol Res, v.42, n.11, p. 1080-1085, 2009.

JAMES, S.L. Role of nitric oxide in parasitic infections. Microbiol Rev, v. 59, n.4, p. 533-47, 1995.

KAVANAGH, T.; MYERS, M.G.; BAIGRIE, R.; MARTEUS, D.J.; SAWYER, P.; SHEPHERD, R. Quality of life and cardiorespiratory function in chronic heart failure, effective of 12 months of aerobic training. Heart. v.76, p.42-49, 1996.

KAZACHKINA, S.S.; BALAKHONOVA, T.V.; LUPANOV. V.P.; POGORELOVA, O.A.; ROGOZA, A.N.; NAUMOV, V.G. Effects of isosorbide-5-mononitrate on clinical condition, bicycle ergometry results, endothelium-dependent vasodilation in patients with ischemic heart disease with stable effort angina. Ter Arkh, v.77, n.10, p.71-75, 2005.

KELBAEK, H.; AGNER, E.; WROBLEWSKI., H.; VASEHUS MADSEN, P.; MARVING, J. Angiotensin converting enzyme inhibition at rest and during exercise in congestive heart failure. Eur Heart J, v.14, n.5, p.692-695, 1993.

KETEYIAN, S.J.; LEVINE, A.B.; BRAWNER, C.A.; KATAOKA, T.; ROGERS, F.J.; SCHAIRER, J.R. Exercise training in patients with heart failure. A randomized, controlled trial. Annals of Intern Med. V.124, p.1051-1057, 1996.

KHARITONOV, S.A. BARNES, P.J. Exhaled markers of pulmonary disease. Am J Respir Crit Care Med, v. 163, p. 1693-1722, 2001.

KHARITONOV, S.A.; YATES, D.H.; CHUNG, K.F.; BARNES, P.J. Changes in the dose of inhaled steroid affect exhaled nitric oxide levels in asthmatic patients. Eur Respir J, v.9, p.196-201, 1996.

KIECHLE, F.L. MALINSKI, T. Nitric oxide: biochemistry, pathophysiology, and detection. Am J Clin Pathol, v. 100, p. 567-75, 1993.

KOSTIKAS, K.; KOUTSOKERA, A.; PAPIRIS, S.; GOURGOULIANIS, K.I.; LOUKIDES, S. Exhaled breath condensate in patients with asthma: implications for application in clinical practice. Clinical and Experimental Allergy, v. 38, p. 557565, 2008.

KÖVESI, T.; SZABO, A.; ROYSTON, D MARCKIN, N. Correlation between pulmonary gas exchange and basal and nitroglycerin (GTN) - induced exhaled nitric oxide (eNO) in patients undergoing cardiac surgery. Vascul Pharmacol, v.43, p.434440, 2005. 
LEONE, A.M.; PALMER, R.M.; KNOWLES, R.G.; FRANCIS, P.L.; ASHTON, D.S.; MONCADA, S. Constitutive and inducible nitric oxide synthases incorporate molecular oxygen in to both nitric oxide and citrulline. J Biological Chemistry, v. 266, n.35, p. 23790-23795, 1991.

MACIEJEWICZ, J.; MAZIARZ, A.; CELIBAŁA, R.; WIŚNIEWSKI, M.; WIŚNIEWSKA, $M$. The impact of nitrates and mono-therapy and nitrates combined with angiotensin converting enzyme inhibitors on left ventricular remodeling and exercise capacity in patients after acute myocardial infarction. Przegl Lek, v.2, p.80-84, 2003.

MARLETTA, M.A.; YOON, P.S.; IYENGAR, R. Macrophage oxidation of L-arginine to nitrite and nitrate: nitric oxide is an intermediate. Biochemistry, v. 27, n. 24, p. 8706$8711,1988$.

MASUTANI, S.; CHENG, H.J.; MORIMOTO, AQ.; HASEGAWA, H.; HAN, Q.H.; LITTLE, W.C.; CHENG, C. P. Adrenergic receptor antagonist improves exercise performance in pacing-induced heart failure. Am J Physiol Heart Circ Physiol, v.305, p. H923-H930, 2013.

MCCURDY, M.R.; SHARAFKHANEH, A.; ABDEL-MONEM, H.;JAVIER ROJO, J.; FRANK K TITTEL, F.K. Exhaled nitric oxide parameters and functional capacity in chronic obstructive pulmonary disease. J. Breath Res, v. 5, 2011.

MCKELVIE, R.S.; TEO, K.K.; ROBERT, R.; MCCARTNEY, K.; YUSUF S. Effects of exercise training in patients with heart failure: the exercise rehabilitation trial (EXERT). Am Heart J. v.144, p.23-30, 2002.

MEHRA, M.R.; LAVIE, C.J.; MILANI, R.V. Predicting prognosis in advanced heart failure: use of exercise indices. Chest. v.110, p.310-312, 1996.

METRA, M.; NODARI, S.; D'ALOIA, A.; MADURERI, A.; ROSSELLI, F.; BONTEMPI, L.; ZANINI, R.; DEI CAS, L. Effects of neurohormonal antagonism on symptoms and quality-of-life in heart failure. Eur Heart J, v.19, Suppl B:B25-B35, 1998.

MOLONEY, E.D.; MUMBY, S.E.; GAJDOCSI, R.; CRANSHAW, J.H.; KHARITONOV, S.A.; QUINLAN, G.J.; GRIFFITHS, MJ. Exhaled breath condensate detects markers of pulmonary inflammation after cardiothoracic surgery. Am J Respir Crit Care Med, v. 169, p 64-69, 2004.

MONCADA, S.; PALMER, R.M.J.; HIGGS, E.A. Nitric oxide: physiology, pathophysiology and pharmacology. Pharmacol Reviews, v. 43, p. 109-42, 1991.

MONTUSCHI, P. Exhaled breath condensate analysis in patients with COPD. Clin Chimica Acta, v. 356, n. 1-2, p. 22-34, 2005.

MORALES, F. J.; MARTíNEZ, A.; MÉNDEZ, M.; AGARRADO, A.; ORTEGA, F.; FERNÁNDEZ-GUERRA, J.; MONTEMAYOR, T.; BURGOS, J. A shuttle walk test for assessment of functional capacity in chronic heart failure. Am Heart J, v.138, p.2918, 1999. 
MURAD, F. Nitric oxide signaling: would you believe that a simple free radical could be a second messenger, autacoid, paracrine substance, neutrotransmitter and hormone? Recent Prog Horm Res, v.52, p.43-60, 1998.

MUTO, E.; HAYASHI, T.; YAMADA, K.; ESAKI, T.; SAGAI, M.; IGUCHI, A. Endothelial-constitutive nitric oxide synthase exists in airways and diesel exhaust particles inhibit the effect of nitric oxide. Life Sci, v.59, p.1563-1570, 1996.

NADZIAKIEWICZ, P.; KNAPIK, P.; ZIORA, D.; NOWAK, D. Moderate exercise decreases nitric oxide exhalation in patients with stable coronary artery disease. $\mathbf{J}$ Physiol Pharmacol, v.57, Suppl 4, p.213-221, 2006.

NERY, R.M.; MARTINI, M.R.; VIDOR, C.R.; MAHMUD, M.I.; ZANINI, M.; LOUREIRO, A.; BARBISAN, J.N. Alterações na capacidade funcional de pacientes após dois anos da cirurgia de revascularização do miocárdio. Rev Bras Cir Cadiovasc, v.25, n.2, p.224-228, 2010.

NODARI, S.; METRA, M.; DEI CAS, L. Beta-blocker treatment of patients with diastolic heart failure and arterial hypertension: a prospective, randomized, comparison of the long-term effects of atenolol vs nebivolol. Eur $\mathbf{J}$ Heart Fail. v.5, p.621-627, 2003.

OMEDĖ, P.; BUCCA, C.; ROLLA, G.; COSTANZO, P.; CASONI, R.; CALACHANIS, M.; MORELLO, M.; MANGIARDI, L.; TREVI, G.P. Cardiopulmonary exercise testing and exhaled nitric oxide in the assessment of patients with mitral stenosis. Minerva Cardioangiol, v.52, n.1, p.29-35, 2004.

ONORATI, P.; ANTONUCCI, R.; VALLI, G.; BERTON, E.; DE MARCO, F.; SERRA, $P$. Non-invasive evaluation of gas exchange during a shuttle walking test vs. a 6 -min walking test to assess exercise tolerance in COPD patients. Eur $\mathbf{J}$ Appl Physiol, v.89, n.3-4, p.331-336, 2003.

OPASICH, C.; PINNA, G.D.; MAZZA, A.; FEBO, O.; RICCARDI, R.; RICCARDI, P.G.; CAPOMOLLA, S.; FORNI, G.; COBELLI, F.; TAVAZZI, L. Six-minute walking performance in patients with moderate to severe heart failure; is it a useful indicator in clinical practice? Eur Heart J. v.22, n.6, p.488-496, 2001.

PALMER, R.M.J.; FERRIGE, A.G.; MONCADA, S. Nitric oxide release accounts for the biological activity of endothelium-derived relaxing factor. Nature, v. 327, p. 524526, 1987.

RAMADAN, R.; QUYYUMI, A.A.; ZAFARI, A.M.; BINONGO, J.N.; SHEPS, D.S. Myocardial ischemia and angiotensin-converting enzyme inhibition: comparison of ischemia during mental and physical stress. Psychosom Med, v.75, n.9, p.815-821, 2013.

REESINK, H.J.; VAN DER PLAS, M.N., VERHEY, N.E.; VAN STEENWIJK, R.P.; KLOEK, J.J.; BRESSER, P. Six-minute walk distance as parameter of functional outcome after pulmonary endarterectomy for chronic thromboembolic pulmonary hypertension. J Thorac Cardiovasc Surg, v.133, n.2, p.510-516, 2007. 
RICCIARDOLO, F.L.M. Multiple roles of nitric oxide in the airways. Thorax, v. 58, p.175-182, 2003.

RICCIARDOLO, F.L.M.; STERK, P.J.; GASTON, B.; FOLKERTS, G. Nitric oxide in health and disease of the respiratory sistem. Physiol Rev, v.84, n.3, p.731-65, 2004.

ROBROEKS, C.M.; ROSIAS, P.P.; VAN VLIET, D.; JÖBSIS, Q.; YNTEMA, J.B.; BRACKEL, H.J.; DAMOISEAUX, J.G.; DEN HARTOG, G.M.; WODZIG, W.K.; DOMPELING, E. Biomarkers in exhaled breath condensate indicate presence and severity of cystic fibrosis in children. Pediatr Allergy Immuno, v.19, n.7, p. 652-659, 2008.

RONDELLI, R.R.; OLIVEIRA, A.N.; DAL CORSO, S., MALAGUTI, C. Uma atualização e proposta de padronização do teste de caminhada dos seis minutos. Fisiot Mov, v. 22, n. 2, p.249-59, 2009.

ROSA, W.F.; CAMELIER, A.; MAYER, A.; JARDIM, J.F. Avaliação da capacidade de exercício em portadores de doença pulmonar obstrutiva crônica: comparação do teste de caminhada com carga progressiva com o teste de caminhada com acompanhamento. J. Bras. Pneumol, v.32, n.2, p.106 -13, 2006.

ROSAMOND, W.; FLEGAL, K.; FURIE, K.; GO, A.; GREENLUND, K.; HAASE, N. et al. Heart disease and stroke statistics-2008 update: a report from the American Heart Association Statistics Committee and Stroke Statistics Subcommittee. Circulation, v.117, n.4, p. 25-146, 2008.

SINGH, S.J. Walking for the assessment of patients with chronic obstructive pulmonary disease. Eur Respir Mon,v.40, n.1, p.148-164, 2007.

SINGH, S.J.; MORGAN, M.D.; SCOTT, S.; WALTERS, D. HARDMAN, A.E. Development of a shuttle walking test of disabilitiy in patients with cronic airways obstruction. Thorax, v.47, p.1019-24, 1992.

SINGH, S.J.; JONES, P.W.; EVANS, R.; MORGAN, M.D. Minimum clinically important improvement for the incremental shuttle walking test. Thorax, v.63, p.775777, 2008.

SOLWAY, S.; BROOKS, D.; LACASSE, Y.; THOMAS, S. A qualitative systematic overview of the measurement properties of functional walk tests used in the cardiorespiratory domain. Chest, v. 119, n. 1, p. 256-270, 2001.

STAMLER, J.S.; JAY, L.; MC MAHON, T.J.; DEMCHENKO, I.T.; BONAVENTURA, J.; GERNET, K. Blood flow regulation by S-Nitrosohemoglobin in the physiological oxygen gradient. Science, v.276, p.2034-2037, 1997.

SULLIVAN, M.; GENTER, F.; SAVVIDES, M.; ROBERTS, M.; FROELICHER, V. The reproducibility of hemodynamic, electrocardiographic and gas exchange data during treadmill exercise in patient with stable angina pectoris. Chest, v.86, p. 375-381, 1984. 
SUMINO, H.; NAKAMURA, T.; KANDA, T.; SATO, K.; SAKAMAKI, T.; TAKAHASHI, T.; SAITO, Y.; HOSHINO, J.; KURASHINA, T.; NAGAI, R. Effects of enalapril on exhaled nitric oxide in normotensive and hypertensive subjects. Hypertension, v.36, p. 934-940, 2000.

SWERTS, P. M. J.; MOSTERT, R.; WOUTERS, E. F. M. Comparison of corridor and treadmill walking in patients with severe chronic obstructive pulmonary disease. PhysicalTherapy, v. 70, n.7, p. 439-442, 1990.

VALENTI, V. E.; ABREU, L.C.; VALENTI, E.E.; FERREIRA, M.; MENEGHINI, A.; MURAD, N.; PEREIRA, R.J.S.; FERREIRA, C. Análise do desempenho em grupo de mulheres adultas no teste de caminhada de seis minutos. Arq. Med ABC, v.32, supl. 2: S51-S54, 2007.

VAN BAAK, M.A. Beta-adrenoceptor blockade and exercise. An update. Sports Med, v.5, n.4, p.209-225, 1988.

VAN DEN HEUVEL, A.F.; DUNSELMAN, P.H.; KINGMA, T.; VERHORST, P.; BOOMSMA, F.; VAN GILST, W.H.; VAN VELDHUISEN, D.J. Reduction of exercise-induced myocardial ischemia during add-on treatment with the angiotensinconverting enzyme inhibitor enalapril in patients with normal left ventricular function and optimal beta blockade. J Am Coll Cardiol, v.37, n.2, p.470-474, 2001.

VANZELLI, A.S.; BARTHOLOMEU, J.B.; MATTOS, L.N.J.; BRUM, P.C. Prescrição de exercício físico para portadores de doenças cardiovasculares que fazem uso de betabloqueadores. Rev Soc Cardiol Estado de São Paulo, v.2, Supl A:10-6, 2005.

VENTO, D.A.; ARCÊNCIO, L.; RODRIGUES, A.J. Nitric oxide in the exhaled breath condensate of healthy volunteers collected with reusable device. Arch Bronconeumol, v.8, n.4, p.120-125, 2012.

VILHENA, F.S.D.S.; LOURO, S.R.W. Mecanismos de nitrosilação de ferroporfirinas por SNAP: cinética de reação e estabilidade em ambiente aeróbico. 2006. 161f. Tese de Doutorado. Rio de Janeiro. Universidade Pontifícia do Rio de Janeiro.

WILLENHEIMER, R.; RYDBERG, E.; OBERG, L.; JUUL-MÖLLER, S.; ERHARDT, L. ACE inhibition with ramipril improves left ventricular function at rest and post exercise in patients with stable ischaemic heart disease and preserved left ventricular systolic function. Eur Heart J, v.20, n.22, p.1647-1656, 1999.

WINLAW, D.S.; SMYTHE, G.A.; KEOGH, A.M.; SCHYVENS, C.G., SPRATT, P.M., MACDONALD, P.S. Increased nitric oxide production in heart failure. Lancet, v.134, p.373-4, 1994. 
10. Anexos

\section{ANEXO 1}

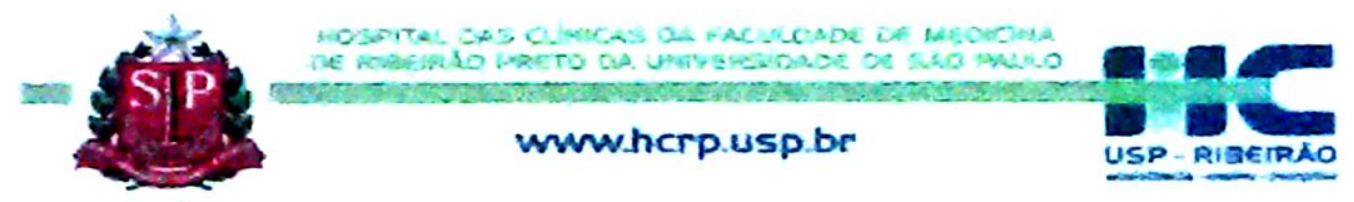

Ribcaräo Preto, 24 de novembro de 2010

Oficio $n^{\circ} 3935 / 2010$

$\mathrm{CEP} / \mathrm{RCC}$

Prezados Senhores,

O trabalho intitulado "CORRELAÇAO ENTRE O CONDENSADO DO EXALADO PULMONAR, O TESTE DE CAMMNHADA DE SEIS MNUTOS E O SHUTTLE WALK TEST EM INDTVIDUOS CARDIOPATA8* foi analisado pelo Comitê de Etıca em Pesquisa, em sua 315 Reuniáo Ordinária realizada em 22/11/2010 e enquadrado na categotia APROVADO, bem como o Termo de Consentimento Livre Esclarecido, de acordo com o Processo HCRP n ${ }^{\circ} 10989 / 2010$

Este Comite segue integralmente a Conferencia Internacianal de Hamonzagao de Boas Princas Clincas (IGH-GCP), bem como a Resolucao n $196 / 96$ CNS/MS.

Lembramos que devem seT apresentados a este CEP, 0 Relatóno Parcial e o Relatorio Final da pesquisa.

Atenciosamerife,

PROF. DR RICARDO DE CARVALHO CAVALEI

Socretírio do Comitẽ de tetica em

Pesquisa do HCRP e da FMRP-USP

Rustrissimos Senhores

MARINA NEVES DO RASCIMENTO

PROF. DR. ALFREDO JOSE RODRIGUES (Orientador)

Depto. de Cirurgia e Anatomia

Comith de Exica em Resquisa HCRP e FNRP-USP - Campus Unwersitano FWA - 0000 2733; IRB - 00002186 e Registro SISNEP/CONEP $n^{\circ} 4$

Fone (16) 3602-2ma - E-mal copio hap topt

Monte Alegre 14048-900 Roberdo Preto So 


\title{
ANEXO 2
}

\section{Termo de Consentimento Livre e Esclarecido}

\author{
Pesquisa: CORRELAÇÃO ENTRE CONDENSADO DO EXALADO PULMONAR, \\ TESTE DE CAMINHADA DE SEIS MINUTOS E SHUTLLE WALK TESTEM \\ INDIVÍDUOS CARDIOPATAS.
}

\section{Aluna: Marina Neves do Nascimento. Orientador: Prof. Dr. Alfredo José Rodrigues}

1. Natureza da pesquisa: Você é convidado(a) a participar desta pesquisa, que tem como finalidade investigar 0 ar dos pulmões exalado pela boca que se liquidifica quando exposto à baixa temperatura do gelo utilizando um dispositivo não invasivo, e avaliar o seu condicionamento físico por meio de dois testes de caminhada diferentes, em que no primeiro você irá caminhar durante seis minutos no ritmo que conseguir realizar e no segundo irá aumentar a velocidade de caminhada a cada minuto pelo tempo que conseguir sustentar antes da sua cirurgia cardíaca.

2. Envolvimento na pesquisa: Ao participar deste estudo você deve permitir que um membro deste projeto entreviste, avalie e execute a coleta do condensado do exalado pulmonar e realize os dois tipos de teste de caminhada com você. É garantido a você esclarecimentos sobre a pesquisa em qualquer momento de sua execução. Todas essas etapas serão realizadas no Hospital das Clínicas de Ribeirão Preto - FMRP/USP.

3. Riscos e desconforto: Os procedimentos utilizados nesta pesquisa obedecem aos Critérios da Ética na Pesquisa com Seres Humanos conforme a Resolução n.196/96 do Conselho Nacional de Saúde, de forma que nenhum teste utilizado nesta pesquisa ofereça riscos a você.

6. Confidencialidade: Todas as informações coletadas neste estudo são estritamente confidenciais. Os relatos da pesquisa serão identificados comum código, e não com o seu nome. Apenas os membros da pesquisa terão conhecimento dos dados.

7. Benefícios: Ao participar desta pesquisa você não deverá ter nenhum beneficio direto. No entanto, no futuro, essas informações poderão ser usadas em beneficio de outros pacientes.

8. Pagamento: Você não terá nenhum tipo de despesa por participar desta pesquisa, bem como nada será pago por sua participação. 
9. Liberdade de Participação: Sua participação neste estudo é voluntária e é seu direito interromper sua participação a qualquer momento sem que isso incorra em qualquer penalidade ou prejuízo a sua pessoa. Você também tem o direito de se excluir deste experimento no caso de abandono dos procedimentos ou condutas inadequadas durante o período de aplicação da intervenção. Em caso de dúvida quanto à pesquisa ou os seus direitos, durante ou após a sua participação neste estudo, você ou seu familiar poderá entrar em contato pessoalmente com o Prof. Dr. Alfredo José Rodrigues ou a Ft. Marina Neves do Nascimento na Divisão de Cirurgia Torácica e Cardiovascular do Hospital das Clínicas de Ribeirão Preto - FMRP/USP, no Campus da USP ou, através do telefone: (16) 3602-2497.

Após estes esclarecimentos, solicitamos o seu consentimento de forma livre para participar desta pesquisa. Portanto, preencha os itens que segue:

Tendo em vista os itens acima apresentados, Eu portador do RG no __ de forma livre e esclarecida, manifestomeuinteresseem participar da pesquisa "CORRELAÇÃO ENTRE CONDENSADO DO EXALADO PULMONAR, TESTE DE CAMINHADA DE SEIS MINUTOS ESHUTLLE WALK TEST EM INDIVÍDUOS CARDIOPATAS".

RibeirãoPreto, de 20 
ANEXO 3

Servico de Fisioterapia Cardiorrespiratória

Ficha de Avaliação

Paciente:

$\begin{array}{lll}\text { Registro: } & \text { Leito: } & \text { Sexo: ( ) fem ( ) masc } \\ \text { Idade: } & \text { Peso: } & \text { IMC: }\end{array}$

Profissão:

Internação:

Avaliação:

Cirurgia:

Diagnóstico Clínico/Cirúrgico:

Antecedentes Pessoais:
( ) HAS
( ) Diabetes
( ) Dislipidemia
( ) HF+ para doença cardiovascular
( ) Sedentarismo
( ) AVC ano:
( ) Infarto prévio ano:
( ) Angioplastia ano:
( ) Doença Arterial Periférica
( ) Doença Venosa Periférica
( ) Doença Reumática
( ) ICC
( ) Tabagista
( ) DPOC
( ) Ex-tabagista
( ) Asma

Sintomatologia: NYHA
( ) IC CF I
( )Dor precordial relacionada aos
( ) IC CF II esforços
( ) IC CF III
( ) DPN
( ) IC CF IV
( ) Ortopnéia 


\section{Atividade física:}

Tipo de exercício:

Duração:

Freqüência (sem.):

\section{Exame físico:}

( ) colaborativo ( ) pouco colaborativo ( ) desorientado

PA: $\mathrm{mmHg}$ FC: bpm FR: ipm

$\mathrm{T}$ :

Cianose: ( ) presente ( ) ausente Edema de MMII: ( ) presente ( ) ausente

Pulsos: ( ) presentes ( ) ausentes qual (is):

AP:

Tipo respiratório: ( ) costal ( ) diafragmático ( ) misto ( ) assincrônico

Ritmo respiratório: ( ) eupneico ( ) taquipneico ( ) bradipineico

( ) Cheyne-Stokes ( ) Biot ( )Kusmaul

Tipo de tórax: ( ) normolíneo ( ) brevilíneo ( ) longilíneo

Forma de tórax: ( ) normal ( ) tonel ( ) pectus carinatum

( ) cifótico( ) escoliótico( ) pectus escavatum

Faz uso da musculatura acessória: ( ) sim ( ) não

Tosse: ( ) eficaz ( ) ineficaz ( ) produtiva aspecto:

Expansibilidade torácica: ( ) preservada ( ) diminuída

Força Muscular: diafragma: intercostais: abdominais:

Diafragma:

Bom: expulsa a mão do fisioterapeuta.

Regular: começa a expulsar a mão do fisioterapeuta, mas termina com respiração costal.

Ruim: sente contração do diafragma, mas realiza apenas respiração costal.

Intercostais:

Bom: sente contração muscular, aumento dos espaços intercostais e horizontalização das costelas. 
Regular: sente contração muscular, aumento dos espaços intercostais e costelas verticalizadas.

Ruim: sente leve contração muscular, sem aumento dos espaços intercostais e costelas imóveis.

\section{Ventilometria:}

CV:

VC:

FR:

VE:

Motivo da não realização:

\section{Manovacuometria:}

PImáx: cmH2O PEmáx: $\mathrm{cmH} 2 \mathrm{O}$

Motivo da não realização:

PeakFlow: $\mathrm{L} / \mathrm{min}$

Exames complementares:

Raio-X de tórax:

\section{Ecocardiograma:}

Desempenho sistólico de VE: ( ) preservado ( ) diminuído-leve ( )moderado ( ) grave

FE (\%):

\section{Espirometria:}

CVF: (\% do predito)

VEF1: (\% do predito)

VEF1/CVF: (\% do predito)

FEF 25-75: (\% do predito)

Gasometria:

$\mathrm{PaO} 2$ : $\mathrm{mmHg}$

HCO3-:

SatO2: $\%$

PaCO2: $\mathrm{mmHg}$

$\mathrm{BE}$ :

$\mathrm{pH}$ :

Medicamentos em uso: 
ANEXO 4

TESTE DE CAMINHADA DE 6 MINUTOS

Nome:

Idade:

Registro:

Estatura:

Peso:

HD:

Medicamentos em uso:

Avaliador:

Data:

Hora:

Fez uso de oxigênio suplementar durante a prova? ( ) Sim ( ) Não

\begin{tabular}{|l|l|l|l|}
\cline { 2 - 4 } \multicolumn{1}{c|}{} & \multicolumn{1}{c|}{ Inicial } & Final & $\begin{array}{c}\text { Recuperação } \\
\text { (após 5') }\end{array}$ \\
\hline PA & & & \\
\hline FC & & & \\
\hline FR & & & \\
\hline $\mathrm{SpO}_{2}$ & & & \\
\hline Dispnéia (Borg) & & & \\
\hline Fadiga (Borg) & & & \\
\hline
\end{tabular}

Houve interrupção da prova? ( ) Sim （） Não

Razão:

Resultado do TC6'

Metragem preditiva:

Metragem do paciente: Percentagem:

Equação de referência:

Equação de Enright\&Sherill (1998)

Homens: TC6 $^{\prime}=(7,57 \times$ altura $\mathrm{cm})-(5,02 \times$ idade $)-(1,76 \times$ peso $\mathrm{kg})-309 \mathrm{~m}$ Mulheres: TC6 $^{\prime}=(2,11 \times$ altura $\mathrm{cm})-(2,29 \times$ peso $\mathrm{kg})-(5,78 \times$ idade $)+667 \mathrm{~m}$

Equação de Iwama e col. (2009)

Homens: TC6 $^{\prime}=622,461-(1,846 \times$ idade $)+(61,503 \times 1)$

Mulheres: TC6 $^{\prime}=622,461-(1,846 \times$ idade $)+(61,503 \times 0)$

Frases encorajadoras ditas ao paciente:

"Você está indo bem. Você tem 5 minutos"

"Mantenha um bom trabalho. Você tem 4 minutos para ir"

"Você está indo bem. Está na metade do caminho"

"Mantenha o bom trabalho. Você só tem 2 minutos restantes"

"Você está indo bem. Você tem apenas 1 minuto" 
ANEXO 5

ESCALA DE BORG

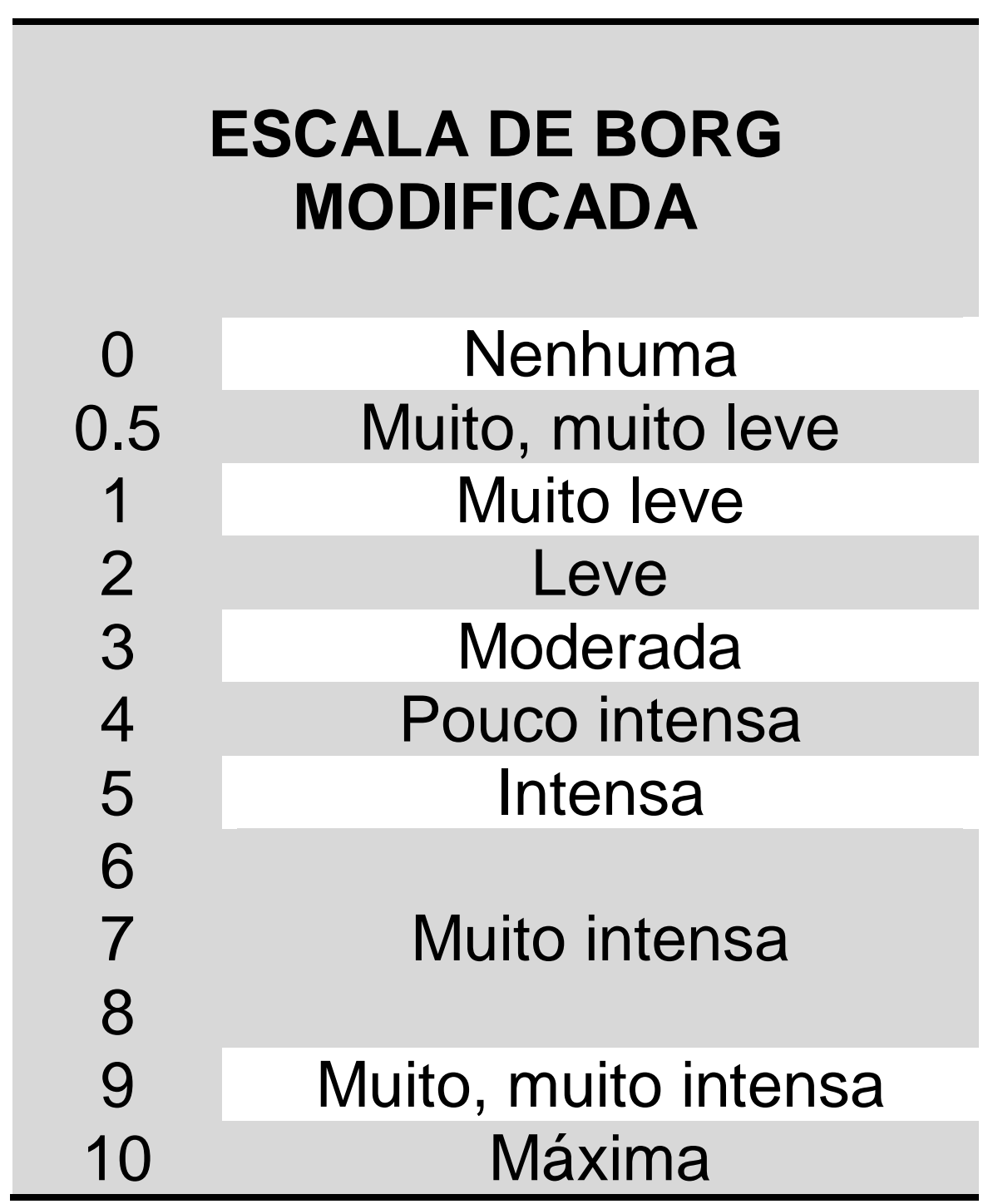


ANEXO 6

\section{SHUTTLE WALK TEST}

Nome:

Idade:

Registro:

Estatura:

Peso:

HD:

Medicamentos em uso:

Avaliador:

Data:

Hora:

SHUTTLE WALK TEST INCREMENTAL

\begin{tabular}{|c|c|c|c|}
\hline & Inicial & Final & $\begin{array}{c}\text { Recuperação } \\
\text { (após 5') }\end{array}$ \\
\hline \multicolumn{4}{|l|}{ FC } \\
\hline \multicolumn{4}{|l|}{ FR } \\
\hline \multicolumn{4}{|l|}{ PA } \\
\hline \multicolumn{4}{|l|}{$\mathrm{SpO}_{2}$} \\
\hline \multicolumn{4}{|l|}{ Dispnéia (Borg) } \\
\hline \multicolumn{4}{|l|}{ Fadiga (Borg) } \\
\hline $\begin{array}{l}\text { Distância } \\
\text { Caminhada }\end{array}$ & & & \\
\hline
\end{tabular}

Obs:

Avaliador: 